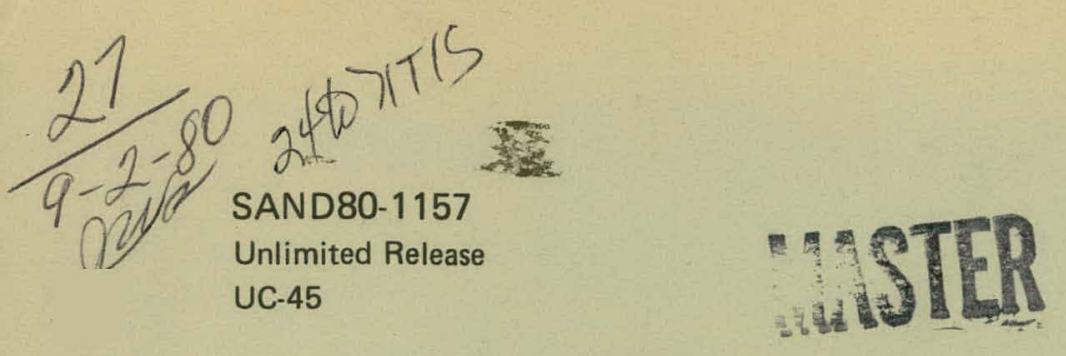

\title{
The Deflagration-to-Detonation Transition Project: Quarterly Report for the Period September Through November 1979
}

Morton L. Lieberman, Editor

Prepared by Sandia Laboratories, Albuquerque, New Mexico 87185

and Livermore, California 94550 for the United States Department

of Energy under Contract DE-AC04-76DPO0789

Printed July 1980

\section{Sandia National Laboratories}




\section{DISCLAIMER}

This report was prepared as an account of work sponsored by an agency of the United States Government. Neither the United States Government nor any agency Thereof, nor any of their employees, makes any warranty, express or implied, or assumes any legal liability or responsibility for the accuracy, completeness, or usefulness of any information, apparatus, product, or process disclosed, or represents that its use would not infringe privately owned rights. Reference herein to any specific commercial product, process, or service by trade name, trademark, manufacturer, or otherwise does not necessarily constitute or imply its endorsement, recommendation, or favoring by the United States Government or any agency thereof. The views and opinions of authors expressed herein do not necessarily state or reflect those of the United States Government or any agency thereof. 


\section{DISCLAIMER}

Portions of this document may be illegible in electronic image products. Images are produced from the best available original document. 
Issued by Sandia Laboratories, operated for the United States Department of Energy by Sandia Corporation.

\section{NOTICE}

This report was prepared as an account of work sponsored by the United States Government. Neither the United States nor the Department of Energy, nor any of their employees, nor any of their contractors, subcontractors, or their employees, makes any warranty, express or implied, or assumes any legal liability or responsibility for the accuracy, completeness or usefulness of any information, apparatus, product or process disclosed, or represents that its use would not infringe privately owned rights. 


\section{PAGES 1 to 2 WERE INTENTIONALLY LEFT BLANK}




\title{
SAND80-1157
}

\author{
Unlimited Release \\ Printed July 1980
}

THE DEFLAGRATION-TO-DETONATION

TRANSITION PROJECT: QUARTERLY REPORT

FOR THE PERIOD SEPTEMBER THROUGH NOVEMBER 1979

M. L. Lieberman, Editor

Initiating and Pyrotechnic Components Division 2515

Sandia Laboratories

Albuquerque, NM 87185

DIBTRIBUTION OF THS DOCUREIT IS UKLIMUTED

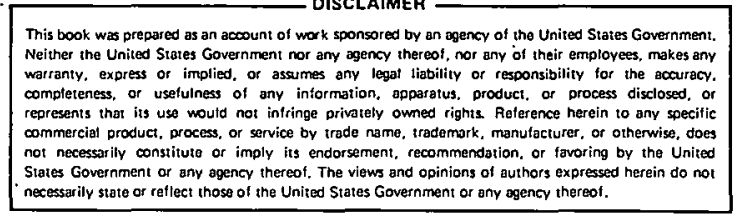

necessarily state or reflect those of the United States Government or any agency thereot. 


\section{ACKNOWLEDGEMENTS}

Numerous individuals contributed to both the writing and technical content of this report. Authorship is indicated by names in parenthesis following section titles. Task leaders and technical contributors are identified at the beginning of Sections II - V. 
SUMMARY OF REPORT

The planned development of the MC3423 detonator has been completed and the final design review meeting has been held. Additional work must be performed to establish satisfactory output function. Electrothermal response measurements have shown that gamma can be used as a measure of no-fire capability of the component and that it remains essentially constant through the environmental sequence testing. Ignition sensitivity data have also been obtained. Ignition and shock testing experiments for development of the MC3533 detonator have been planned. An initial version of the component will utilize available MC3423 headers, while the final design will incorporate a new header that has been designed and ordered. Detonator performance studies have been planned to optimize CP density-length factors. Feasibility studies on the MC3196A detonator have continued in an effort to obtain a reliable 50-200 us function time. Compatibility and aging studies have continued. Because of concern regarding thermal mismatch, the expansion coefficient of $\mathrm{CP}$ pellets was determined $\left(\sim 58 \times 10^{-6}{ }^{\circ} \mathrm{C}^{-1}\right)$. No slippage of pellets was detected during repeated thermal cycles. In support of the MC3196A program, a Iimited coupon study of $\mathrm{CP} / \mathrm{B} / \mathrm{CaCrO}_{4}$ with Kovar and Tophet $\mathrm{A}$ has commenced. Samples analyzed after 94 days showed no evidence of corrosion of the metals. Thermal analysis of the aged powders were identical to that of the baseline material. The structure of the amidine chelate has been determined by single crystal x-ray diffraction techniques. It has been conclusively established that the tetrazole ring is $\mathrm{N}-1$ bonded to the co atom. This suggests that the formation of the compound in the solid state is unlikely.

The studies of chemical analogs of CP continue to indicate that chemical tailoring of properties is viable. Additional measurements of selected materials have been planned. NMR. spectra of the analogs in DMSO solution have supported the proposed structures and shown that the materials are sufficiently stable in solution to permit transportation 
in that form. Impact sensitivity measurements have shown that $0.5 \mathrm{M} \mathrm{CP}$ in DMSO solutions provide no apparent impact hazards. The electrostatic discharge behavior of $\mathrm{CP}$ as a function of density has been determined and found to exhibit a broad minimum. At relatively high density (> 1.8 $\mathrm{Mg} / \mathrm{m}^{3}$ ) the material is relatively insensitive to ignition from a spark source. Electrothermal response testing of $\mathrm{CP}$ under load shows that gamma increases smoothly with increasing density and that the value obtained at high pressure $(70 \mathrm{kpsi})$ is retained three weeks after the removal of the load. Synthesis of CP lots EL-58633 and EL-58636 have been performed. These materials were more difficult to sieve than were earlier materials. Preliminary analysis suggests an increased degree of agglomeration may exist. Photoacoustic spectroscopy has been used to characterize CP. If existing problems could be eliminated its limit of detection for amide impurity would be 28 .

Clear header DDT studies have shown that growth to detonation is significantly affected by density in the range $1.42-1.62 \mathrm{Mg} / \mathrm{m}^{3}$. Gun impact experiments have been performed to obtain the shock Hugoniot of unreacted CP. The relationship between shock velocity and particle velocity is

$$
\begin{aligned}
U_{s}=0.49+2.26 u_{p} \text { for } \rho_{0}= & 1.47 \mathrm{Mg} / \mathrm{m}^{3} \text { and } \\
& 0<u_{p}<0.5 \mathrm{~km} / \mathrm{s}
\end{aligned}
$$

and

$$
\begin{aligned}
u_{s}=0.53+3.57 u_{p} \text { for } \rho_{o}= & 1.66 \mathrm{Mg} / \mathrm{m}^{3} \text { and } \\
& 0<u_{p}<0.7 \mathrm{~km} / \mathrm{s} .
\end{aligned}
$$

Optical studies of CP transmission time have yielded a time-distance profile given by the relation

$$
t=1.8796+0.9719 s+(-0.0241) \mathrm{s}^{2} .
$$

Preliminary data obtained with a VISAR system indicate the ChapmanJouget (CJ) pressure of $\mathrm{CP}$ to be 22.0 and $27.5 \mathrm{GPa}$ at 1.52 and $1.77 \mathrm{Mg} / \mathrm{m}^{3}$, respectively. 
I. Introduction

II. Physics of CP DDT

A. Overview

B. Modeling DDT

C. Clear Header DDT Studies

D. Unreacted Hugoniot Measurements

E. Mound Optical Studies of CP Transmission Time

F. Detonation Pressure Measurements in CP

G. Cylinder Expansion Tests

III. Materials Development

A. New Materials

B. NMR of CP Analogs

C. Electrostatic Discharge/Electrothermal Response

D. Impact Sensitivity of CP Solutions . 46

E. CP Synthesis

F. Analytical Studies of $C P$ at Mound

IV. Compatibility

A. Introduction

65

B. TMA Studies with CP

C. $\mathrm{CP} / \mathrm{B} / \mathrm{CaCrO}_{4}$ Coupon Studies

D. CP Compatibility Study

E. Structure Determination of Amidine Chelate

75

V. Components

A. MC3423 Detonator. 79

B. MC3533 Detonator 84

C. CP Detonator Performance Studies 86

D. MC3196A Detonator 86 
INTENTIONALLY LEET BLANK 
THE DEFLAGRATION-TO-DETONATION TRANSITION PROJECT:

QUARTERLY REPORT FOR THE PERIOD SEPTEMBER THROUGH NOVEMBER 1979

I. INTRODUCTION (M. L. Lieberman)

The Sandia Laboratories project on deflagration-to-detonation transition (DDT) has been underway since september, 1978. Major support is being provided by Unidynamics/Phoenix, Inc. and Mound Facility, while a variety of other institutions are performing specialized tasks. The activities of this project pertain primarily to the development of small, safe, low-voltage, hot-wire detonators. Its major goals are (a) the formulation of a modeling capability for DDT of the explosive 2-(5-cyanotetrazolato) pentaamminecobalt(III) perchlorate (CP); (b) the development of improved DDT materials; (c) the establishment of a data base for corrosion, compatibility, and reliability of CP-loaded detonators; and (d) the design and development of advanced DDT components.

Because many people are involved in these activities, quarterly reports $(1-4) *$ are being issued as a means of disseminating current preliminary information on a timely basis. The report for the first quarter provided an overview of the project activities, specific objectives, plans, and current data, the latter primarily in the areas of compatibility and MC3423 detonator design: (1) Accomplishments of the second quarter included showing that $\mathrm{CP}$ is relatively insensitive to initiation from a stab stimulus, synthesizing eight analogs of CP for explosive evaluation, establishing that all of the loose powder $C P$ analogs are insensitive to initiation by the human body equivalent electrostatic discharge, showing an absence of CP compatibility problems $\overline{{ }^{*} \text { All references }}$ are given in one section at the end of the document. 
after 612 days of aging, obtaining activation energy data for various CP samples, establishing the attractiveness of using CP in a flying plate detonator, completing ignition sensitivity studies and drawings for the MC3423 detonator, and showing the feasibility of developing a detonator with a function time of $125 \pm 75 \mu \mathrm{s}$. (2)

During the third quarter, ${ }^{(3)}$ implementation of many of the prior plans commenced. In the physics activities, the hydrocode wONDY was selected for incorporation in a two-phase reactive flow model. of nnT, a $\mathrm{CP}$ burn rate of $0.4-0.5 \mathrm{~km} / \mathrm{s}$ was determined for column lengths of $1.6-$ $2.4 \mathrm{~mm}$, average detonation velocities of $5636-5932 \mathrm{~m} / \mathrm{s}$ were measured for various types of $\mathrm{CP}-1$ loaded mild detonating fuze, and contracts were placed to determine the equation of state of $\mathrm{CP}$ detonation products, C-J pressure, unreacted Hugoniot, and shock threshold. Materials studies showed that $C P$ in loose powder or unconfined pellet form is sparkinsensitive in a variety of atmospheres. All chemical analogs of CP under investigation were shown to be spark-insensitive in the unconfined pellet form. Impact testing showed that these materials in loose powder form exhibit considerable variation, whereas in unconfined and confined pellet form they generally exhibit values and behavior similar to $\mathrm{CP}$. The one notable exception to these trends was obtained from the only analog that contained a large organic moiety.

Compatibility studies showed an absence of corrosion attributable to $\mathrm{CP}$ in mini-dets after 795 days and little decomposition of the powder at or below $80^{\circ} \mathrm{C}$. An investigation of the $\mathrm{CP} / \mathrm{B} / \mathrm{CaCrO}_{4}$ system commenced; the chromate salt of $\mathrm{CP}$ was found to be highly insoluble in aqueous solution and it exhibited no exothermic behavior up to $500^{\circ} \mathrm{C}$. Tests showed that $C P$ can be contained in copper tubes for limited periods of time, i.e., 3-4 months. Processing studies performed on the MC3423 detonator included bridgewire welding, igniter loading, TIG welding, and stitch welding. Electrothermal response measurements established a relationship 
between no-fire level and bridgewire height. Feasibility of achieving a function delay in a detonator similar to the MC 3196 was achieved by utilizing a $\mathrm{CP} / \mathrm{B} / \mathrm{CaCrO}_{4}$-loaded igniter. Design of the MC3533 detonator was initiated.

Further progress was made in all areas during the fourth quarter. Optical measurements of CP $\left(1.3 \mathrm{Mg} / \mathrm{m}^{3}\right)$ DDT by fiber optic techniques yielded a stable deflagration rate of $0.54 \mathrm{~km} / \mathrm{s}$ and transition at $\sim 8 \mathrm{~s}$. Transparent header optical measurements yielded a terminal burn velocity of $0.65 \mathrm{~km} / \mathrm{s}$ at somewhat greater densities. Samples were fabricated for determination of the CP unreacted Hugoniot, reacted equation of state, and Chapman-Jouget pressure. Continuing studies of CP analogs showed that none of the analogs examined in confined pellet form is as sensitive. to ignition from an electrostatic discharge (ESD) stimulus as is CP. Over the density range examined, ESD sensitivity generally increases with increasing density. Only 3,5 DNPhTzPCP was ESD insensitive under, all test conditions. All of the compounds except 3,5 DNPhTzPCP exhibited DDT and all sustained detonation. Growth to detonation occurred best at low densities. The chloro and nitro analogs of $\mathrm{CP}$ were the only ones to yield greater output than CP in growth to detonation tests. Densities, optical microscopy, and thermal analyses of the analogs were performed. Proton and ${ }^{13} \mathrm{C}$ NMR spectra of the compounds were obtained and found to be consistent with the proposed chemical structures.

Impact testing of $\mathrm{CP}$ (lot 47344 ) reconfirmed the conclusion that the material is most sensitive in the form of unconfined pellets. Its specific heat $(\mathrm{cal} / \mathrm{g}-\mathrm{K})$ was determined to be $0.1545+0.0003 \mathrm{~T}$ over the temperature range $350-478 \mathrm{~K}$. Semi-quantitative values of solubility of $\mathrm{CP}$ in eighteen solvents were determined. Photoacoustic spectra were obtained for CP, its precursors, and known impurities. NMR spectra were obtained of loosely packed CP and its solution in DMSO. X-ray diffraction measurements showed that no residual lattice strain was introduced by 
pressing the powder at 10, 25, or $40 \mathrm{kpsi}$. Optical and scanning electron microscopy were performed on several CP lots, CP precursors, and known impurities. Lots 47344,47345 , and 52211 were found to be very similar in crystal forms and size; pressed pellets $(10,25,40 \mathrm{kpsi})$ exhibited considerable fracturing of crystals. The coefficient of thermal expansion of $\mathrm{CP}$ was found to be $i 60 \times 10^{-6} \mathrm{~mm} / \mathrm{mm}-{ }^{\circ} \mathrm{C}$. Crystals were grown for the $x$-ray diffraction structure determination of the amidine chelate. Compatibility studies of Tophet $\mathrm{A}$ and Kovar with $\mathrm{B} / \mathrm{CaCrO}{ }_{4} / \mathrm{CP}$ in support of the MC3196A detonator commenced. Mass spectroscopy showed that similar product distributions and activation energies were obtained for $\mathrm{CP}$ and $\mathrm{B} / \mathrm{CaCrO}_{4} / \mathrm{CP}$.

Development of the MC3533 detonator commenced; a contract was placed for determination of suitable ignition conditions and hardware was fabricated for planned shock ignition tests. Performance studies were planned to optimize DDT detonator design. The feasibility of utilizing ceramic varistors of several compositions to protect detonators from inadvertent ignition from electrostatic discharge stimuli was established. Several mixtures of CP with other constituents were screened as ignition materials in the MC3196A detonator. It was shown that with the spark gap of the MC3423 detonator removed, a voltage in excess of $15 \mathrm{kV}$ was required to fire the device. This established the fact that the spark gap provides suitable protection, since its breakdown was at a considerably lower voltage. The output of the MC3423 detonator was increased by increasing the density and mass of CP loaded in the output column. Electrothermal response testing was performed on MC 3423 igniters which had had their bridgewires pressed against the header surface prior to loading. These units were subsequently shown to easily meet all-fire and no-fire goals. 
II. PHYSICS OF CP DDT

Task Leader - P. L. Stanton, 2513

Technical Contributors: E. A. Igel, 1556

R. J. Haushalter, 1556

D. J. Mullikin, 2513

E. E. Jones, 2514

J. W. Nunziato, 5131

H. Krier, Combustion Sciences, Inc.

J. Mohler, Mound

J. W. Fronabarger, UMC

c. Rittenhouse, UMC

I. M. Lee, AFWL

A. Overview (P. I. Stanton)

Much of the experimental work orfginally planned for the physical characterization of reacting $C P$ has been completed. The remainder is in progress and should be completed soon. These studies, along with the modeling effort and experience with CP components have suggested additional areas for fruitful investigation. These areas are being studied both as a continuation of preceding work and as new activities.

B. Modeling DDT (P. L. Stanton)

Modeling efforts are proceeding at Combustion Sciences, Inc. and. Sandia. It now appears that as many as three different computer codes will eventually be available for modeling DDT.

The contract work at Combustion Sciences, Inc. is progressing. The WONDY code is operational and modifications are being made to incorporate the two-phase flow aspects required for DDT. Also, Dr. Krier, working in couperation with J. W. Nunziato, 5131, is making improvements and additions to his model for DDT in propellants. 
In addition to those efforts, Nunziato is developing a onedimensional code which embraces those aspects of continuum mechanics which he considers to be necessary for DDT to occur.

It is the objective of these various approaches to find the one which best simulates DDT in CP and in other explosives.

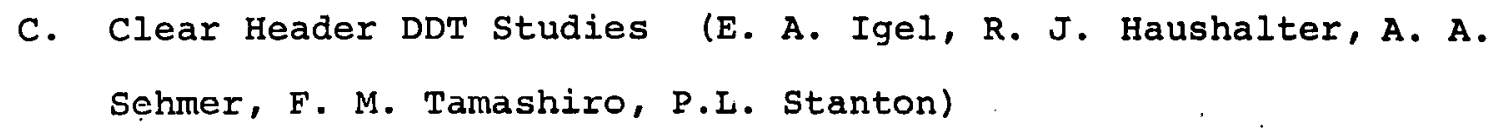

Additional experiments have been performed in this study of hot wire ignition of $\mathrm{CP}$. In each shot the burn was successfully recorded on all instrumentation, including the image converter camera, used in the streak camera mode.

CP pellets (UMC Lot No. $47344,5 \mathrm{~mm}$ diameter by $0.5 \mathrm{~mm}$ high), were pressed at densities of 1.42 and $1.62 \mathrm{Mg} / \mathrm{m}^{3}$ and were hot wire ignited by one ohm Nilstain bridgewires which were energized at an average power level of 5500 watts. The results of four firings, two at each listed density, are shown in Figure II.C.I and Table II.C.1. The displacement vs. time functions were obtained from photographic streak records in which the luminous propagation is viewed along a line located midway and perpendicular to the bridgewire.

Figure II.C.I clearly shows that the total burn time is different for the two CP densities and this difference is primarily attributable to the initial expansion rates, $0.050 \mathrm{vs} .0 .330 \mathrm{~km} / \mathrm{s}$ for $\mathrm{CP}$ at 1.42 and $1.62 \mathrm{Mg} / \mathrm{m}^{3}$, respectively. Following thio initial lincar expansion, the burn grows exponentially to a near constant velocity. Mean terminal velocities are 0.932 and $1.035 \mathrm{~km} / \mathrm{s}$ for the respective densities. When the propagation over the last millimeter of distance is caretully examined we find the velocity to be slowly increasing at a constant acceleration of $0.25 \mathrm{~mm} / \mu \mathrm{s}^{2}$. One apparent velocity anomaly, shown as a dashed line for $\mathrm{CP}$ at $1.42 \mathrm{Mg} / \mathrm{m}^{3}$, has a value of $1.17 \mathrm{~km} / \mathrm{s}$ while its physically 
symmetrical counterpart gave a value of $0.932 \mathrm{~km} / \mathrm{s}$. We have no explanation for this result. All values quoted relate to the burn phenomena at a CP-sapphire (single crystal) interface.

TABLE II.C.I

Temperature and Total Energy to Bridgewire at CP-Ignition

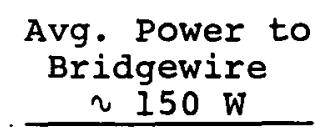

1.46

$195 \pm 10$

$578 \pm 10$

$25 \pm 1$

1.55

$172 \pm 5$

$554 \pm 10$

$23 \pm 1$
CP Density, $\mathrm{Mg} / \mathrm{m}^{3}$

Ignition Time, $\mu \mathrm{s}$

Bridgewire Temp., $\mathrm{K}$

$\sum E$ at Ignition, $\mathrm{mJ}$

$\mathrm{CP}$ Density, $\mathrm{Mg} / \mathrm{m}^{3}$

Ignition Time, $\mu s$

Bridgewire Temp., $\mathrm{k}$

$\Sigma E$ at Ignition, $\mathrm{mJ}$
Avg. Power to Bridgewire

$\sim 5500 \mathrm{~W}$

1.42

$13 \pm 1$

$983 \pm 10$

$59 \pm 6$

1.62

$10 \pm 1$

995

$47 \pm 5$

Tolerances in Table II.C.I are based on estimated instrumental errors: Listed ignition times were obtained from photodiode measurements. There is some disparity between photodiode and photographic measurements of ignition time, the time between application of current and chemical reaction, i.e., ignition. The relative difference of a couple of microseconds is presumably due to dissimilar sensitivities of the two measuring techniques. Additional olear header experiments are scheduled to examine thermal effects ahead of the burn front.

Because growth to detonation does not occur in the $2.5 \mathrm{~mm}$ radius of the $C P$ charge in the clear header assembly, a clear column experiment has been designed and DDT experiments will be conducted in which the transition may be photographically observed. 


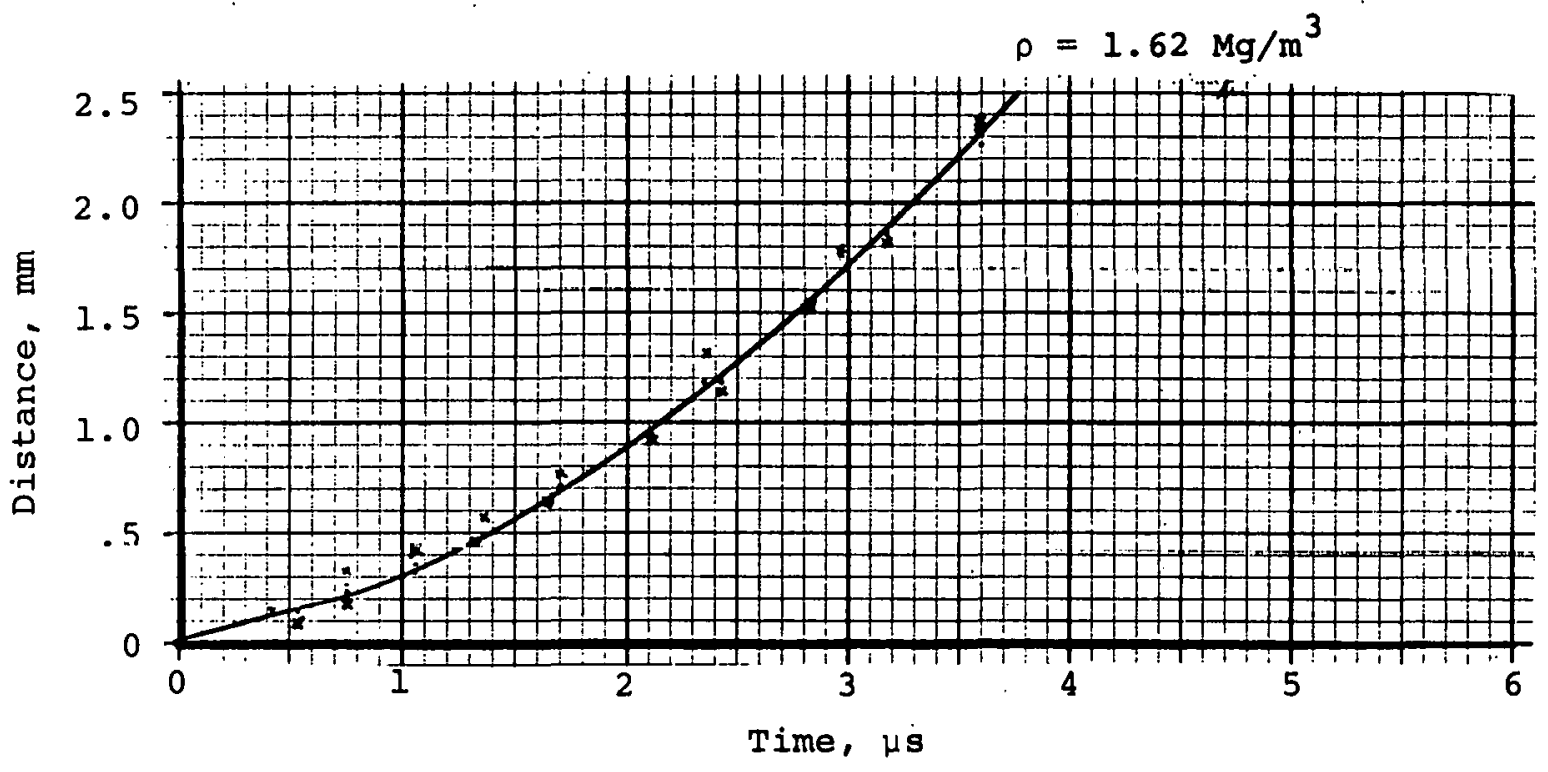

$\rho=1.42 \mathrm{Mg} / \mathrm{m}^{3}$

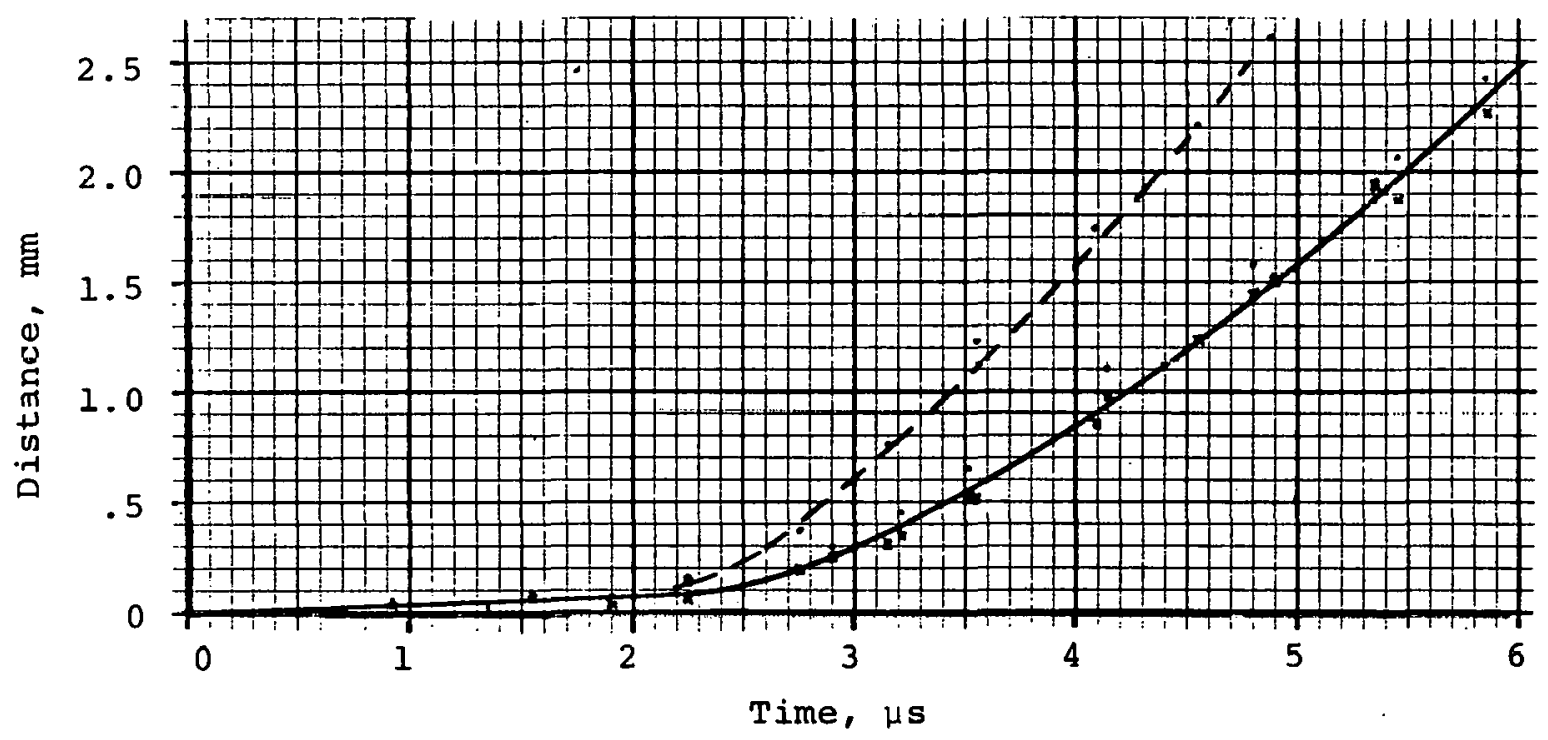

FIGURE II.C.I CP Burn at a CP-Sapphire Interface 
D. Unreacted Hugoniot Measurements (P. I. Stanton)

Under contract to Sandia, the Air Force Weapons Laboratory (AFWL) has completed a series of gun impact experiments for the measurement of the shock Hugoniot for unreacted CP. These experiments provided not only the desired Hugoniot, but also some unexpected data on impact ignition sensitivity and possible additional information regarding the growth to detonation and the residual pressure behind the detonation. These latter aspects of the data are still undergoing analysis.

The impact experiment configuration is illustrated in Figure II.D.I. A tungsten carbide or steel buffer plate is mounted in a smooth-bore gun projectile and driven to a planar impact on the explosive sample, producing a step shock wave in the sample. The amplitude of the stress at the' impact interface is monitored by the quartz guage on the other side of " the buffer plate. The known values in the impact are the impact velocity, which is measured accurately, and the stress-particle velocity Hugoniot for the buffer material and the quartz guage. A series of these experiments in which the impact velocity is varled produces the desired Hugoniot data for the target material.

Representative stress-time data are shown in Figure II.D.2. The first jump in each stress profile indicates the response of the unreacted $\mathrm{CP}$ material. Later in time, the stress begins to ramp up. The delay between the initial jump and the beginning of the ramp decreases with increasing impact stress, and the rate of rise of the ramp increases with increasinq impact stress.

The resulting Hugoniot for the unreacted CP material is shown in Figures II.D.3 and II.D.4. The observed relationship between shock velocity and particle velocity is

$$
U_{s}=.49+2.26 u_{p} \text { for } \rho_{o}=1.47 \mathrm{Mg} / \mathrm{m}^{3} \text { and } 0<u_{p}<0.5 \mathrm{~km} / \mathrm{s}
$$

and

$$
u_{s}=.53+3.57 u_{p} \text {. for } \rho_{o}=1.66 \mathrm{Mg} / \mathrm{m}^{3} \text { and } 0<u_{p}<0.7 \mathrm{~km} / \mathrm{s} \text {. }
$$




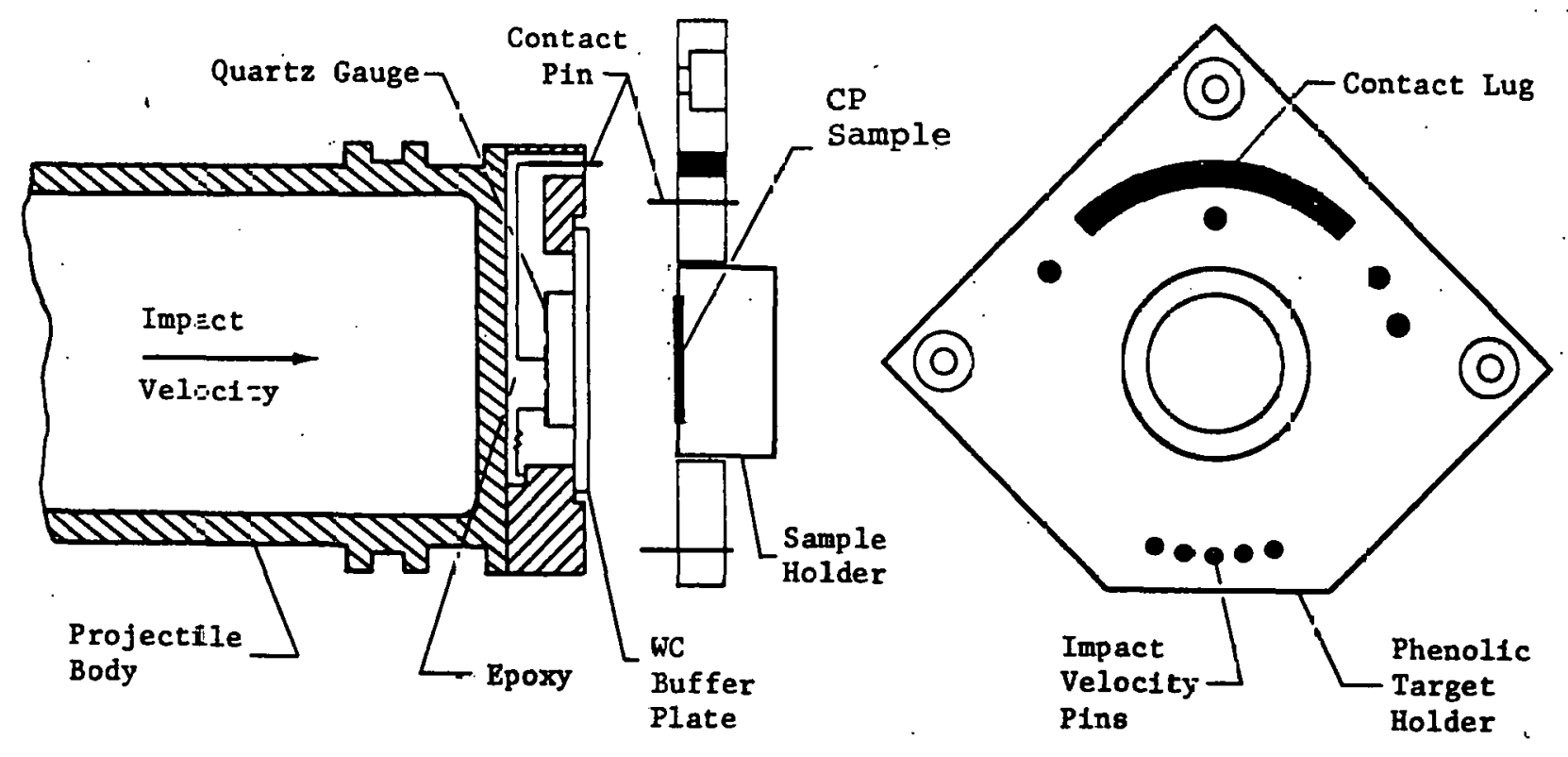

Figure II.D.1 Schematic of the Projectile and Target Configuration Jsed to Generate the CP Hugoniot Data. 


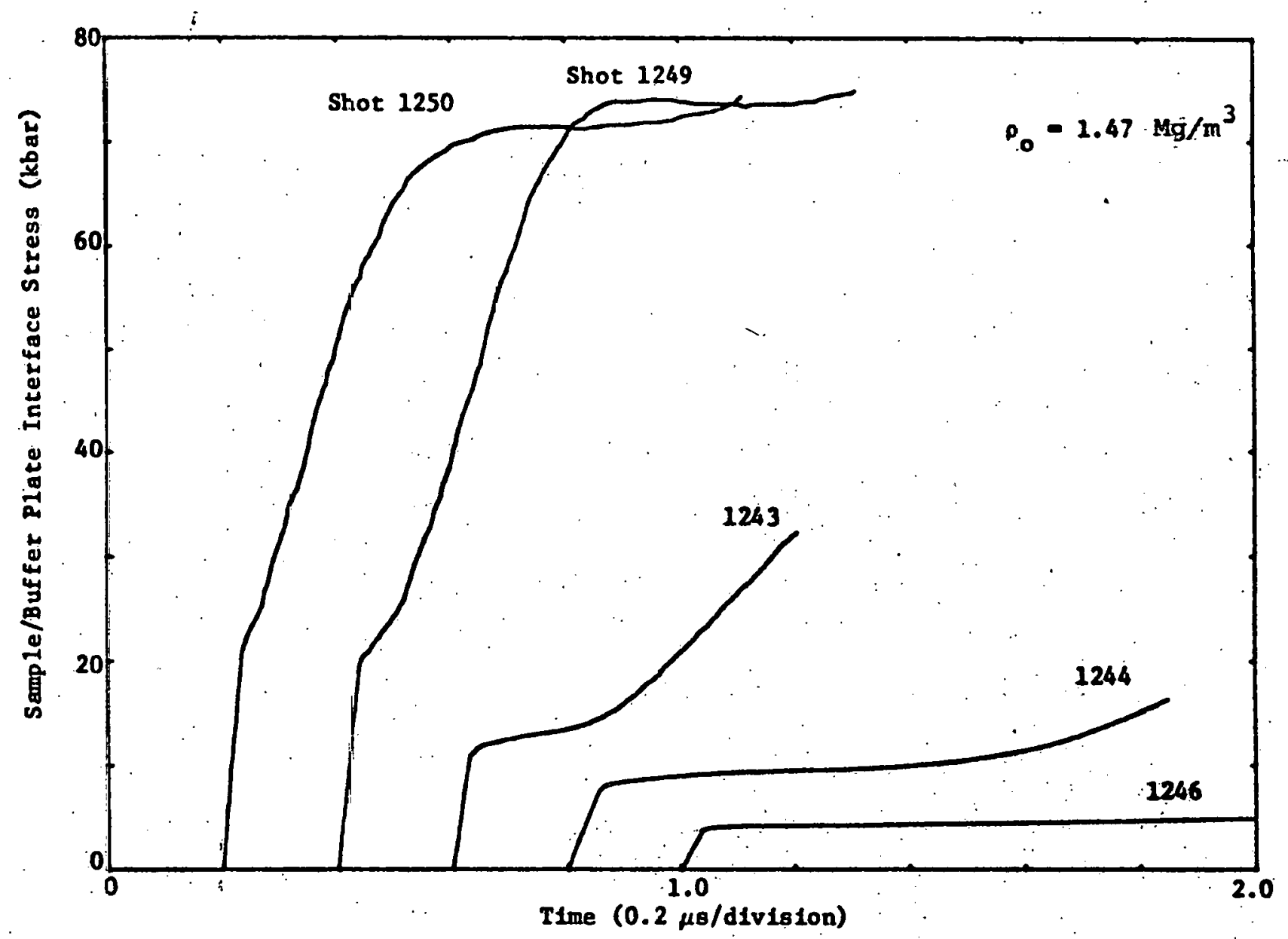

FIGURE II.D.2 Summary of Low Density CP stress-time Data from Impact Experiments. 


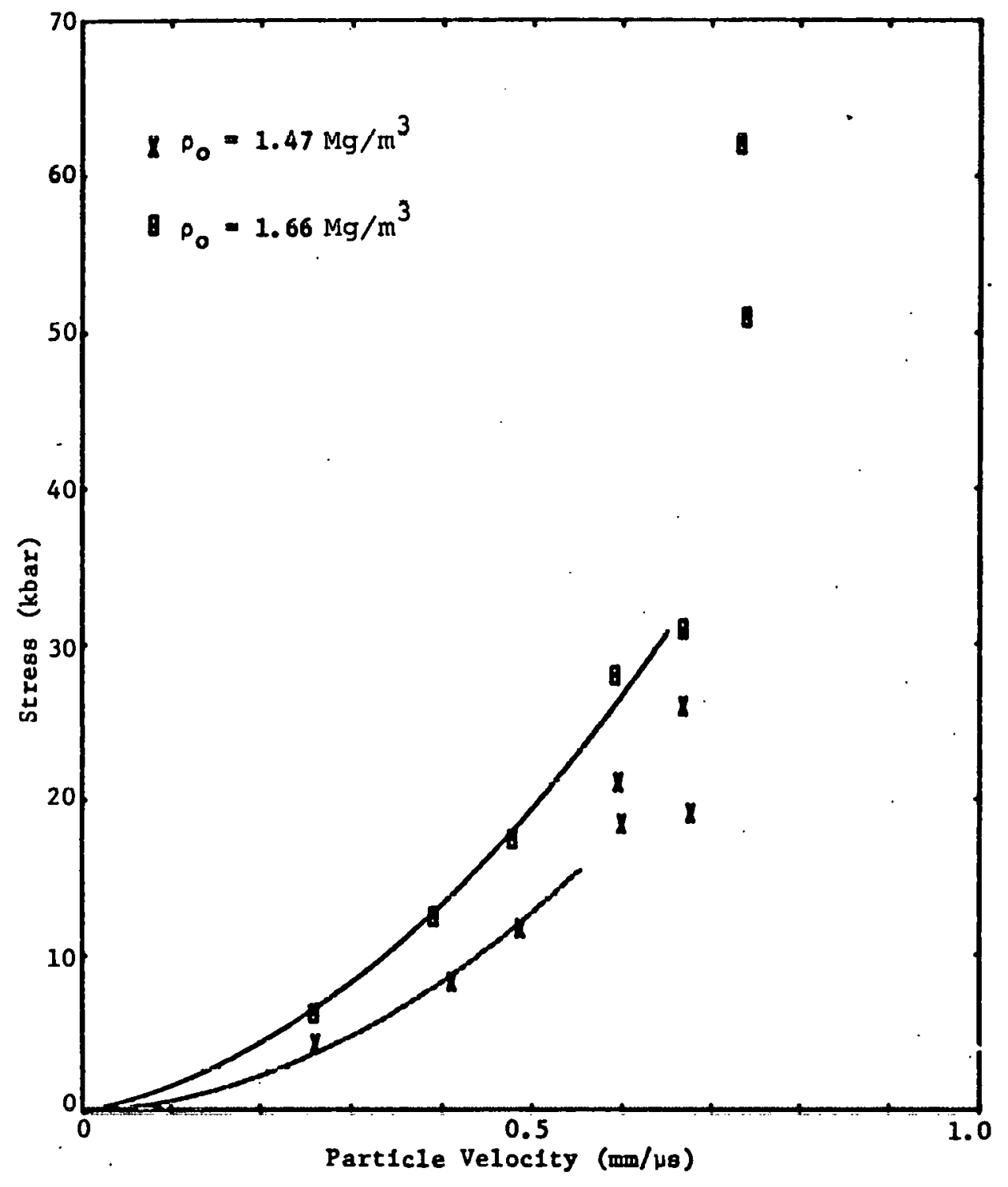

FICURE II.D. 3

Hugonlot Data for Explosive Material (CP). 


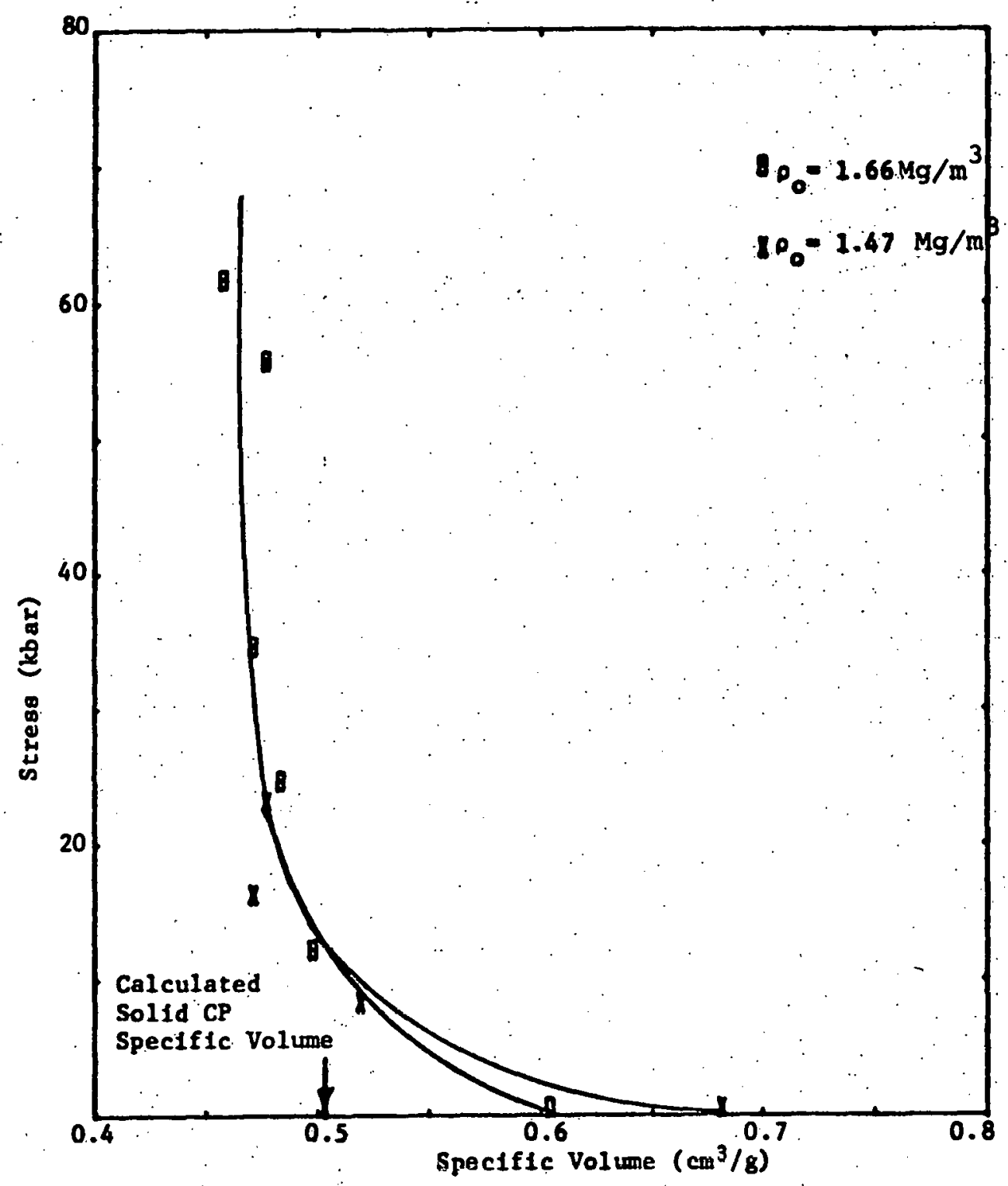

FIGURE II.D.4 Stress-specific volume Hugoniot data for porous CP explosive. 
In the higher stress level experiments, the Hugoniot data is difficult to ascertain because the reaction ramp begins almost immediately (see Figure II.D.2). In these cases, the stress appears to reach $a^{\circ}$ plateau which remains until edge effects enter. This plateau is thought to represent the residual pressure in the $C P$ detonation products following a one-dimensional expansion behind the detonation front, which is moving away from the measurement point. This, in conjunction with VISAR studies described below, may yield information on the value for $\gamma$, the adiabatic gas exponent for the detonation products.

A complete report on this test series is in preparation at AFWL.

E. Mound Optical Studies of CP Transmission Time (P. L. Stanton)

Deflagration-to-detonation studies started by J. Mohler (Md) duriṇ̣ the previous quarter were extended to higher density loadings of $\mathrm{CP}$. New tooling having a closer fit between the punch and the body of the tooling, and having a better finish solved the sticking problem encountered in previous loading. Loading the powder in small (1 $\mathrm{mm}$ ) increments had the dual benefit of reducing the force required to attain the desired density and producing uniform density along the load axis. With our present tooling, a density of $1.58 \mathrm{Mg} / \mathrm{m}^{3}$ can be achieved by loading incrementally.

Thirteen detonators with $1.5 \mathrm{Mg} / \mathrm{m}^{3}$ loads ranging in length from $2 \cdot \mathrm{mm}$ to $10 \mathrm{~mm}$ were tested in the manner described in the previous report. The time-distance profile traced by the transmissiun limes measured for this set of detonators is shown in Figure II.E.I. The coefficients of a second degree linear equation fit to this set of points are $B^{0}=1.8796$, $\mathrm{B}^{1}=0.9719, \mathrm{~B}^{2}=-0.0241\left(t=\mathrm{B}^{0}+\mathrm{B}^{1} \mathrm{~S}+\mathrm{B}^{2} \mathrm{~S}^{2}\right)$, where $t$ is time in $\mu \mathrm{s}$ and $\mathrm{S}$ is distance in $\mathrm{mm}$. This function indicates that the deflagration velocity is increasing, relatively slowly, with time and distance. The velocity is $1.1 \mathrm{~mm} / \mu \mathrm{s}$ at $2 \mathrm{~mm}$ from ignition and $2.0 \mathrm{~mm} / \mathrm{\mu s}$ at $10 \mathrm{~mm}$. 


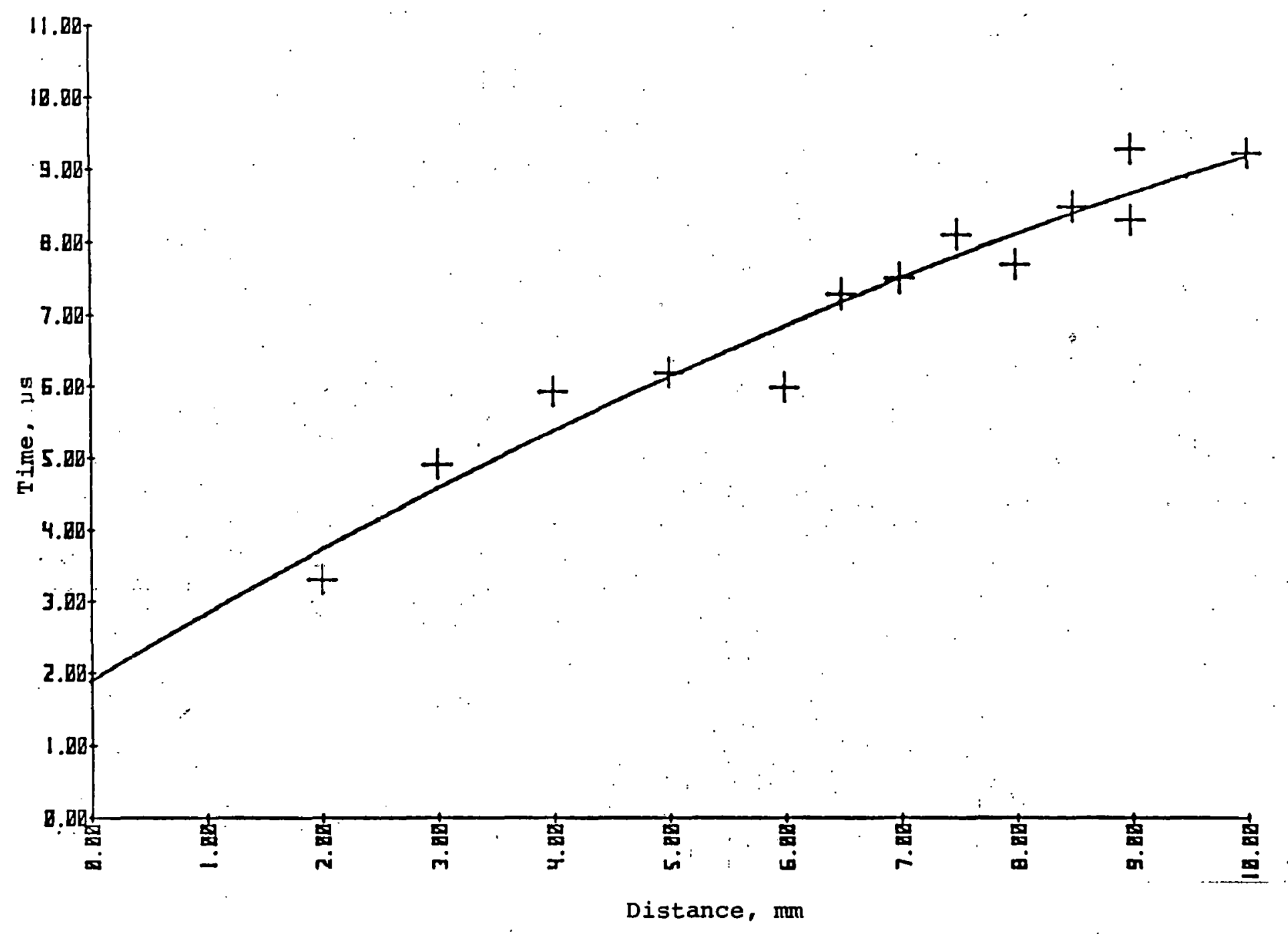

FIGURE II.E.l No Clear DDT is Apparent Before $10 \mathrm{~mm}$ at $1.5 \mathrm{Mg} / \mathrm{m}^{3}$ Density. 
As noted previously, the width of the optical pulse decreases as the deflagration proceeds. A dramatic narrowing and intensification occurs at approximately $8 \mathrm{~mm}$. This behavior was associated in the previously reported profile with the transition from deflagration-todetonation. Unfortunately, the transition could not be confirmed by observation of a corresponding velocity increase since the apparent transition occurs too near the end of the $10 \mathrm{~mm}$ load length limit. This puise narrowing behavior is illustrated in Figure II.E.2.

An improvement in instrumentation and data handling software was made during this report period. Data recorded by transient pulse recorders is transferred via the PDP-1l system to an HP2647A intelligent graphics terminal where peak locations are digitized from the control console. A typical data display is shown in Figure II.E.3.

The transition point inferred by the data reported here will be confirmed by building and firing even longer detonators. Further data will be collected for $1.1 \mathrm{Mg} / \mathrm{m}^{3}$ loadings to complete a useful profile at this density.

F. Detonation Pressure Measurements in CP (P.'L. Stanton, D. J. Mullikin, E. E. Jones)

A series of experiments to measure the Chapman-Jouget (CJ) pressure of $\mathrm{CP}$ is in progress. The first experiments have been completed and preliminary indications suggest a much higher $C P$ pressure and a higher detonation velocity than previously expected.

The experiments are being conducted at Sandia's Area II explosive test facility, using the dual delay leg VISAR system. The experimental setup is illustrated in Figure II.F.1. A CP charge, pressed into a steel housing, is initiated by an RP-2 detonator. The interaction of the detonation wave in $C P$ with a thin buffer plate is monitored using VISAR. By using buffer plates of various impedances, it is planned to map out the recompression Hugoniot and the unloading isentrope for the detonation 


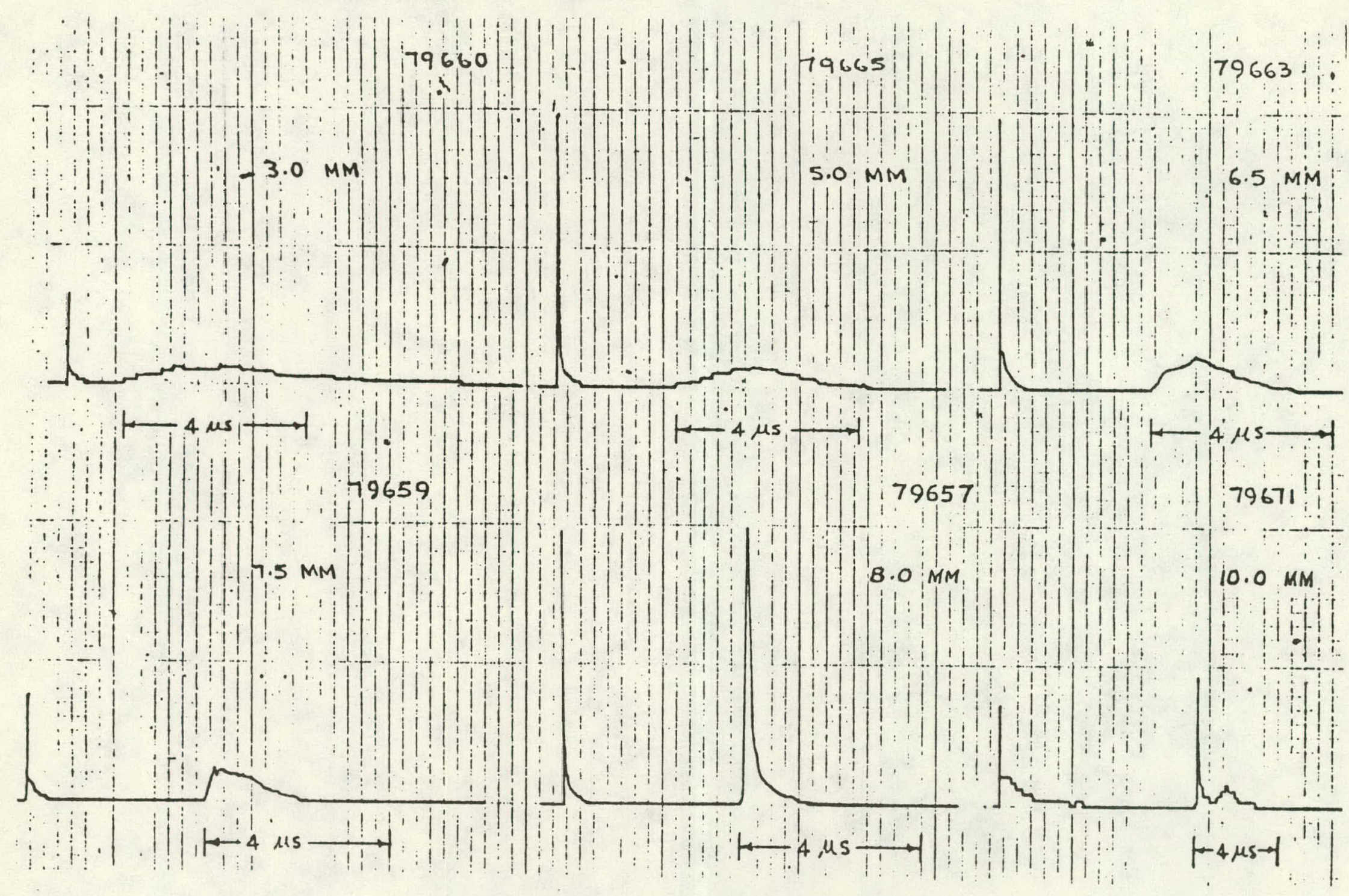

FIGURE II.E.2 Light Emission Becomes Sharper and More Intense as Deflagration Proceeds 


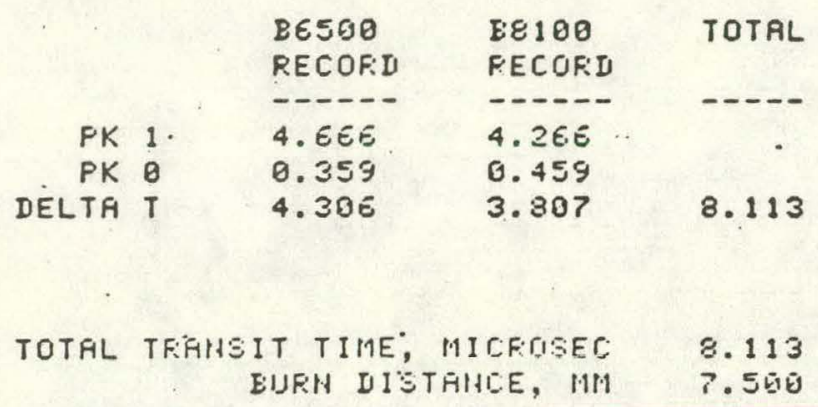

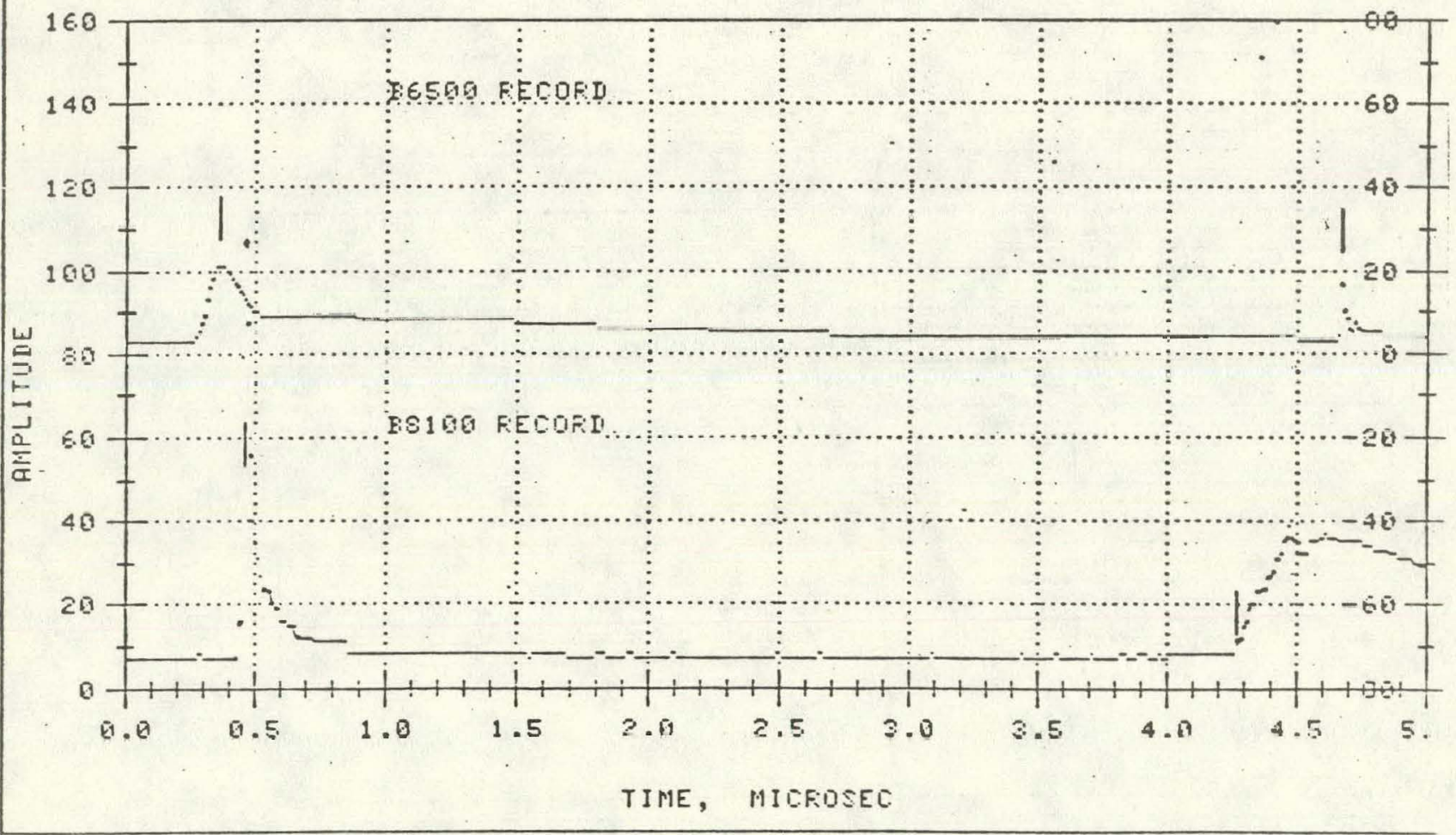

FIGURE II.E.3 CP Firing Data are Plotted and Peak Locations Determined on an HP-2647A Terminal. 


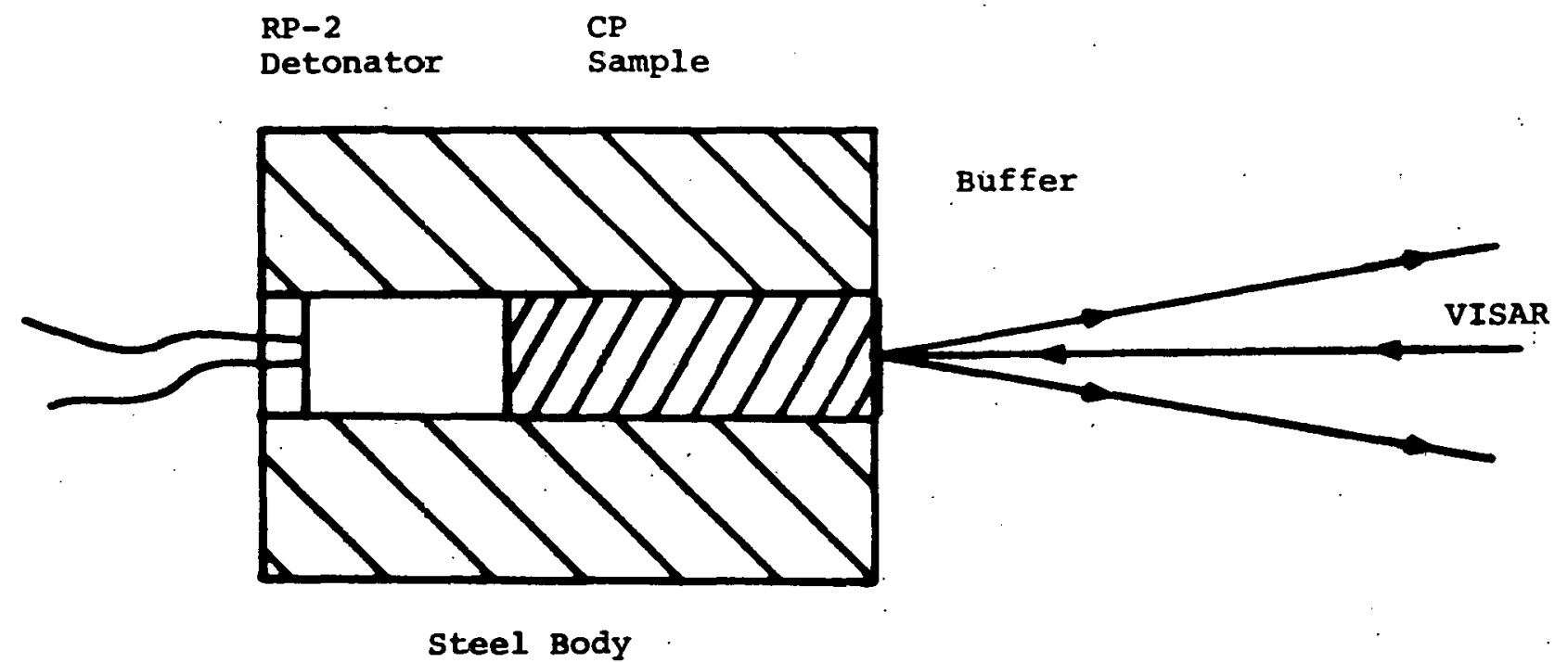

Setup for CJ Pressure Measurements

FIGURE II.F.1 
products and obtain the CJ point as the intersection of that isentrope in the pressure-particle velocity plane with the line having the slope equalling the product of initial density and detonation velocity. The average detonation velocity is measured precisely in each experiment. The preliminary results are shown in Figure II.F.2 for two initial densities of $\mathrm{CP}$. The detonation velocities were measured as $6.03 \pm 0.18$ $\mathrm{km} / \mathrm{s}$ for $\mathrm{CP}$ density of $1.52 \mathrm{Mg} / \mathrm{m}^{3}$ and $6.79 \pm 0.09 \mathrm{~km} / \mathrm{s}$ for $\mathrm{CP}$ density of $1.77 \mathrm{Mg} / \mathrm{m}^{3}$. The estimated CJ pressures are 22.0 and $27.5 \mathrm{GPa}$, respectively, for the two densities.

G. Cylinder Expansion Tests (P. L. Stanton)

Copper cylinders have been loaded with CP at Unidynamics/Phoenix and are ready to be shipped to Pantex for testing. The small scale configuration has been exercised at Pantex using PBX 9404 explosive. Thus, the way is prepared for the $\mathrm{CP}$ experiments. The results of these experiments will be to provide data for computing JWL parameters of the $C P$ detonation products. 


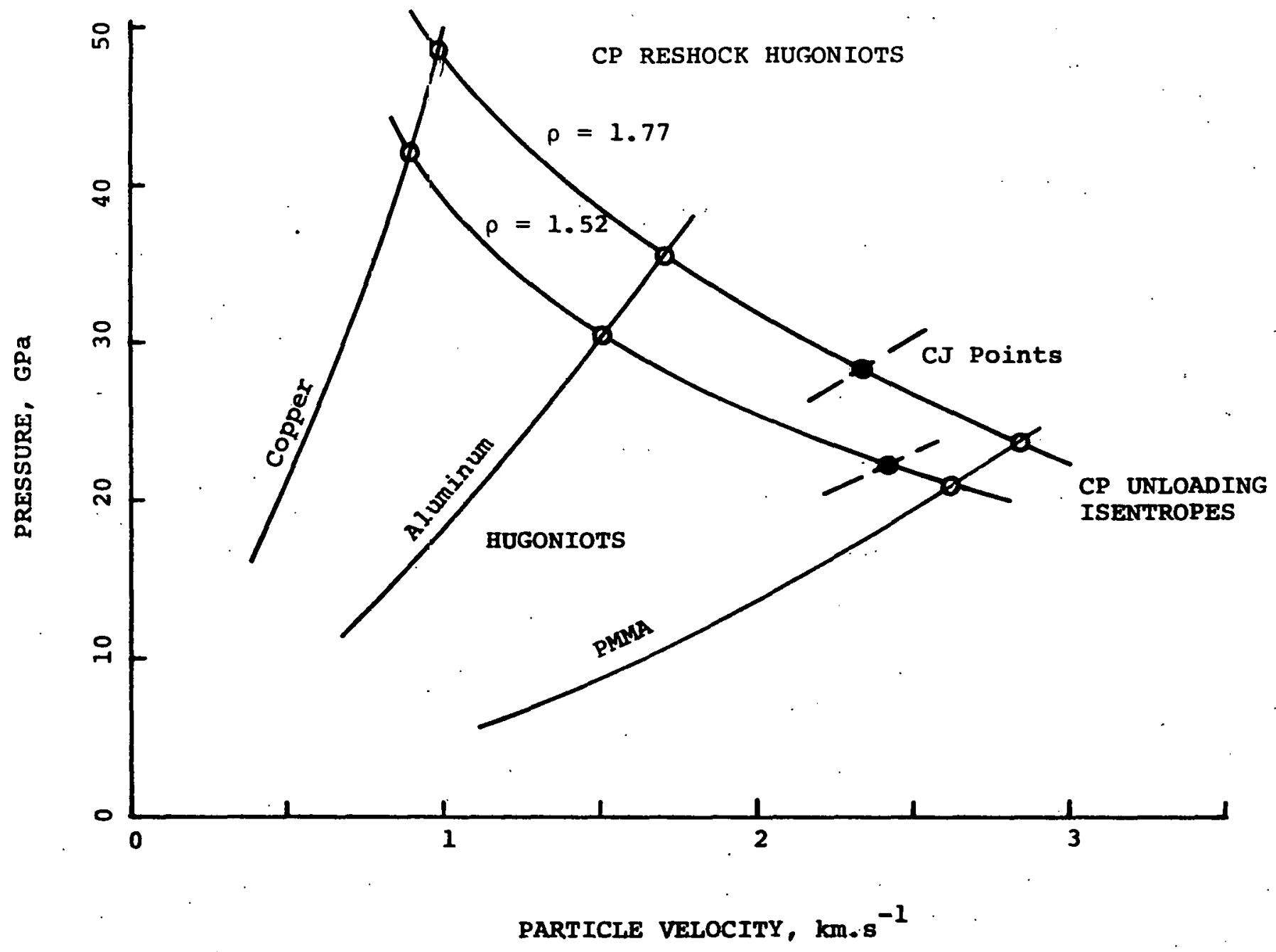

FIGURE II.F.2 
III. MATERIALS DEVELOPMENT

Task Leader - M. L. Lieberman, 2515

Technical Contributors - V. M. Loyola, 2516

E. J. Graeber, 5822

B. Morosin, 5154

R. $\mathrm{Ng}, 8442$

A. Attalla, Mound

K. Bullock, Mound

A. Burke, Mound

K. C. Coleman, Mound

I. W. Collins, Mound

D. M. Colman, Mound

B. Craft, Mound

J. Gill, Mound

C. Kinard, Mnund

w. Fleming, UMC

J. Fronabarger, UMC

A. New Materials (M. L. Lieberman)

The evaluation of compounds chemically similar to SP has been progressing satisfactorily. Work described in previous quarterly reports ${ }^{(1-4)}$ has provided initial characterization and performance data. The results have been highly encouraqing in suggesting that rhemiral modifications of 'l' can be achieved which are considerably safer and offer a variety of other property tradeoffs including greater output in detonation and pyrotechnic behavior.

As a result, additional performance studies of some of the materials have been planned. Contracts have been placed at UMC to obtain additional spark sensitivity data for several of the compounds in detonator hardware. Pyrotechnic behavior of 3,5 DNPhTzPCP will be assessed in Variable 
Explosive Chamber (VEC) tests performed by $R$. Ng (8442). Preliminary discussions regarding supportive quantum mechanical calculations have taken place with M. Schroeder (Army Ballistics Laboratory) and C. Cámpana (UNM). A structure determination of $\mathrm{CH}_{3} \mathrm{TzPCP}$ by single crystal $\mathrm{X}$-ray diffraction techniques has been initiated by B. Morosin (5154).

B. NMR of CP Analogs (V. M. Loyola)

As reported previously, ${ }^{(4)}$ the structure of the CP analogs has been studied by NMR spectroscopy. During the period covered by this report, the NMR studies have continued along the following lines:

1) aging studies of the $C P$ analogs in dimethylsulfoxide (DMSO) solution for the purpose of establishing the stabilities of the analogs in solution.

2) ${ }^{15} \mathrm{~N}$ NMR studies for the purpose of establishing the coordination of the heterocyclic ligand to the pentaammine cobalt(III) complex.

The aging studies have been completed and the results are as follows.

With the exception of 5-trifluoromethyltetrazolatopentaamminecobalt(III) perchlorate, which is contaminated with isopropyl alcohol, all of the CP analogs are stable in $\mathrm{DMSO}^{-\mathrm{d}_{6}}$ solution over a period of 40 days, at least to the limits of NMR detectability of degradation products. For the stable analogs aging in DMSO- $d_{6}$ causes no changes in their ${ }^{1} \mathrm{H}$ and ${ }^{13} \mathrm{C}$ NMR spectra as can be seen by comparing their aged spectra, Figures III.B.1-III.B.8, with these same spectra of the fresh solutions found in the preceding quarterly report. (4) The sole exception, 5-trifluoromethyltetrazolatopentaamminecobalt(III) perchlorate, Figure III.B.3, can be seen to have changed peak intensities of the $\mathrm{NH}_{3}$ NMR peaks in going from fresh to aged solution. This shift in peaks is attributed to an exchange mechanism involving the isopropyl alcohol by 
$4-\mathrm{NO}_{2}-\mathrm{V}-\mathrm{TrPCP}$

Lot \# EL 52285

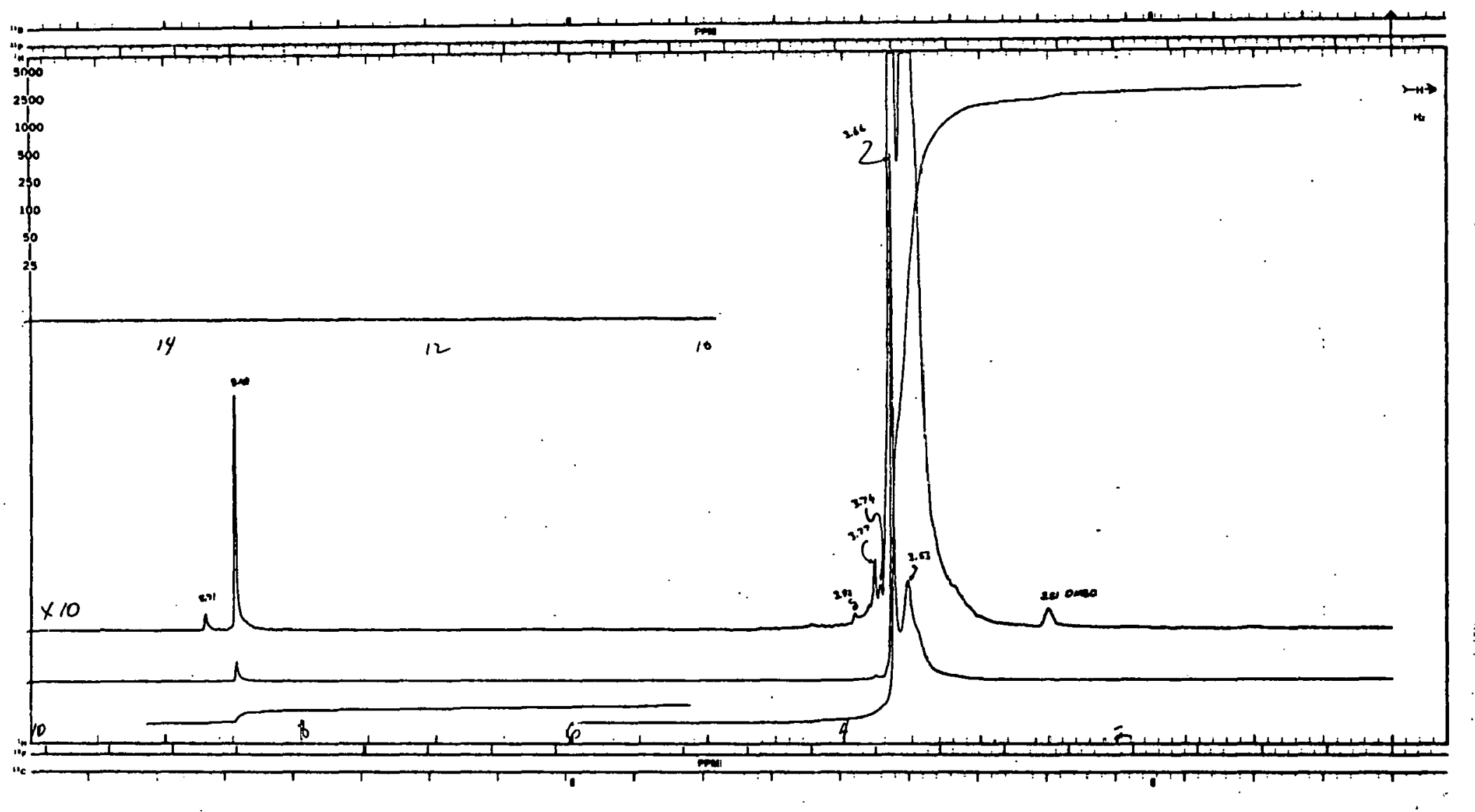

FIGURE III.B.1 $1_{H}$ spectrum of "Aged" 4-Nitro-1,2,3-Triazolatopentaamminezobalt(III) perchlorate. 
$3-\mathrm{NO}_{2}-\mathrm{S}-\mathrm{TrPCP}$

Lot \# EL 56032

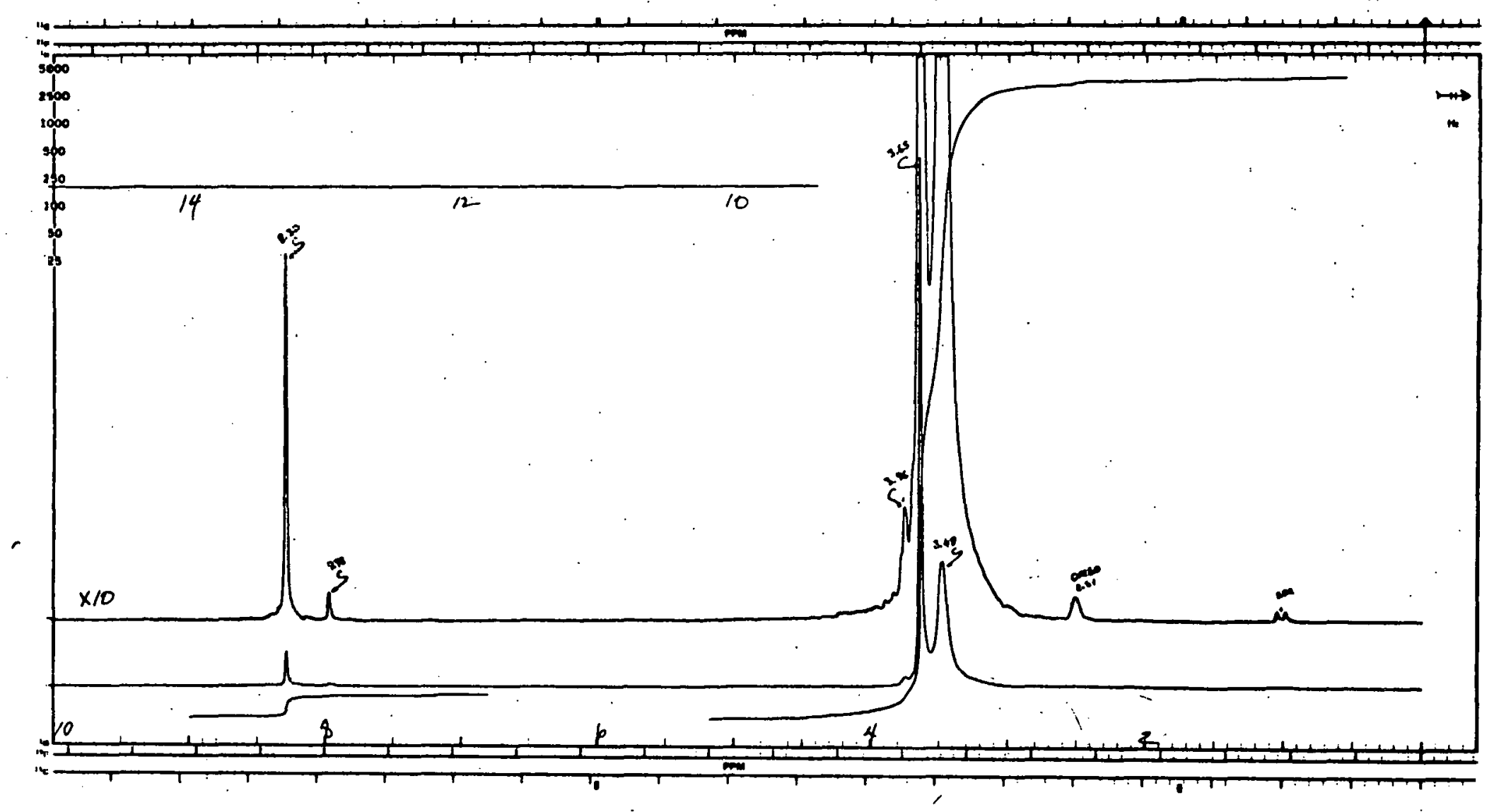

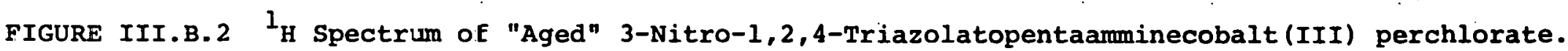


$5-\mathrm{CF}_{3}$ TzPCP

Lot \# EL 52273

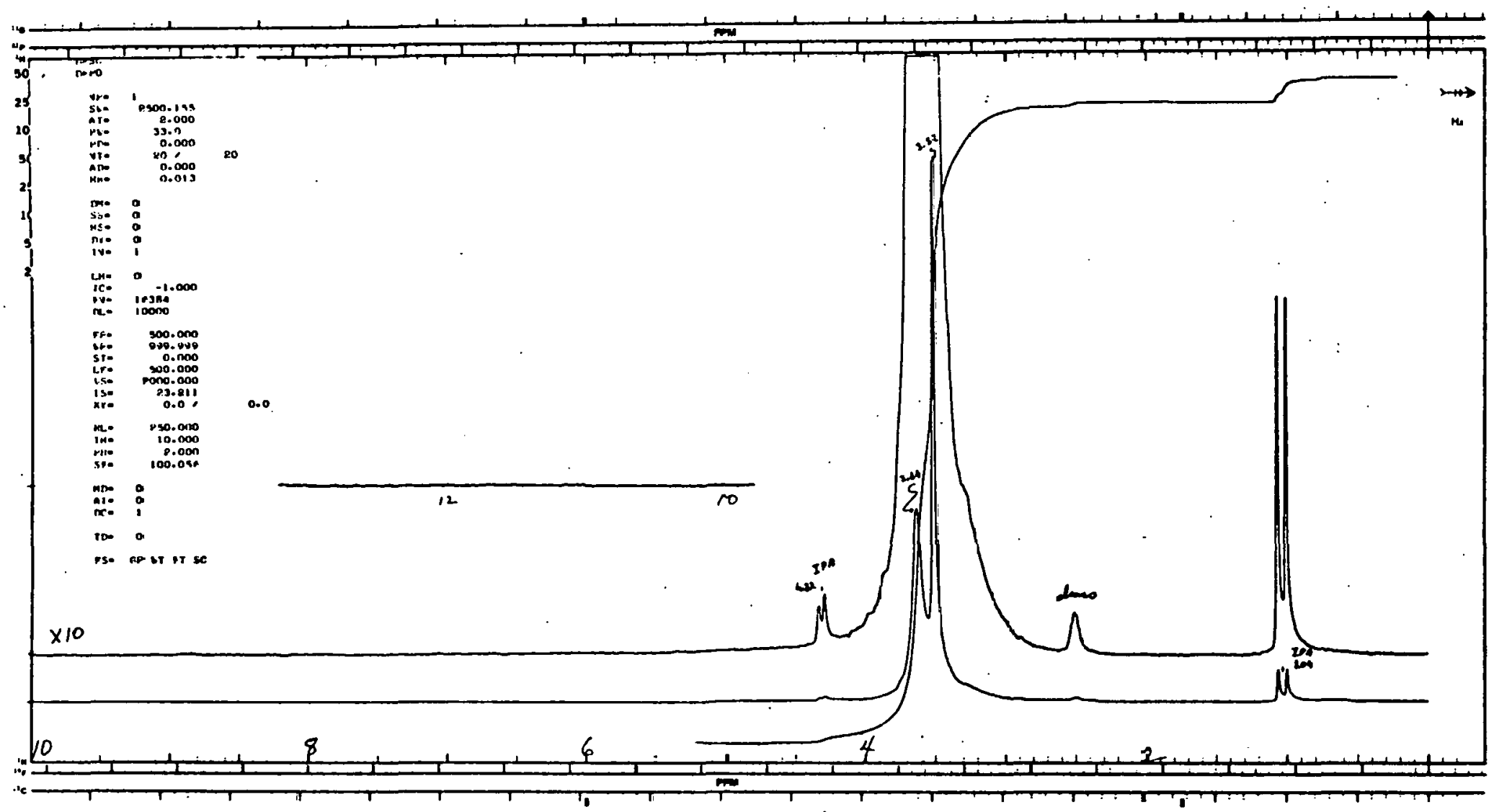

FIGURE III.B.3 5-Trifluoromethyltetrazolatopentaaminecobalt (III) perchlorate: 
$5-\mathrm{CH}_{3} \mathrm{TzPCP}$

Lot \# EL 52275

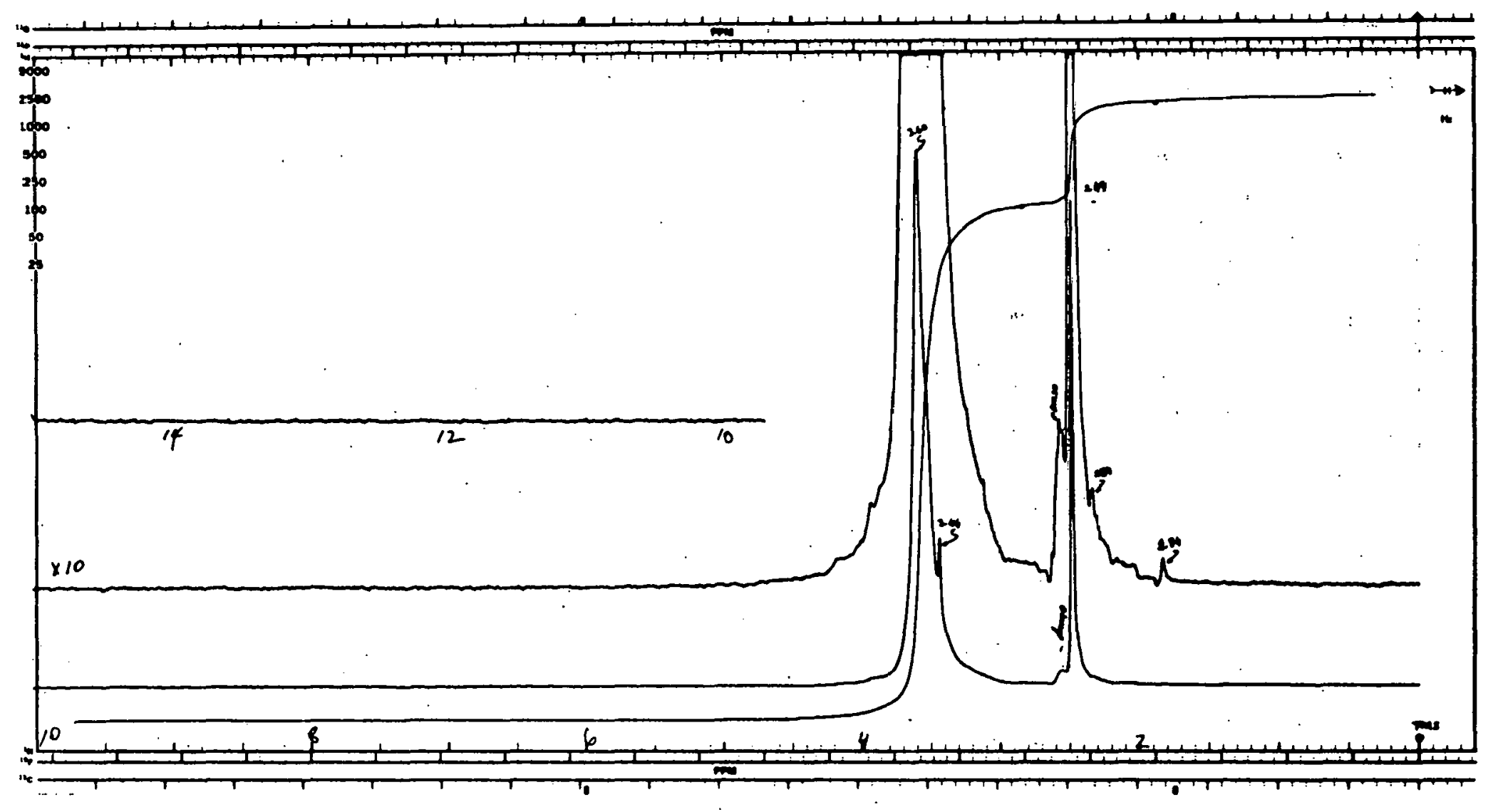

FIGURE III.B.4 ${ }^{1}$ H Spectrun of "Aged" 5-Methyltetrazolatopentaaminecobalt(III) perchlorate. 
HTzPCP

Lot \# EL 52260

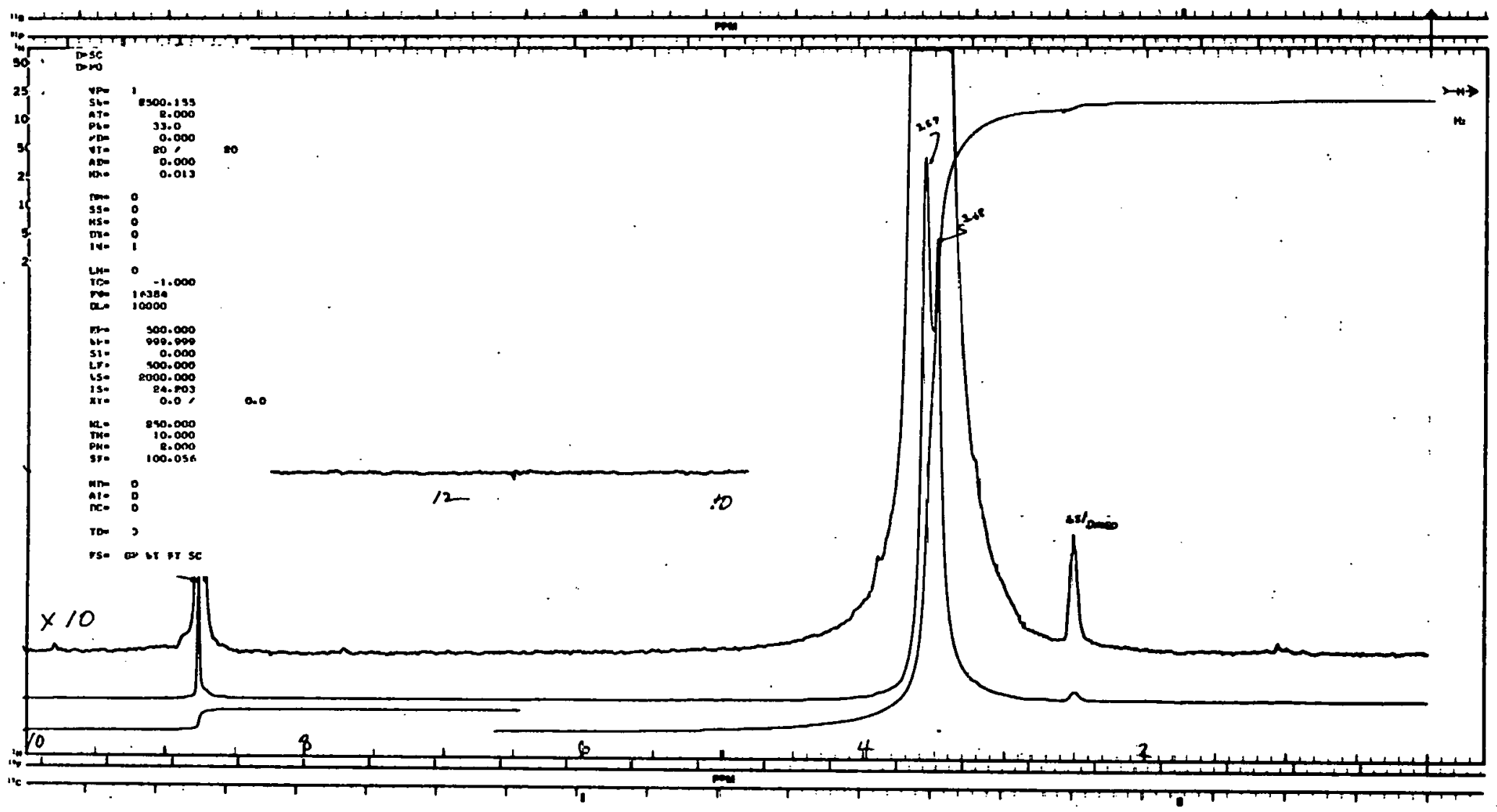

FIGURE III.B.5 ${ }^{1}$ H Spectrum of "Aged" 5-Tetrazolatopentaaminecobalt(III) perchlorate. 
5-ClTzPCP

Lot \# EL 52286-2

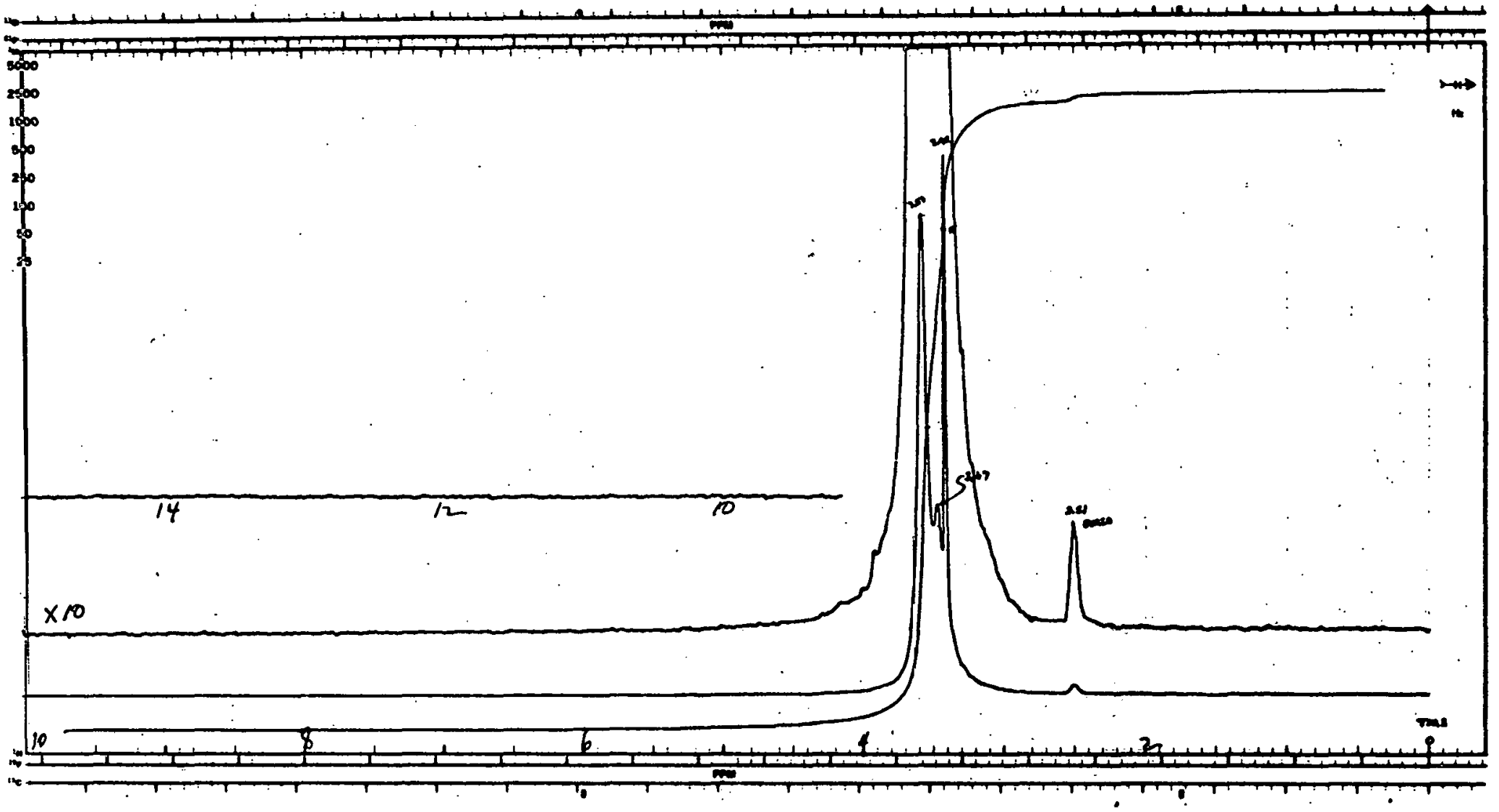

FIGURE III.B.6 ${ }^{1}$ H Spectrum OE "Aged" 5-Chlorotetrazolatopentaamminecobalt(III) perchlorate. 
5-NO 2 TzPCP

Lot \# EL 52262

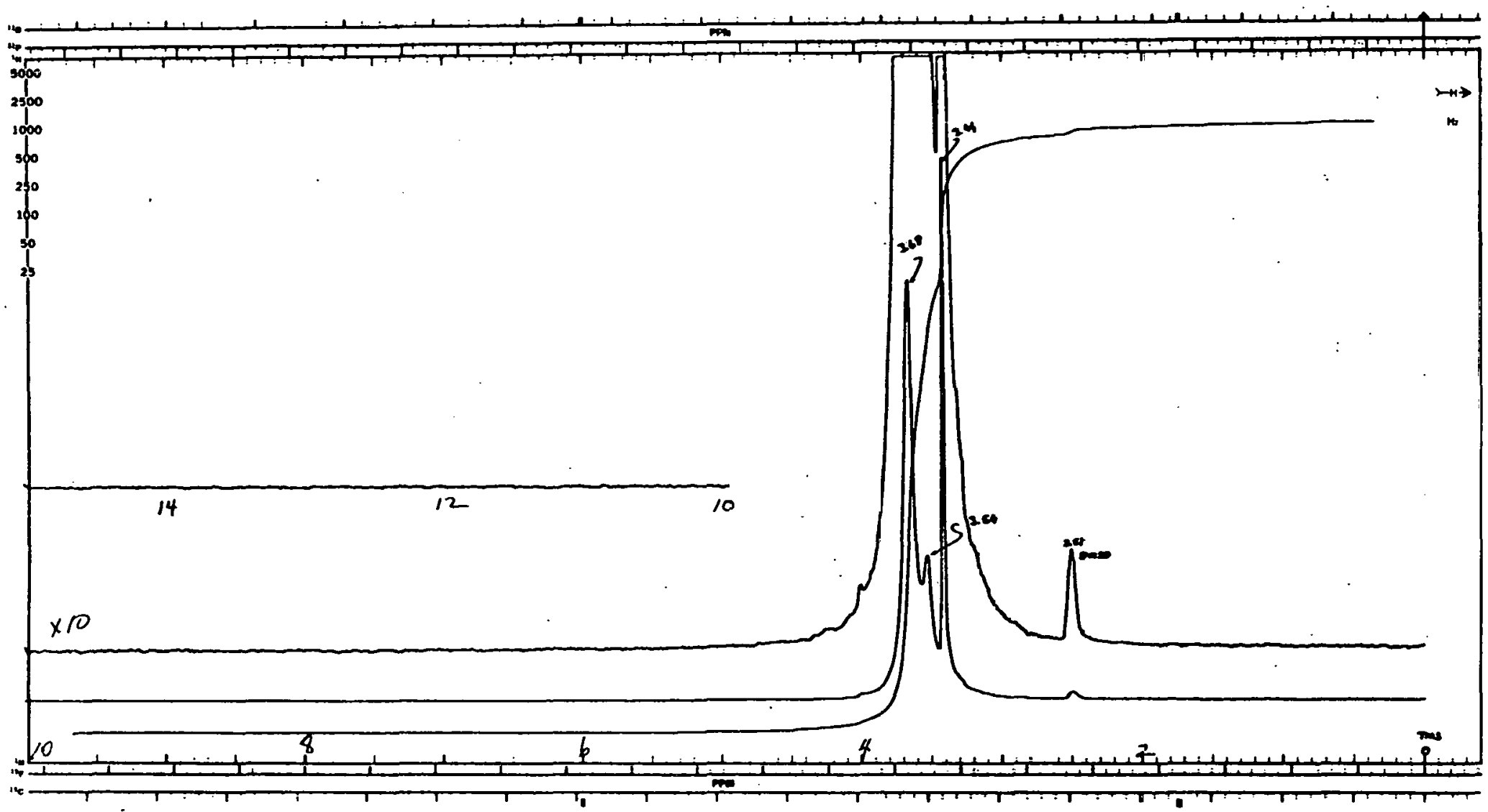

FIGURE III.B.7 $1_{\mathrm{H}}$ Spectrum of "Aged" 5-Nitrotetrazolatopentaaminecobalt(III) perchlorate. 
5- (3,5-DnPh) TzPCP

Lot \# EL 52257-B

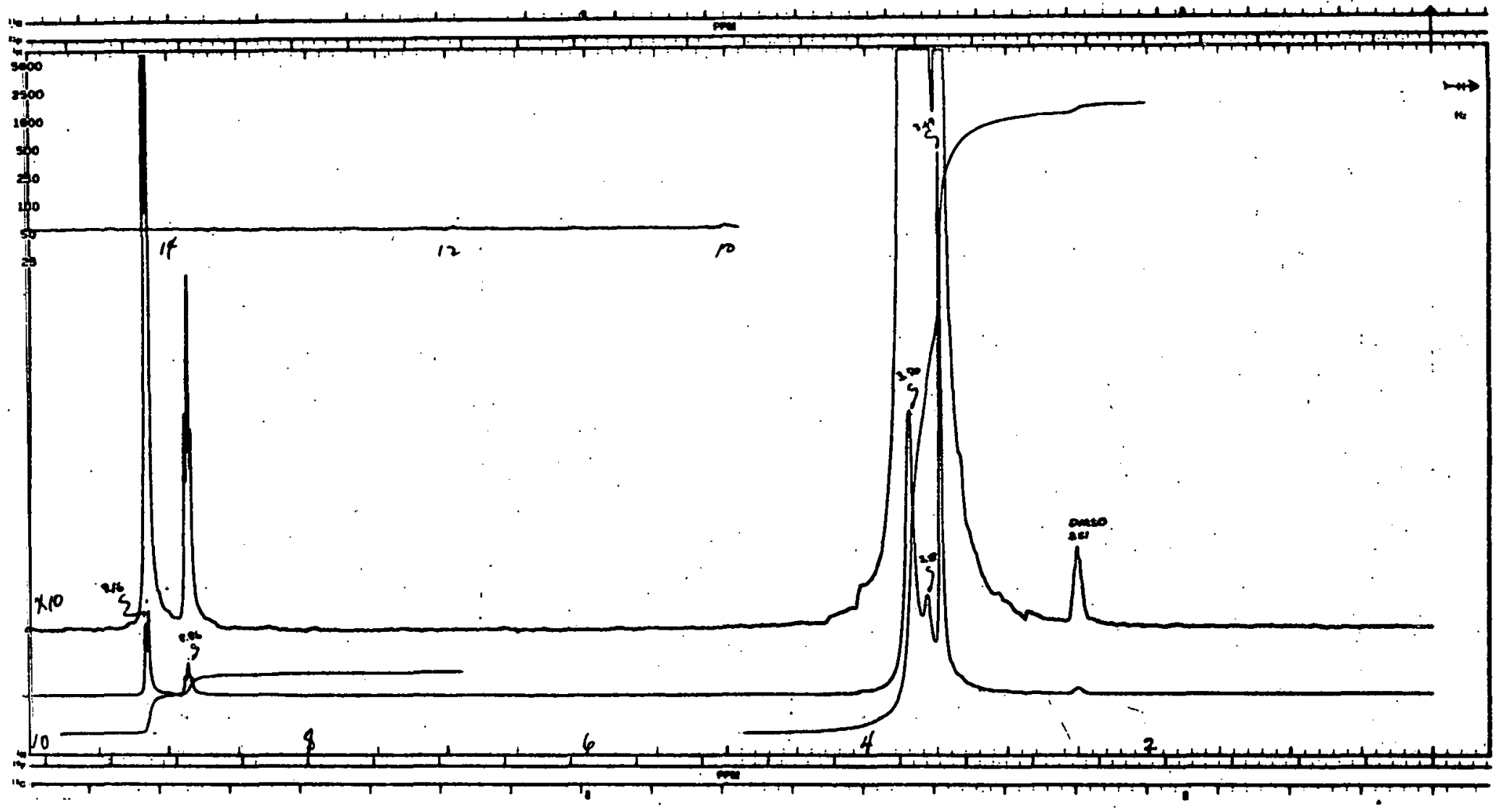

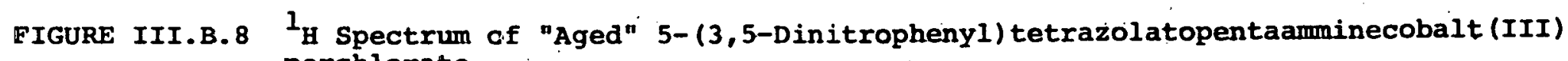
perchlorate. 
which the $\mathrm{NH}_{3}$ protons are exchanged for deuterium from DMSO- $\mathrm{d}_{6}$. The mechanism is not known but is presumed to involve isopropyl alcohol because it is seen only for the 5-trifluoromethyltetrazolato complex and not for any of the other analogs which are free of the isopropyl alcohol contaminant. An exchange mechanism is involved because the same type of $\mathrm{NH}_{3} \mathrm{NMR}$ peak shifts have been observed for $\mathrm{CP}$ when $\mathrm{D}_{2} \mathrm{O}$ was added to DMSO-d $d_{G}$ solution (Final Report SRI Project No. PYD-4610, prepared for Sandia Laboratories by Lois L. Gerchman).

In the cases of 3-nitro-1,2,4-triazolatopentaamminecobalt(III) perchlorate and 4-nitro-l,2,3-triazolatopentaamminecobalt(III) perchlorate the aging studies show no evidence of decomposition due to aging, but increasing the instrument sensitivity by a factor of ten, Figures III.B.I and III.B.2, does show the presence of ${ }^{1_{H}}$ peaks not detected previously. Careful inspection of the fresh solution NMR spectra of these complexes, ${ }^{(4)}$ shows that these extraneous peaks were present there also, but were not detected because sensitivity was not great enough. These extraneous peaks are believed to arise from the presence of small amounts of a second coordination isomer for each of these analogs: it is not, howeveri, known which isomer corresponds to major and which to minor species. This dilemma very clearly points out the need for either ${ }^{15} \mathrm{~N} N M R$ or $x$-ray structural work to determine the structure of the major species. As mentioned previously, (4) $15 \mathrm{~N}$ NMR work is being pursued at the Colorado State University Regional NMR Center in hopes of elucidating the heterocyclic coordination to cobalt(III) in these compounds. To date no positive results have been obtained in the attempts to obtain $15 \mathrm{~N}$ natural abundance spectra, but investigations are continuing in an attempt to optimize conditions by which such spectra can be obtained. The experiments to date have been limited to attempts at obtaining the ${ }^{15} \mathrm{~N}$ spectra of the tetrazole, 5-methyltetrazole and 5-chlorotetrazole ligands. The initial investigations are being limited to the ligands 
in order to avoid the handling of the explosive analogs at CSU until suitable procedures are established.

The conclusions which can be drawn with the work done to date are:

1) The CP analogs are pentaamminecobalt(III) complexes.

2) The CP analogs are either single isomers or formation of one isomer is heavily favored over another.

3) The CP analogs are sufficiently stable in solution to allow the preparation of DMSO solutions for transportation to CSU for NMR experimentation without concern for the molecular integrity of the complexes concerned.

C. Electrostatic Discharge/Electrothermal Response of CP (M. L. Lieberman)

A study of the ESD/ETR behavior of CP is being performed at Unidynamics. The first part of the study involves measuring ESD and ETR in the identical igniters. Approximately fifteen igniters of the special design shown in Figure III.C.I were loaded at each of five different densities. Loading pressures of $5,10,15,40$, and $60 \mathrm{kpsi}$ were employed. ETR measurements yielded the curve shown in Figure III.C.2. The point at zero density corresponds to the unloaded units. Whether ur nut a sharp discontinulty in the data occurs cannot be stated with certainty. However, it is clear that heat transfer from the bridgewire to the rest of the system is enhanced, in these units, at densities and/ or loading pressures beyond $1.4 \mathrm{Mg} / \mathrm{m}^{3}$ and/or $10 \mathrm{kpsi}$, respectively. This could be due to a variety of factors including a decrease in the film heat transfer coefficient, an increase in the CP powder-bridgewire surface contact due to increased crushing of the powder, or an increase in the heat transfer from the bridgewire to the ceramic header due to an increased displacement of the briagewire in the direction of the header. Additional analysis of the data and some units is planned.. 


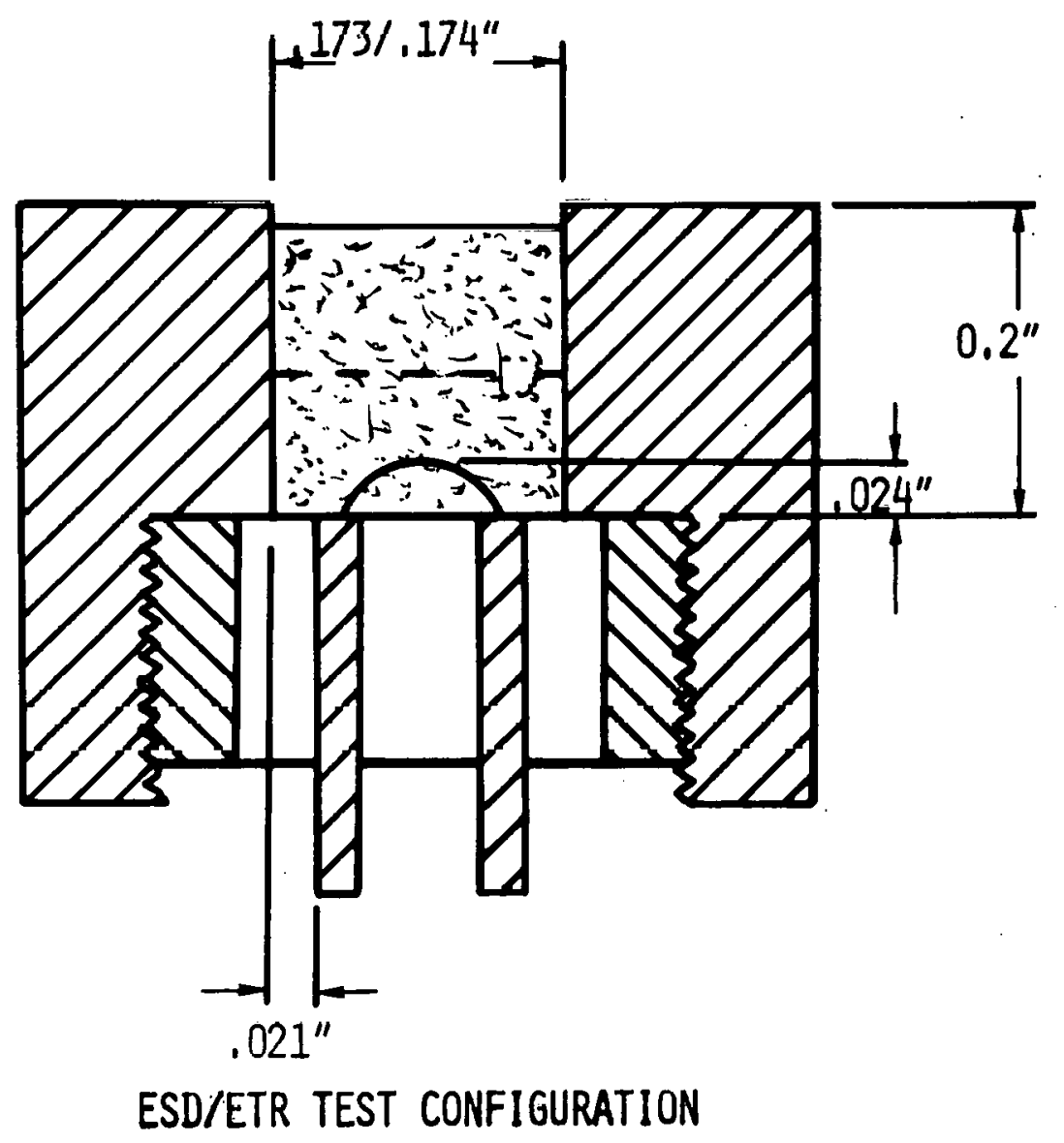

FIGIIRE III.C.I 


$$
D
$$


Following the ETR measurements, ESD testing was performed. A relatively small number of additional units were loaded at $25 \mathrm{kpsi}$ in order to obtain more complete ESD data in the previously untested higher density region. The spark gap was 21 . mils. $C P$ was loaded at $5,10,15$, 25, 40, and $60 \mathrm{kpsi}$. Results are shown in Figure III.C.3. The lowest fire--highest no-fire bar is a measure of ignition sensitivity, while the lowest breakdown--highest no-breakdown bar is a measure of dielectric strength. Note that the ignition curve is more or less U-shaped. Prior studies $(5,6)$ had been limited to densities below $1.6 \mathrm{~g} / \mathrm{cm}^{3}$. In that density range the spark sensitivity increases (decreasing voltage) with increasing density. At greater densities, however, the spark ignition sensitivity decreases markedly with increasing density. Spark response in the higher density range is thus consistent with that of other explosives, i.e., spark ignition sensitivity decreases with increasing density. An important implication of this result is the fact that electrostatic safety in CP-loaded detonators can be improved by loading the ignition charge to greater densities.

The unusual U-shaped curve may seem puzzling. This can be rationalized by considering it as the result of two competing factors, namely, the intrinsic spark sensitivity of the material and its breakdown voltage (or dielectric strength). Figure III.C.4 illustrates this condition. At low densities, spark ignition is controlled by the intrinsic spark sensitivity of the material, whereas at high densities the ignition is limited by the breakdown voltage. Thus, the resultant curve is obtained from the greater voltage of the two separate factors. This is clearly shown by the data in Figure III.C.3. At a density of $1.3 \mathrm{~g} / \mathrm{cm}^{3}$ the breakdown bar is considerably lower than that of the ignition condition. At all other densities, however, the ignition and breakdown bars are virtually identical. Another part of the study involved the determination of ETR data for CP under load in MC3423 igniters. Data were obtained for several units 


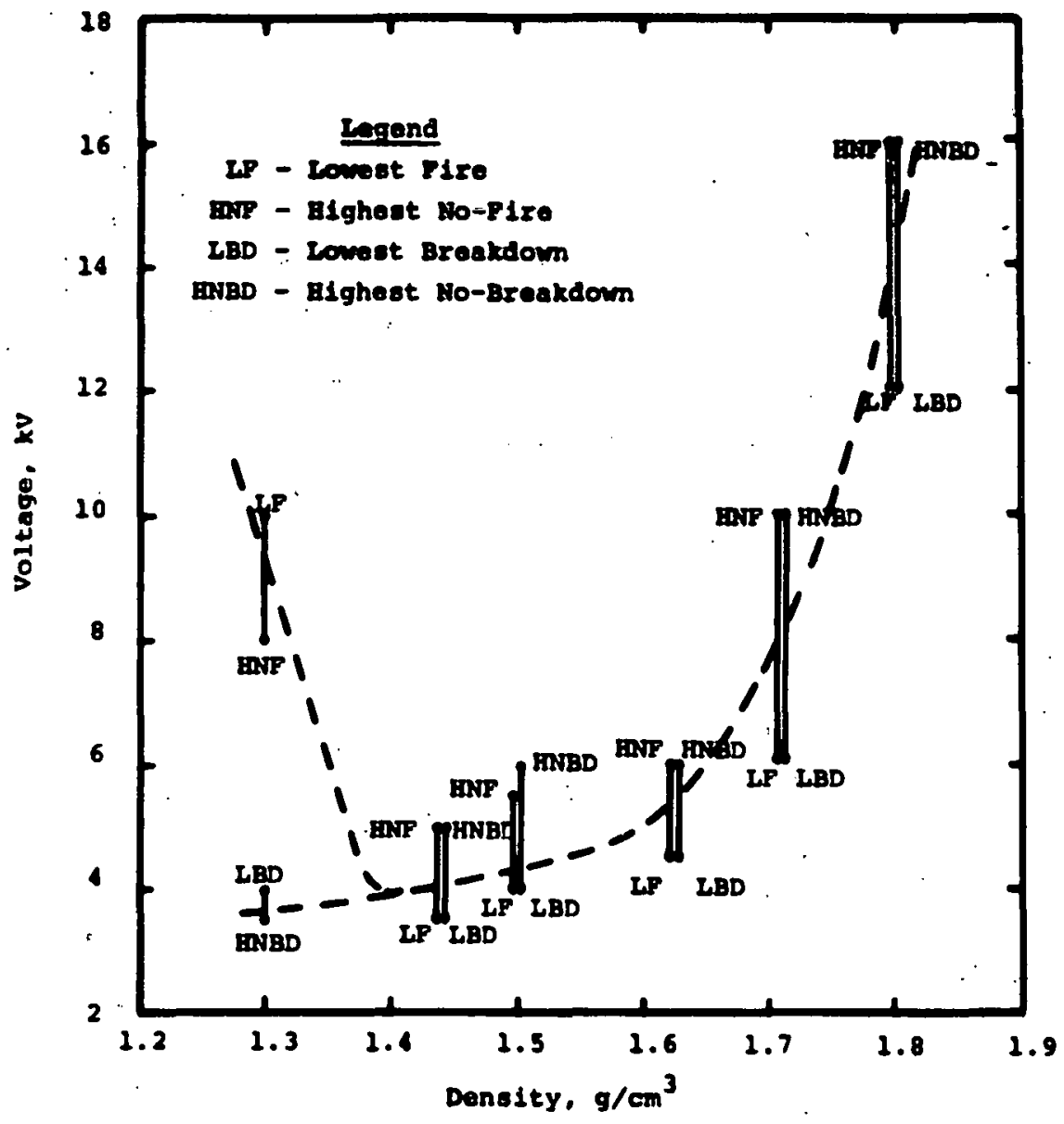

FIGURE III.C.3 Electrostatic discharge sensitivity of CP.

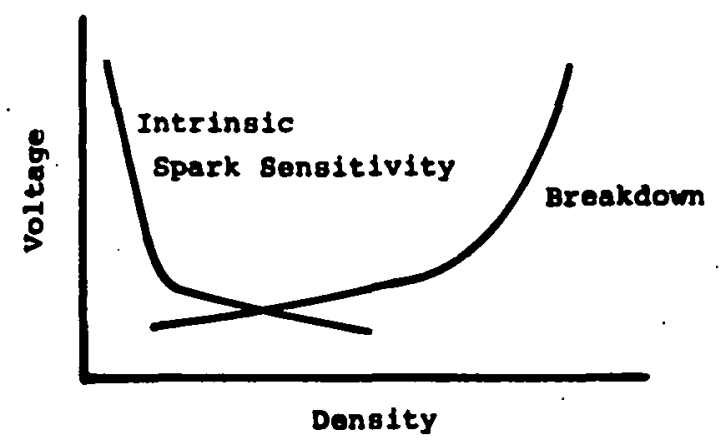

FIGURE III.C.4 Factors affecting electrostatic discharge sensitivity of $\mathrm{CP}$. 
under conditions of increasing load to $\sim 70 \mathrm{kpsi}$ and then under conditions of decreasing load. Figure III.C.5 is a representative plot of theta versus load. The discontinuous change in theta near $40 \mathrm{kpsi}$ is due to a change in current pulse applied during the ETR measurement. Gamma versus load is shown in Figures III.C.6 and III.C.7 for two tests. Both show relatively smooth increases in gamma with increasing load. Since the density-loading pressure curve for $C P$ is approximately exponential, these figures suggest that the near exponential increase in gamma with increasing load is simply a reflection of increasing density. It is significant to note that with reduction and removal of load gamma is not reduced. This indicates that the powder does not relax and move away from the bridgewire. Also, note that three points are shown for complete removal of load. These correspond to (a) reduction to zero load, (b) removal of loading ram, and (c) three weeks later. In both figures gamma decreases in the order $\gamma_{a}>\gamma_{b}>\gamma_{c}$. An important point is the fact that the value of gamma remains quite constant for a considerable period after removal of load. Figure III.C.8 shows a representative curve of ram travel as a function of lodd.

D. Impact Sensitivity of CP Solutions (M. L. Lieberman)

In order to help evaluate possible hazards associated with $\mathrm{CP}$ in solutions a qualitative assessment of the impact sensitivity of $0.5 \mathrm{M}$ solutions of CP in DMSO was performed by L. W. Collins (Mound). An olinMathieson drop weight tester with a five kilogram load was used in the testing. This load represents a significant overtest since the "standard" Bureau of Mines test utilizes only two kilogram loads. However, the sample holder was not designed to test solutions, so the overtest was desirable to compensate for any errors introduced by the test configuration.

For the tests, 0.2 to $0.3 \mathrm{ml}$ of the $\mathrm{CP}$ solution was sealed (nonhermetic) in a small aluminum pan which was then placed inside a brass 
UNIT D

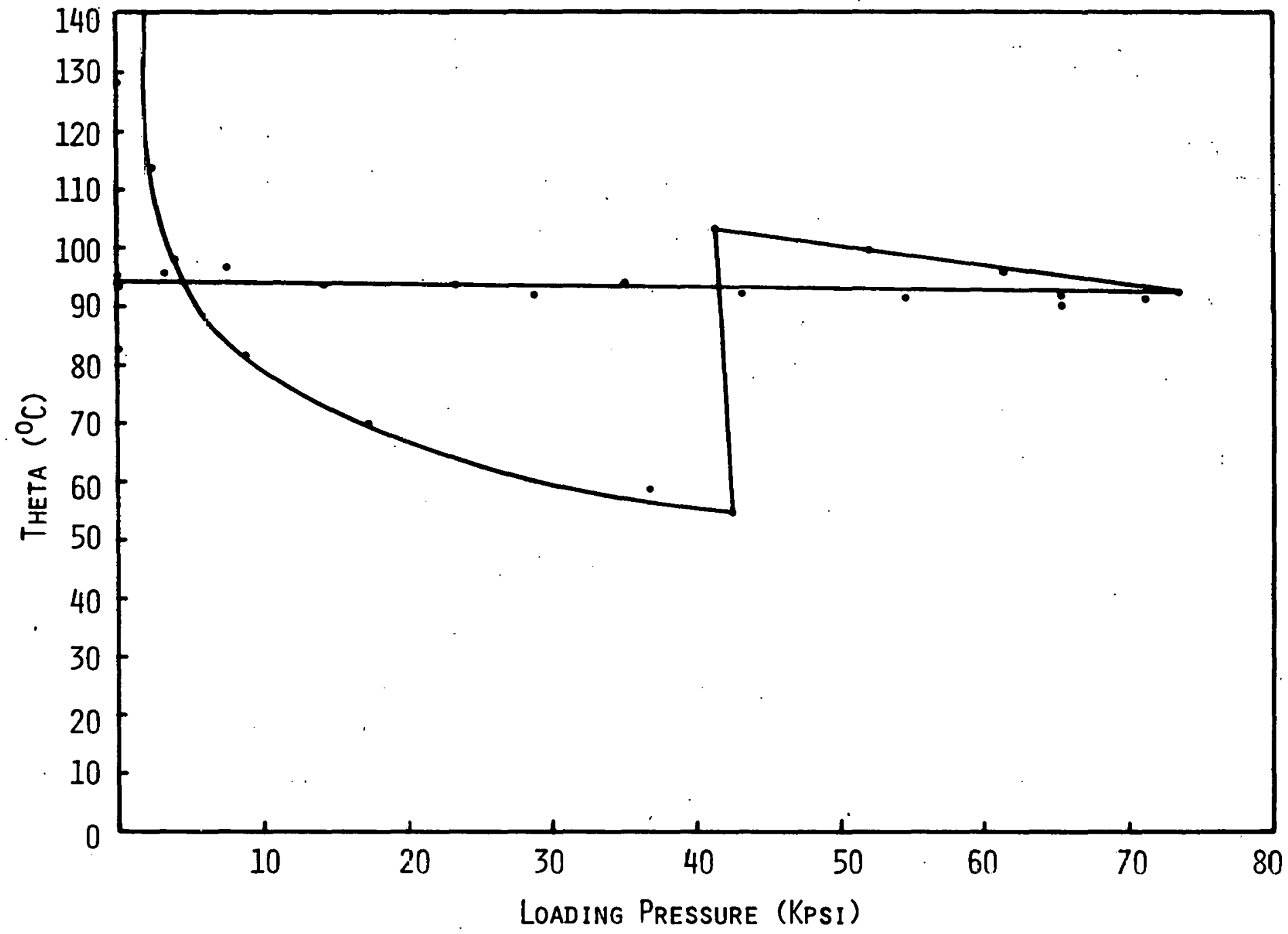

FIGURE III.C.5 Theta as a function of loading pressure for CP in MC 3423 igniter unit $\mathrm{D}$ : 
UMIT 7

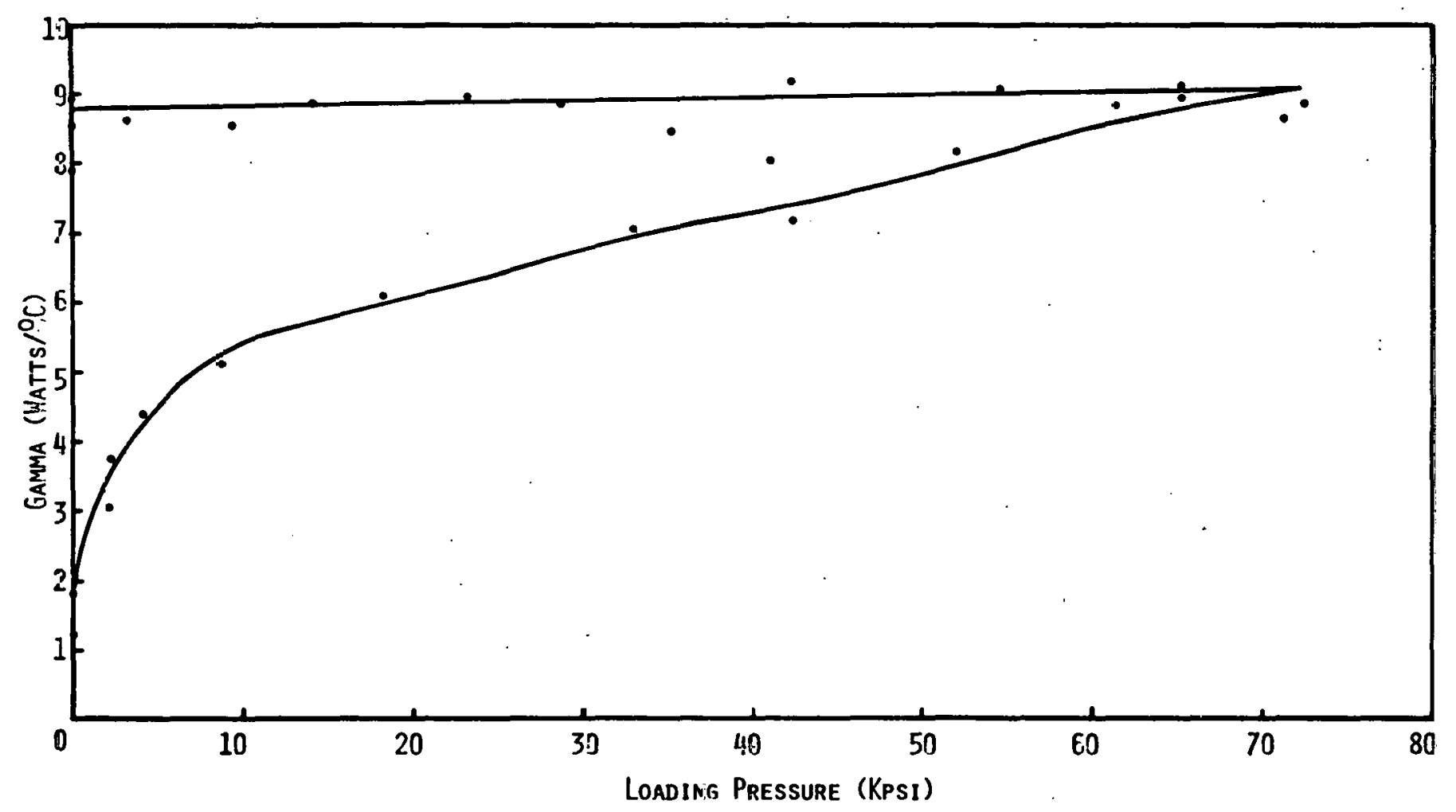

FIGURE III.C.6 Gamma as a function of loading pressure for CP in MC 3423 igniter unit $D$. 


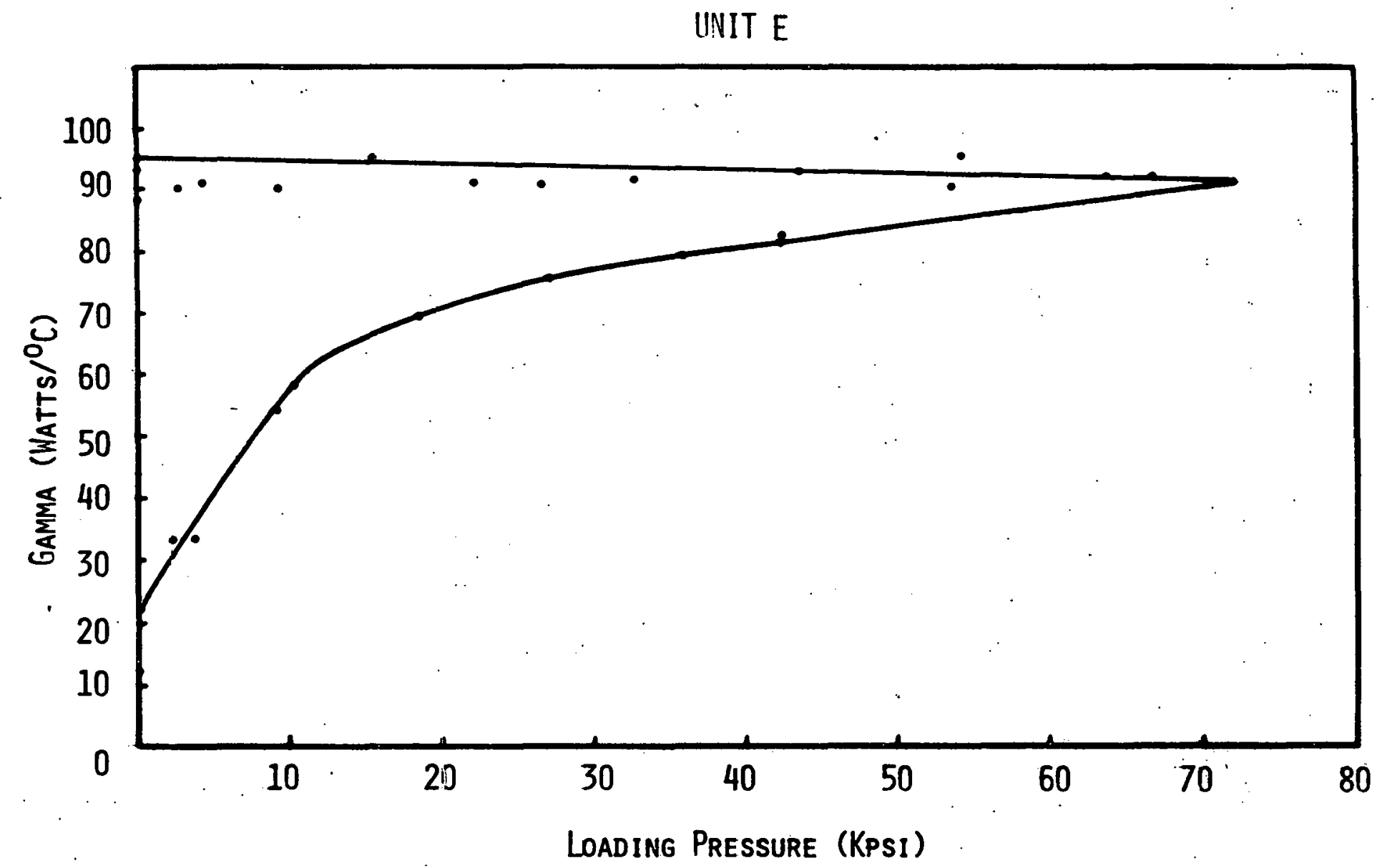

FIGURE III.C.7 Gamma as a function of loading pressure for CP in MC 3423 igniter unit $\mathrm{E}$. 


\section{UNIT D}

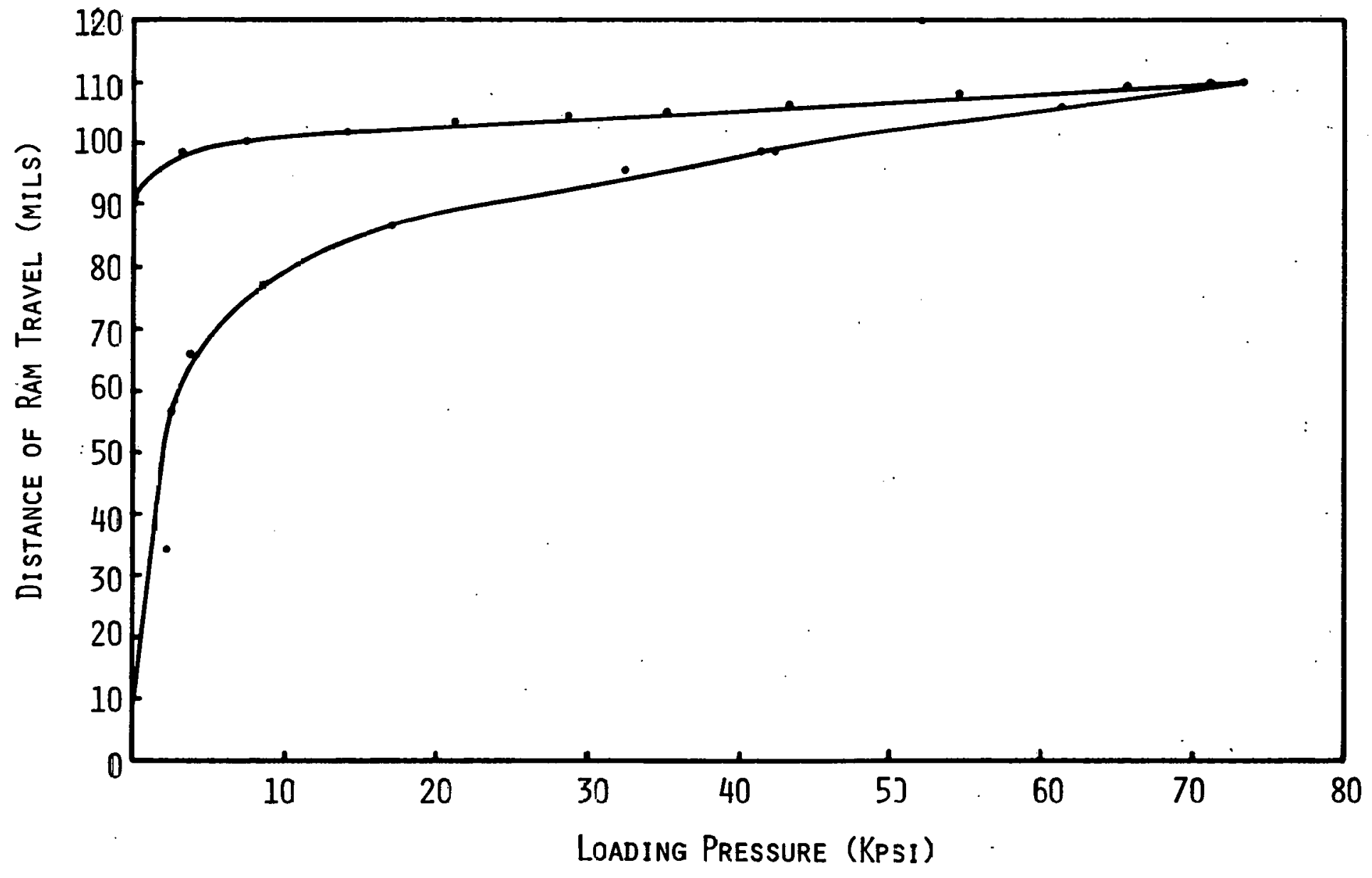

FIGURE III.C.8 Distance of ram travel as a function of loading pressure for CP is MC3423 igniter unit $D$. 
cup on the anvil of the drop tester. The hammer fit snuggly into the brass cup to help contain the solution on impact. The aluminum pan containing the solution was completely crushed by the impact of the five kilogram load." The pans should not have absorbed a significant amount of the impact energy since they were fragile enough to be easily crushed between fingertips. For this configuration, there were no ignitions, either audible or visible, in twenty attempts. Ten trials were also run in which the CP solution was placed directly into the brass cup. In every case, the solution was forced from the pan upon impact but again there were no ignitions.

In summary, $0.5 \mathrm{M}$ solutions of $\mathrm{CP}$ in DMSO appear to be insensitive to impact initiation.

\section{E. CP Synthesis (M. I. Lieberman)}

Three additional lots of $\mathrm{CP}$ are being synthesized at Unidynamics. Two have been purchased by Mound for MC3423 detonator requirements and the third has been purchased by Sandia for development studies. Precursors and ligands for all three lots have been obtained. Two lots of CP, EL-58633 and EL-58636, have been synthesized. It was found that the former was somewhat more difficult to sieve than prior lots (EL-47344, EL-47345, and EL-522II) and that the latter was considerably more difficult. Analyses of these materials are underway and preliminary results are given in Sections III.F.I - III.F.3.

F. Analytical Studies of CP at Mound (M. I. Lieberman)

1. Microscopy. Samples from lots EL-58633 and 58636, that did not sieve well through a 140 mesh screen, were submitted for examination. Two samples from each lot were examined, material that passed through the 140 mesh screen and material that did not pass through the screen. The difference between the crystals that passed through the screen and those that did not is the degree of agglomeration. Crystal size and 
shape, in all the preparations examined, is essentially the same. Comparison of these two lots to lot EL-47344 shows that there are other differences that may or may not be significant.

Lots EL-58633 and EL-58636 seem to have a considerable amount of "amorphous" material, which apparently is acting as a binder to agglomerate the individual crystals.

The second major difference is the considerable degree of crystal interpenetration, locking the crystals together. A third difference between these two lots and EL-47344 is the various crystal shapes that are

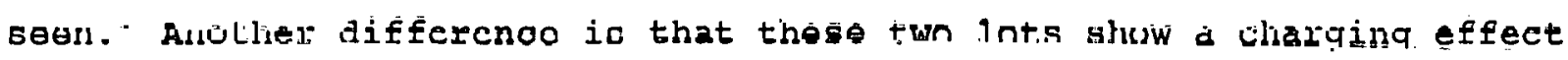
under the electron beam, even though the crystals are gold coated (to prevent charging). This charging effect was not observed in lots EL-47344, EL-47345, and EL-52211. The cause of these differences between lots EL-58633 and EL-58636 and the previous lots examined may be due to a different nucleation mechanism.

The attached photomicrographs (Fiyures III.F.I and III.F.3) show the above mentioned observations graphically.

2. Infrared spectroscopy. Infrared spectra of CP lots EL-58633 and EL-58636 (two samples of each) were obtained. Comparison of the spectra of those samples passing through a 140 mesh sieve and those that did not as well as between the two lots showed no difference in these samples. Comparison with a spectrum of lot El-47344 shows only a slight shift in some bands but no chemical differences.

3. X-ray diffraction. The recent CP samples, from lots EL-58633 and EL-58636, were examined using x-ray powder diffraction methods. The initial patterns, obtained using copper $\mathrm{K}_{\alpha_{1}}$ radiation, showed several very faint lines that had not been detected previously in CP samples. Further examination, using iron radiation to minimize the background darkening caused by cobalt fluorescence, confirmed the presence of seven previously 

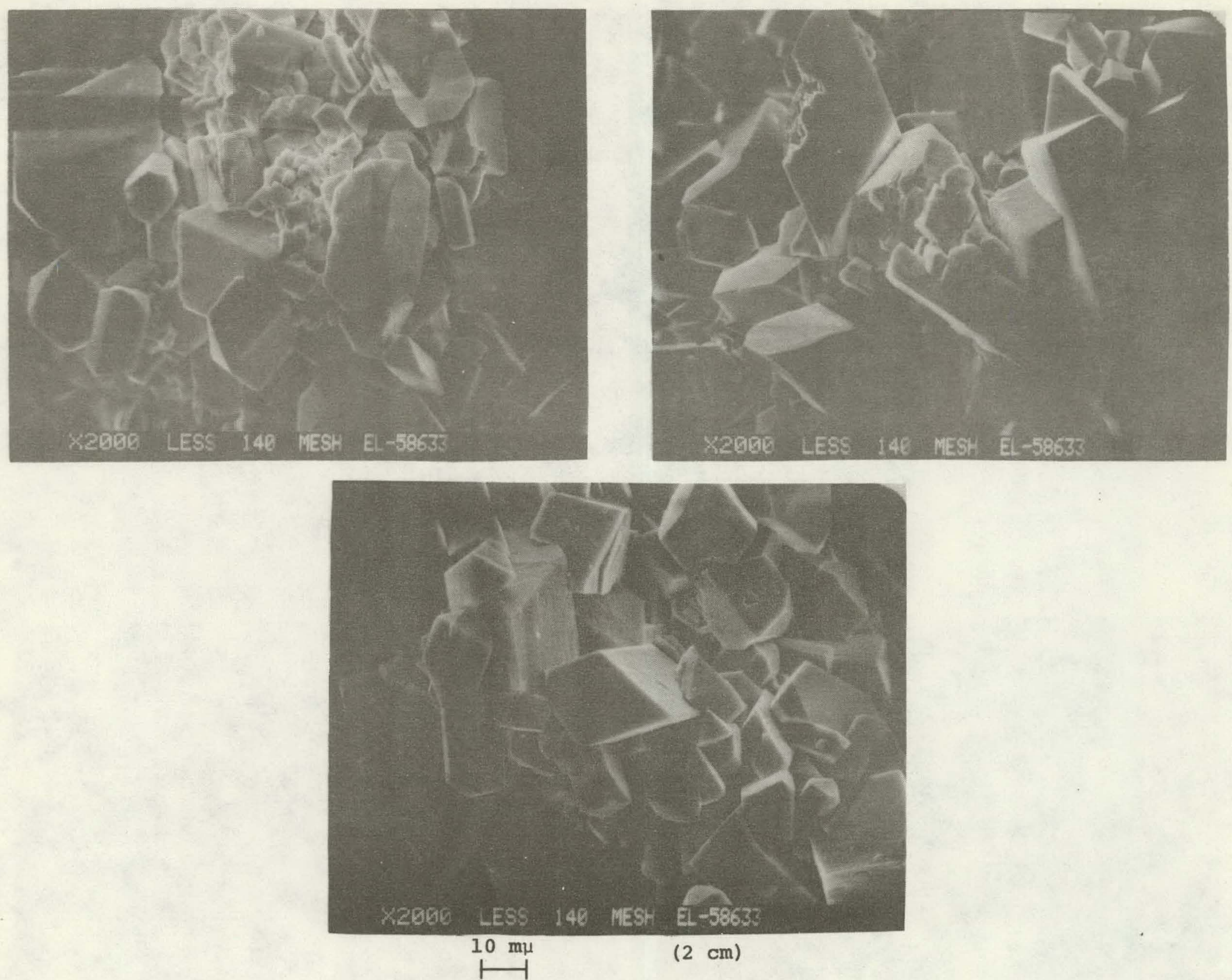

FIGURE III.F.1 Scanning Electron Photomicrographs of CP Lot EL-58633 Material that Passed Through the 140 Mesh Sieve 
(a)
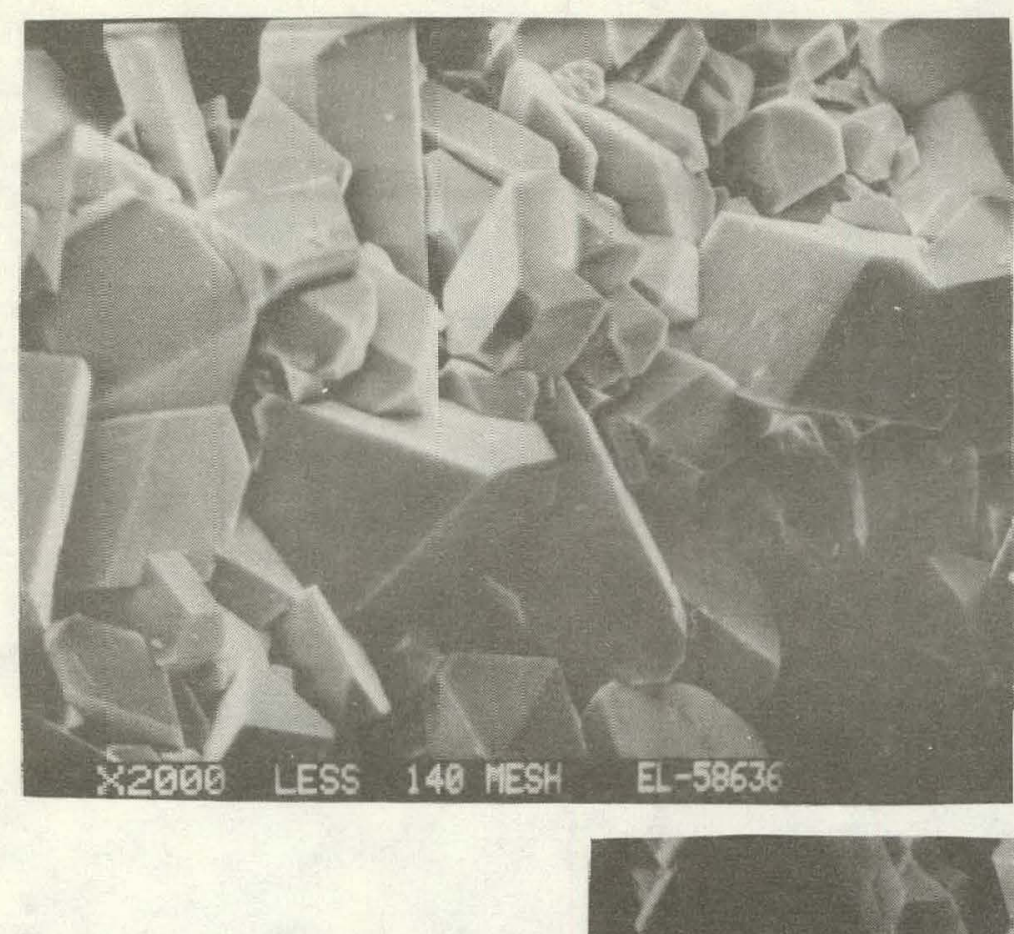

X2Q00 GREATER 149 NSSH EL -58636

$$
10 \mathrm{m \mu}
$$$$
(2 \mathrm{~cm})
$$

FIGURE III.F.2

Scanning Electron Photcmicrographs of CP Lot EL-58636.

(a) and (b) are Material that Passed Through the 140 Mesh

Sieve; (c) is Material Retained by the Sieve. (c) (b) 
undetected lines. Reexamination of an earlier CP sample (Lot EL-47344) using iron radiation indicates that at least some of these lines are also faintly present in this sample. The identification of these lines as due to a possible CP contaminant is awaiting comparison with a theoretical CP powder pattern which is being calculated by E. Graeber at SLA using his single crystal structure of CP. Meanwhile, samples of other CP lots and the other complexes (amide, amidine, tetrazolato and APCP) are being reexamined using iron radiation.

4. Photoacoustic spectroscopy. Efforts this quarter were directed at determining if photoacoustic spectroscopy (PAS) could be useful in quantitative analysis of $\mathrm{CP}$ for the amide complex. It appears that PAS could indeed be used if l) either a pure CP sample or a CP sample with known amide concentration could be obtained and 2) proper sample preparation is used. This is based on the following results.

Figure III.F.3 shows the PAS spectrum of CP and the amide complex (CPA) in the region from 500 to $2750 \mathrm{~nm}$. These spectra are very similar. However, there are peaks at 1450 and $1900 \mathrm{~nm}$ in the spectrum of CPA that do not appear in the spectrum of CP. While it is believed that these peaks are due to overtone bands of the amide carbonyl, it has also been suggested that these peaks could also be due to unbound water associated with the amide.

Attempting to determine if unbound water could cause these peaks, a sample of CPA was deuterated. Both the ammonia hydrogens and any water hydrogens should be exchanged causing a shift in the peak locations. Figure III.F.4 shows that all the peaks shifted except for the peaks at 1450 and $1900 \mathrm{~nm}$ which remained unchanged.

The differential capability of the PAS spectrometer was used in the attempts at quantitation. In this mode CP lot EL-47344 was arbitrarily called zero percent amide. Subtraction of this from samples of EL-47344 with amide added to it effectively removes all peaks but the $1900 \mathrm{~nm}$ peak. 


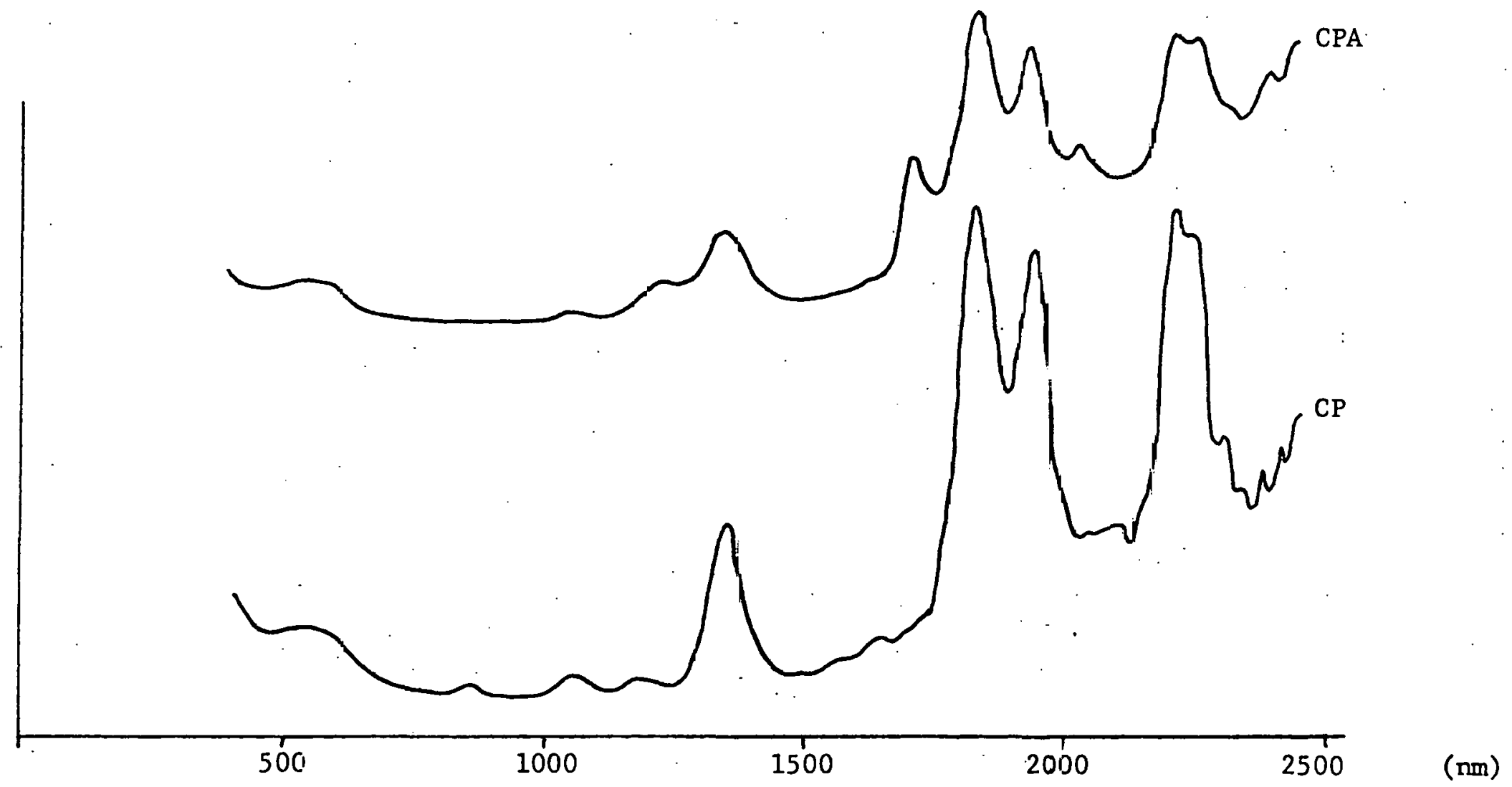

FIGURE III.F.3 Photcacoustic spectrum of CP a.nd CPR 


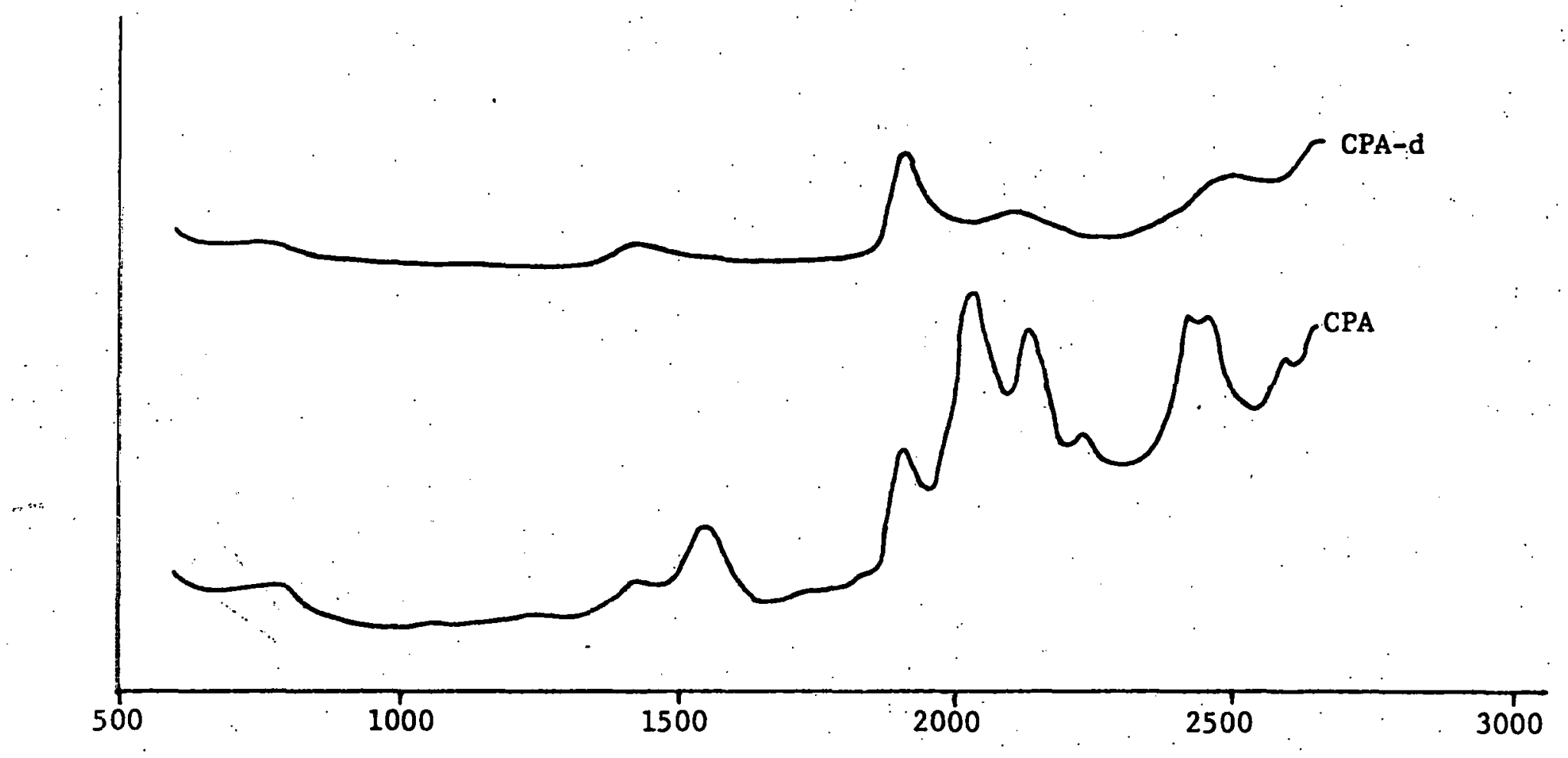


Accordingly, samples of EL-47344 with added amide were prepared as shown in Table III.F.1. The added amide ranged from zero to seventeen percent. Samples of each mixture were carefully weighed into the sample holder in an effort to get a constant mass of sample in the beam path. The photoacoustic spectrum of each mixture was obtained and the spectrum of the undoped CP subtracted from it. The area of the resulting peak was determined using a DuPont curve resolver. The percentage of added amide was then plotted versus the area of the $1900 \mathrm{~nm}$ peak and is shown in Figure III.F.5. The results are very encouraging. However, it was found that the peak area is very dependent on sample orientation in the cell holder. The seventeen percent sample was removed from the cell, tapped and replaced. The area changed from $\sim 1625$ to 1950 . This points out the need to work with a sample of known weight, pressed into a die of known dimensions at a known density of pressing. This would eliminate the problem of sample orientation. It is felt that with this system the limit of detection of this method would be two percent amide.

TABLE III.F.1

SAMPLES OF CP (EL-47344) DOPED WITH SAMPLES OF CPA

Sample

. 1

2

3

4

5

6
\& Amide Added

(by weight)

0

2.88

5.27

7.21

10.54

17.06 


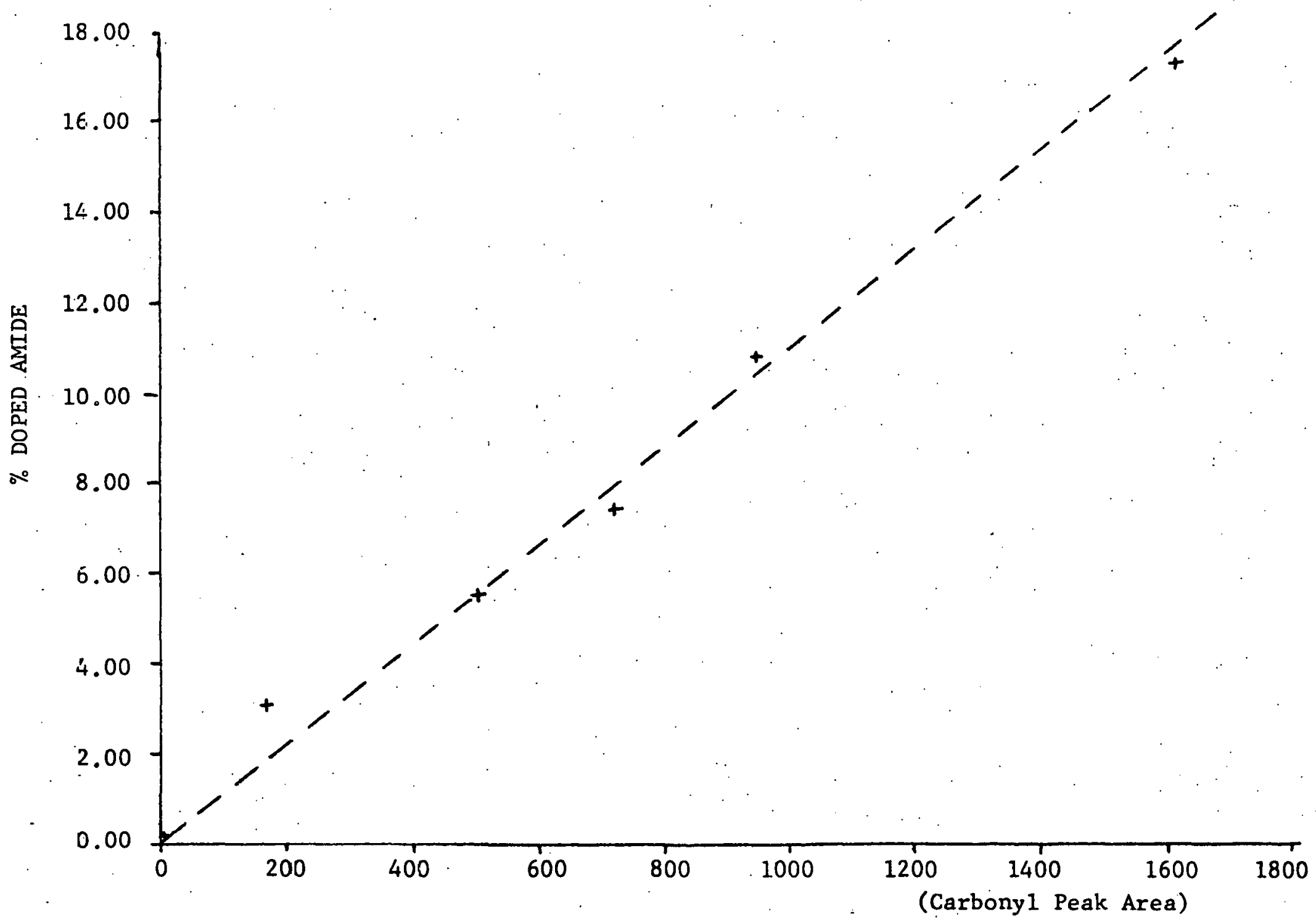

FIGURE III.F.5 Results of Differential Spectra

ज 
5. Laser Raman spectroscopy. Mound Analytical received its laser Raman spectrometer in late August and had it operational in mid september. The laser Raman spectra of 5-cyanotetrazole, 5-carboxyamido tetrazole and tetrazole, in the solid state, were obtained with this instrument (Figures III.F.6-III.F.9). The purpose of this work was many fold. It provided a chance to give the instrument time to shakedown - unearthing a few computer interfacing problems. These samples allowed the operators time for training on operation and handling of the system. Running these samples also provided an opportunity to develop sample handling procedures and to develop safety procedures for handling the explosive materials. As a result of this preliminary work, a problem with sample fluorescence was detected and steps are being taken to minimize this problem. In addition, the instrument is being modified to use a red laser instead of the original $513 \mathrm{~nm}$ laser. This should minimize the absorption of the sample, and hopefully, minimize the possibility of laser initiation. Once this work is complete and the system has been checked out, work will begin on Ci. 
A: TETRAZOLE

B: 5-CARBOXYAMTDOTETRAZOLE

C: 5-CYANOTETRAZOLE

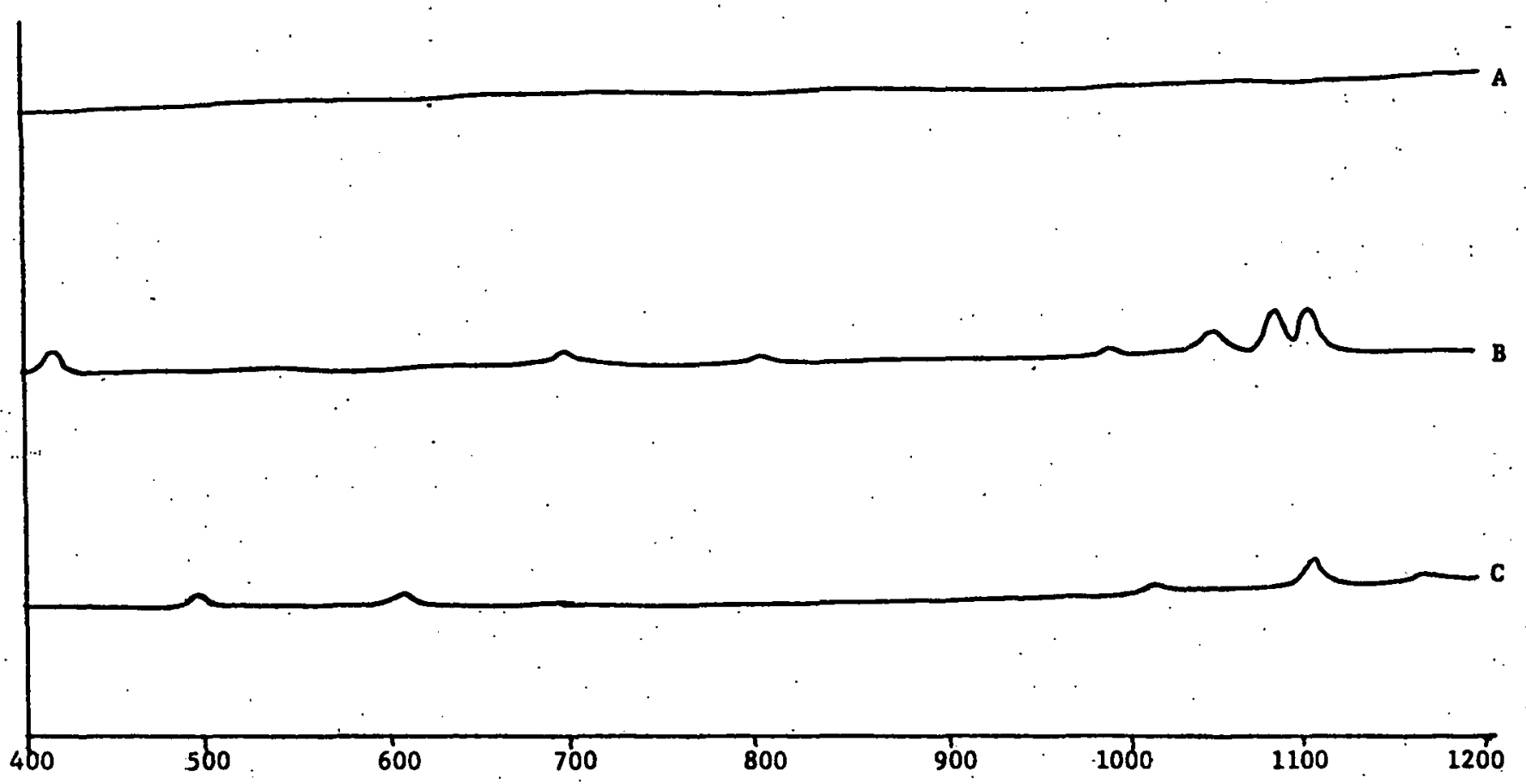

FIGURE III.F.6 Laser Raman Spectra of CP Ligands: 400-1200 $\mathrm{cm}^{-1}$ 
A: TETRAZOLE

B: 5-CARBOXAMIDOTETRAZDLE

C: 5-CraNoteTRAZOLE

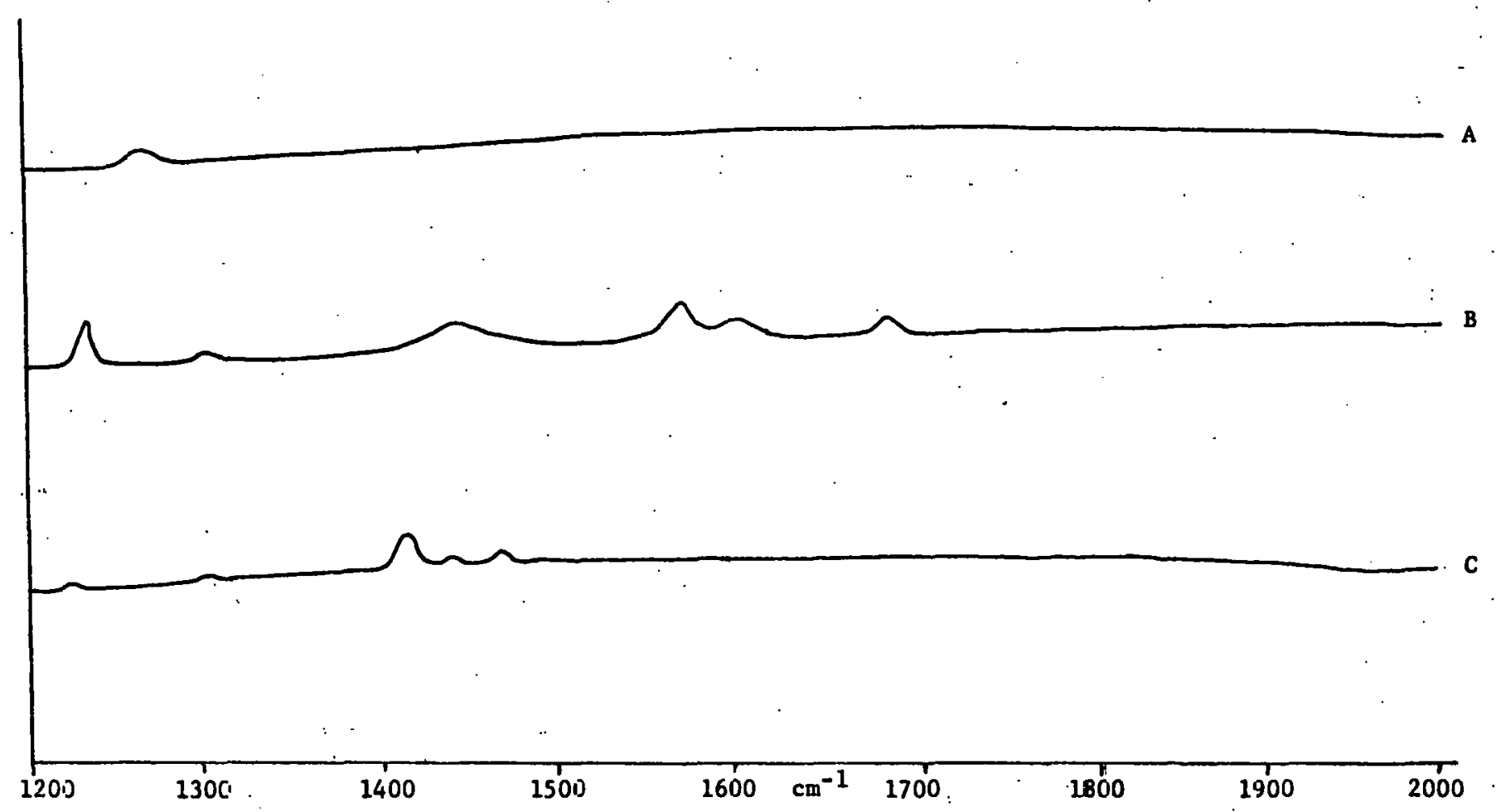

FIGURE III.F.7 Laser Faman Spectra of CP Ligands: $1200-2000 \mathrm{~cm}^{-1}$ 


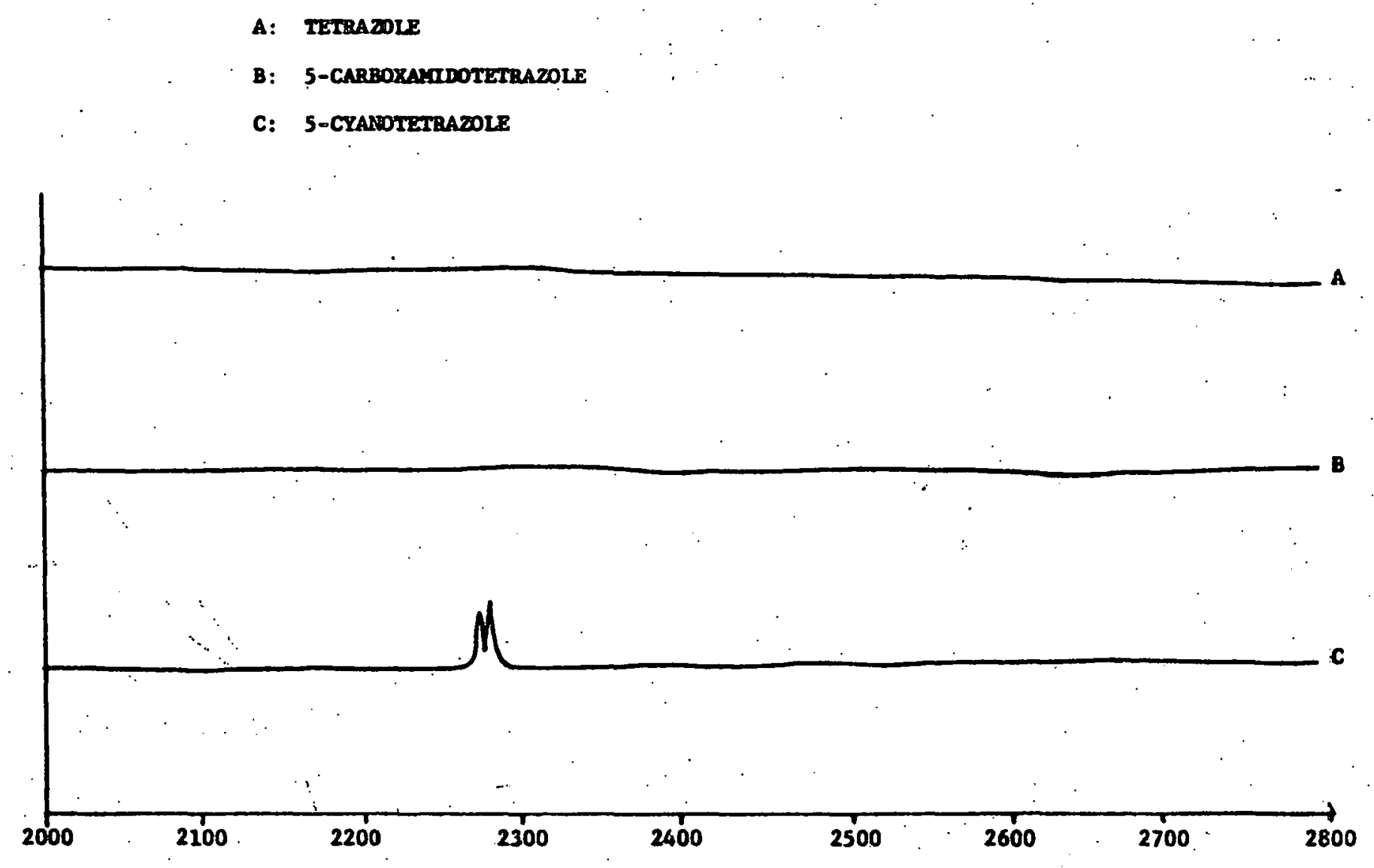

FIGURE III.F.8 Laser Raman Spectra of CP Ligands: $2000-2800 \mathrm{~cm}^{-1}$ 


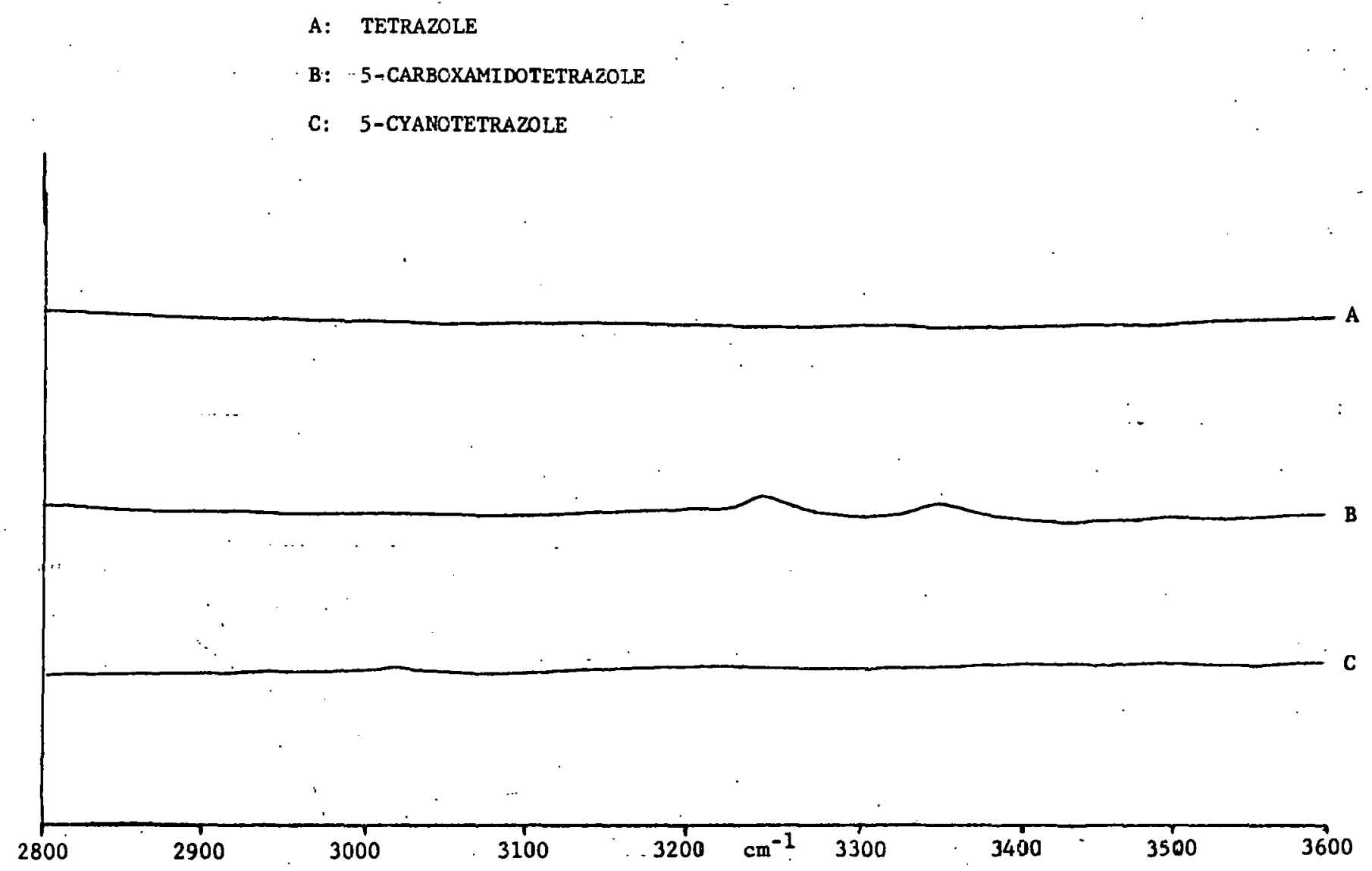

FIEURE III.F.9 Laser Raman Spectra of CP Ligands: $2800-3600 \mathrm{~cm}^{-1}$ 
IV. COMPATIBILITY

Task Leader - T. M. Massis, 2516

Technical Contributors: 0. L. Burchett, 2515

M. I. Liëberman, 2515

A. P. Montoya, 2515

P. K. Morenus, 2516

B. Morosin, 5154

E. J. Graeber, 5822

D. H. Huskisson, 5822

A. Introduction (T. M. Massis)

As in the past ${ }^{(1-4)}$, the primary purpose of this task has been to determine the compatibility of various materials, i.e., CP, with materials of construction used in the various DDT component designs and studies. Also included are stability studies on various DDT materials to various environmental conditions and material property studies.

Highlights during this time period are the TMA studies on CP, compatibility studies on the $\mathrm{CP} / \mathrm{B} / \mathrm{CaCrO}_{4}$ system, and structure determination of the amidine chelate. In addition Mound's contract with Unidynamics, in which SLA will do the aging, has been started.

No mini-det samplings took place during this quarter. The rescheduled sampling is January, 1980.

Continued thermal characterization of the homologs of CP is in a hold due to delays.in shipping new DSC cells for the characterization program. The older DSC cells have been damaged due to repeated explosion from these DDT materials during past studies previously reported. (4)

B. TMA Studies with CP (T. M. Massis)

The last project quarterly report ${ }^{(4)}$ described thermo-mechanical analysis (TMA) studies on CP pellets to provide coefficients of thermal expansion data. A nominal value of $58 \times 10^{-6}{ }^{\circ} \mathrm{C}^{-1}$ was obtained. Relative to 
the charge holder materials now being used for CP, either steel or ceramic, this expansion value is much larger than either of these materials. Steel has an expansion coefficient of less than $20 \times 10^{-6}$, whereas ceramic is between $5 \times 10^{-6}$ and $10 \times 10^{-6}{ }^{\circ} \mathrm{C}^{-1}$.

Previous work with $\mathrm{TiH} .65^{/ \mathrm{KClO}} 4$, which also has a large nominal expansion coefficient $\left(40 \times 10^{-6}\right)$, has shown that serious problems with decoupling of the powder from the bridgewire/pin interface can take place when the surrounding materials have a low expansion coefficient. (7) Since similar conditions exist for various CP components it was desired to subject CP loaded charge holders to a similar test.

Figure IV.B.l shows the test setup and sample configuration. The CP-loaded charge holder is purposely under-loaded to permit movement of the $\mathrm{CP}$ relative to the charge holder if movement occurs during thermal cycling.

Figures IV.B.2 and IV.B. 3 are results for $\mathrm{TiH} .65^{/ \mathrm{KC} \cdot 10_{4}}$ when subjected to this test procedure. Both ceramic and epoxy loaded charge holders resulted in pellet slippage of the $\mathrm{TiH} .65^{/ \mathrm{KClO}_{4}}$ in relation to the stationary charge holder. Figures IV.B.4 and IV.B.5 are results of CP (loaded at two different pressures) in a ceramic charge holder. No movement of the $\mathrm{CP}$ was observed after repeated thermal cycles. The force loading during the TMA procedure was equivalent to 1000 "G's". Both the surface interaction and frictional properties of CP compared to TiH. $.6 S^{\prime}$ $\mathrm{KClO}_{4}$ are considerably different from each other to provide the different behavior of the two materials to this test procedure.

Following the TMA procedure the $C P$ loaded charge holders were sent to org. 2515 for measurement of the push out force required to move the CP from the ceramic charge holder. Table IV.B.l lists the actual push out force for the CP loaded charge holders (loaded at 10 and $15 \mathrm{kpsi}$ ) and typical TiH $.65 \mathrm{KClO}_{4}$ epoxy charge holder with the one-way washer concept for comparison. 


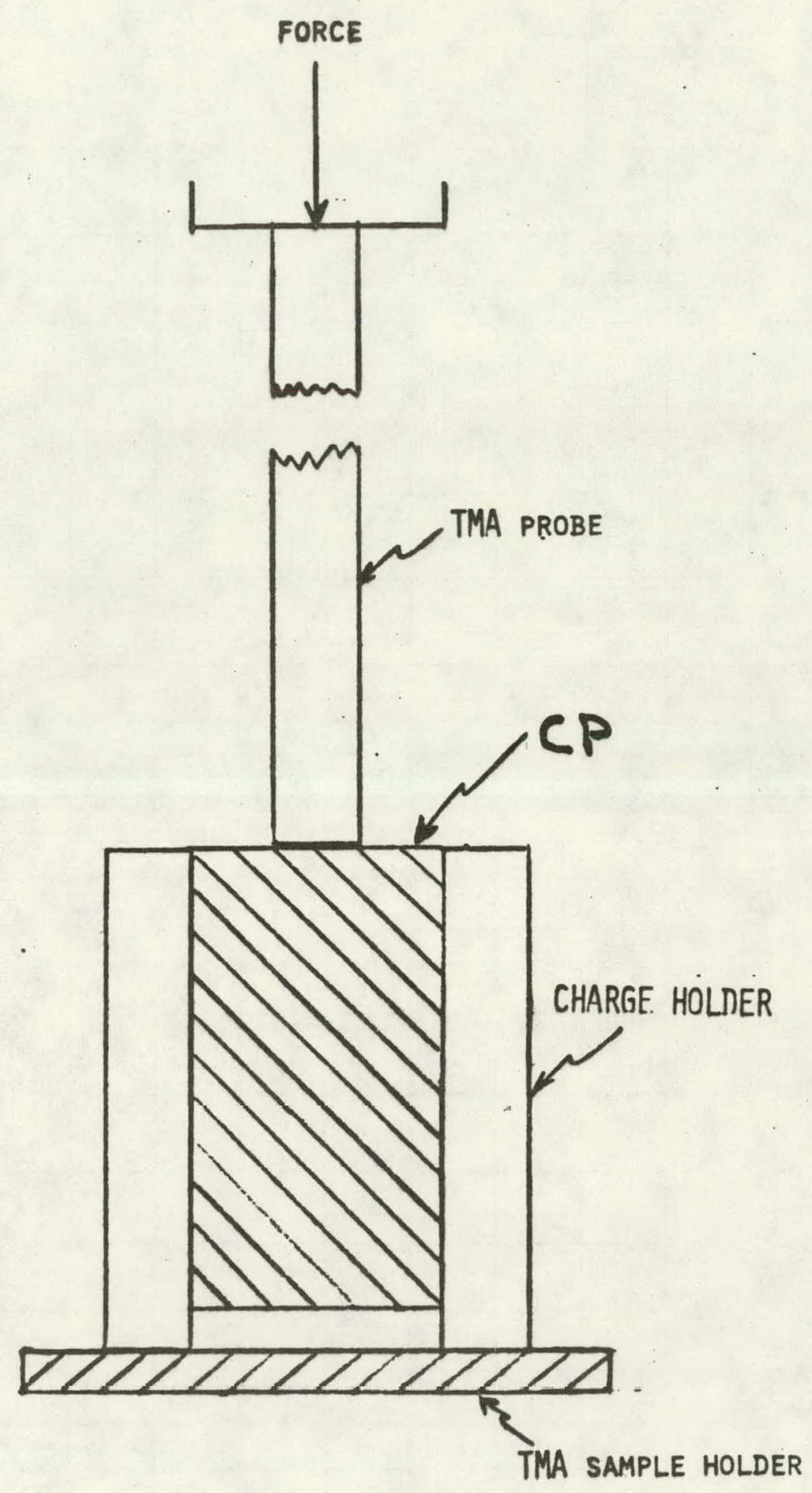

FIGURE IV.B.I TMA Apparatus 


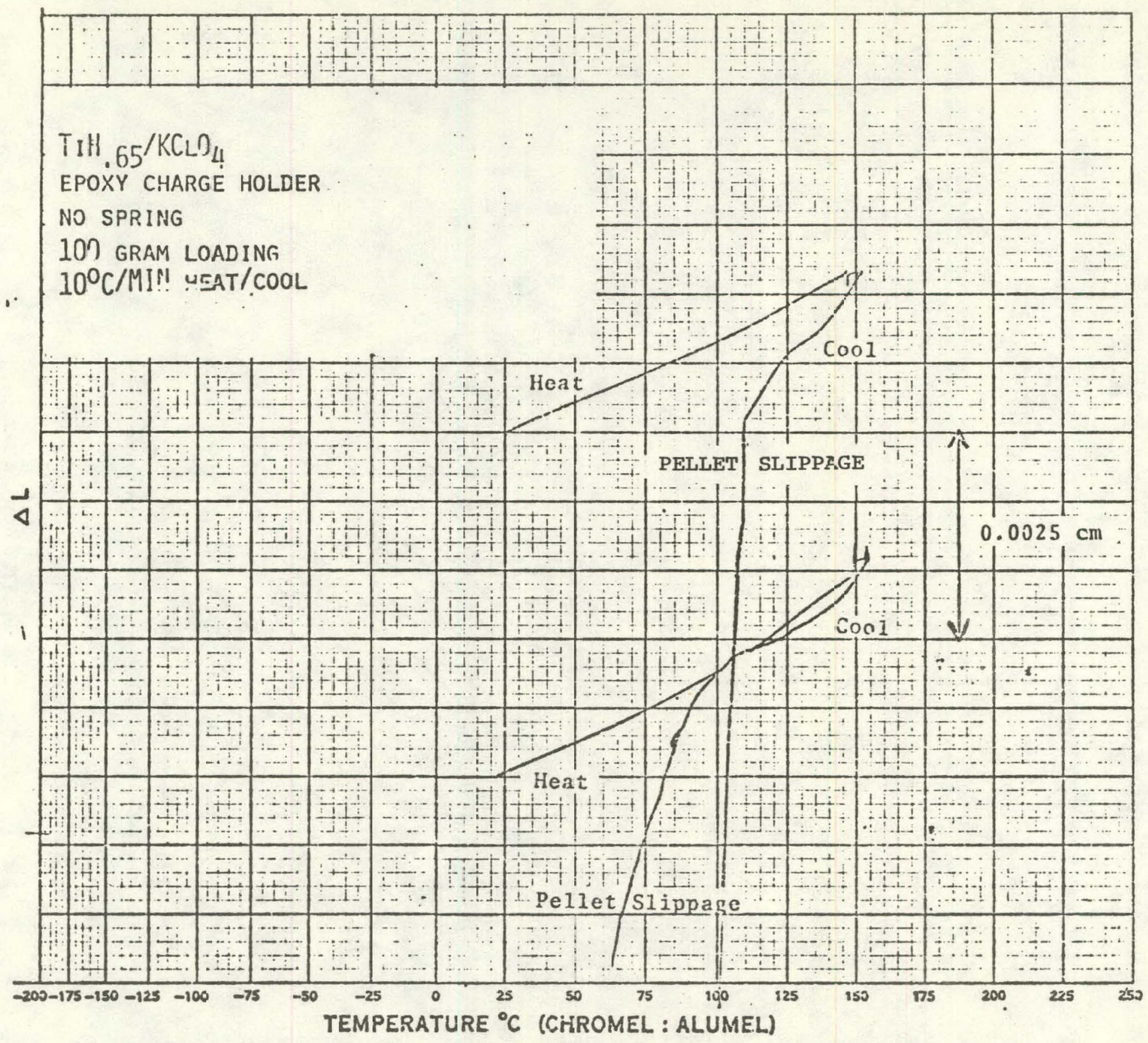

FIGURE IV.B.2 TMA Measurəment of TiH $.65^{/ \mathrm{KClO}} 4$ in Epoxy Charge Holder 


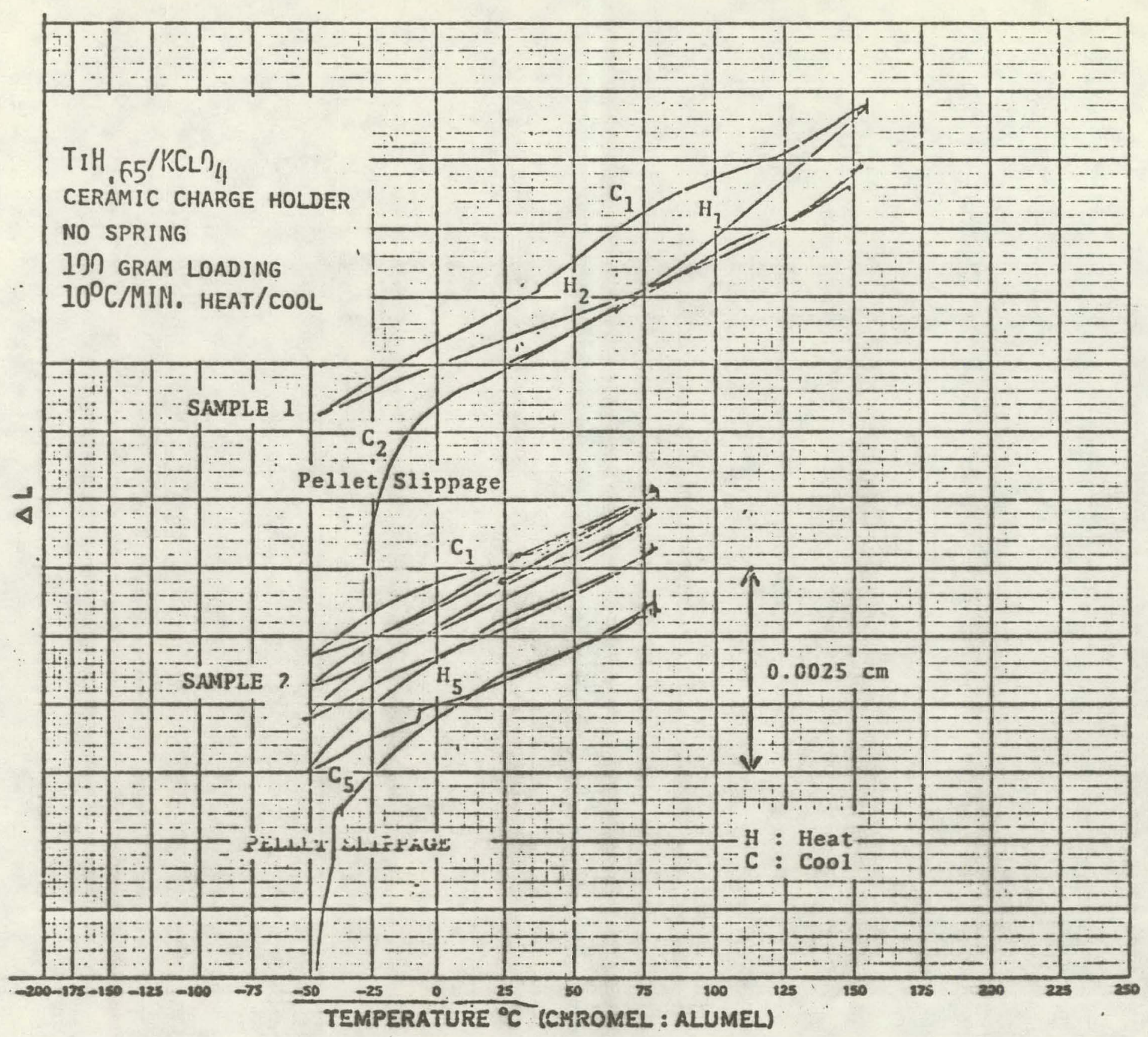

FIGURE IV.B. 3 TMA Measurement of $\mathrm{TiH} .65 / \mathrm{KClO}_{4}$ in Ceramic Charge Holder 


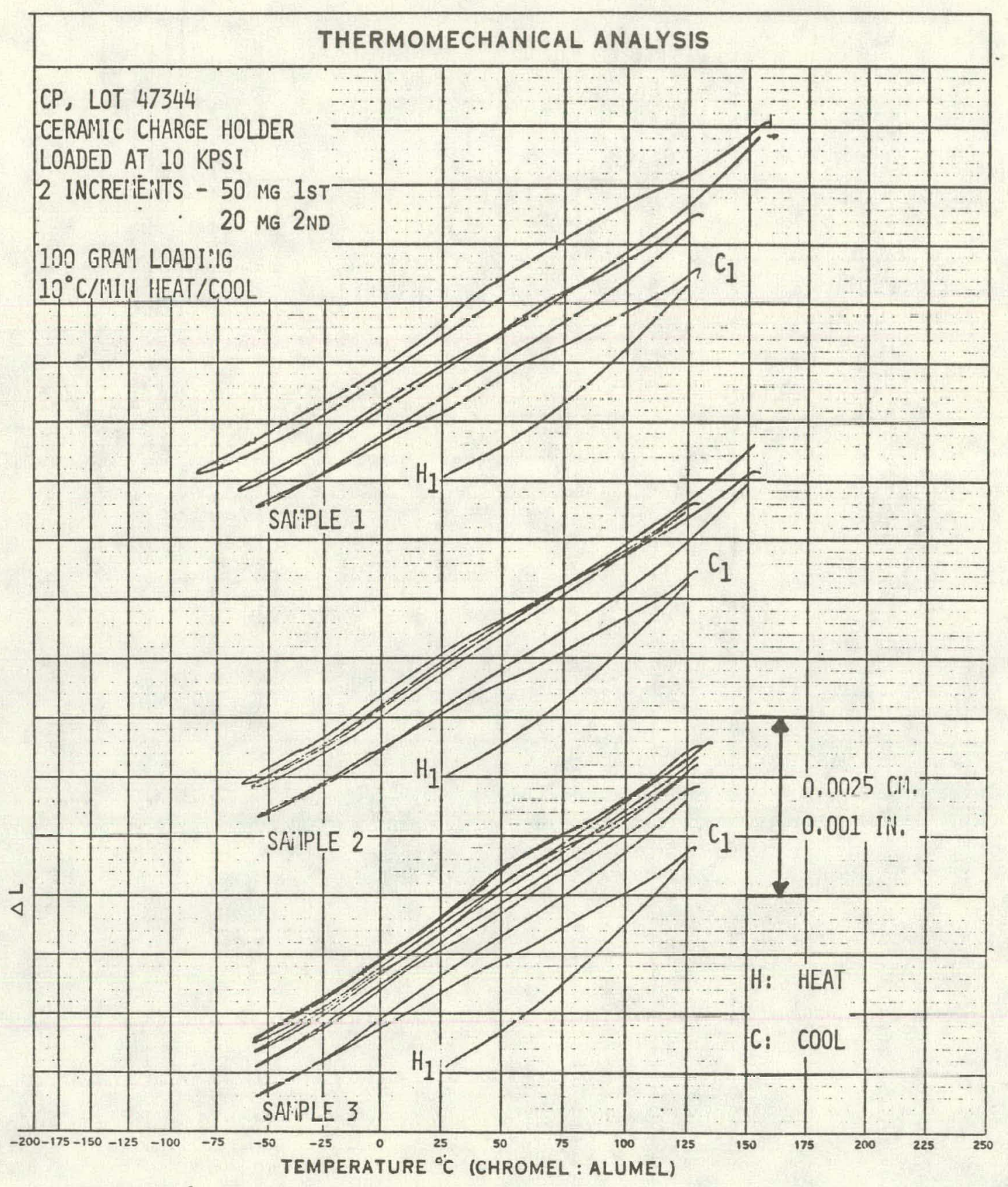

FIGURE IV.B.4 TMA Measurement of CP Loaded at

$10 \mathrm{kpsi}$ in Ceramic Charge Holder. 


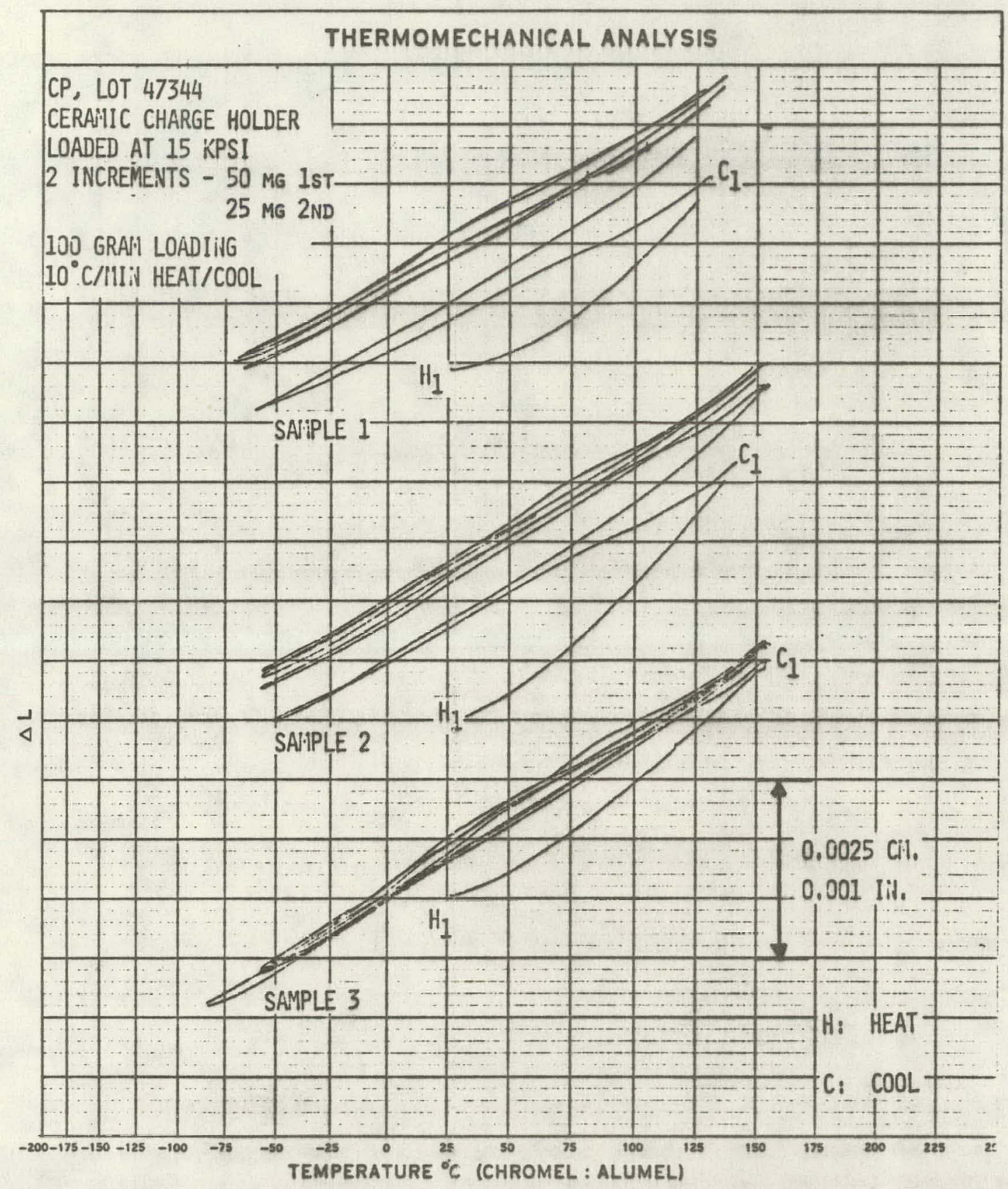

FIGURE IV.B.5 TMA Measurement of CP Loaded at 15 kpsi in Ceramic Charge Holder. 
TABLE IV.B.I

PUSH OUT FORCE DATA

Sample

$\mathrm{CP} /$ Ceramic Charge Holder (loaded at $10 \mathrm{kpsi}$ )
\# 2

\# 3

\#4

CP/Ceramic Clisye Huldes (loaded at $15 \mathrm{kpsi}$ )

$\begin{array}{ll}\# 1 & 30 \\ \# 2 & 36 \\ \# 3 & 38 \\ \# 4 & 23\end{array}$

Maximum Push Out Force $(\mathrm{kg})$

26

25

25

31

30

36

38

23

$\mathrm{TiH} .65 / \mathrm{KClO}_{4}$ Epoxy

Charge Holder (with

one-way washer)

Mound loaded

71

Unidynamics loaded

47

The same procedure will be repeated shortly for CP loaded into steel charge holders plus ceramic charge holders at higher consolidation pressures.

C. $\mathrm{CP} / \mathrm{B} / \mathrm{CaCrO}_{4}$ Coupon Studies (T. M. Massis)

In support of the MC3196A program, a limited coupon study of $\mathrm{CP} / \mathrm{B} / \mathrm{CaCrO}_{4}$ with Kovar and Tophet A was started. The conditions were $60^{\circ} \mathrm{C}, 120^{\circ} \mathrm{C}, 50 \% \mathrm{RH}$ at room temperature and $92 \% \mathrm{RH}$ at room temperature. Fiqure IV.C.1 shows the coupon test assembly. The first sampling was 94 days at $60^{\circ} \mathrm{C}$ and $120^{\circ} \mathrm{C}$ and 68 days at $50 \% \mathrm{RH}$ and $92 \% \mathrm{RH}$. No corrosion of the Kovar or Tophet A was observed optically or with the SEM. Also there were no differences between the humidity and thermally aged samples. Outside of silica as an impurity on the Kovar wires and $\mathrm{CP} / \mathrm{B} / \mathrm{CaCrO}_{4}$ particulate on all wire materials the Kovar and Tophet $\mathrm{A}$ materials were clean. 


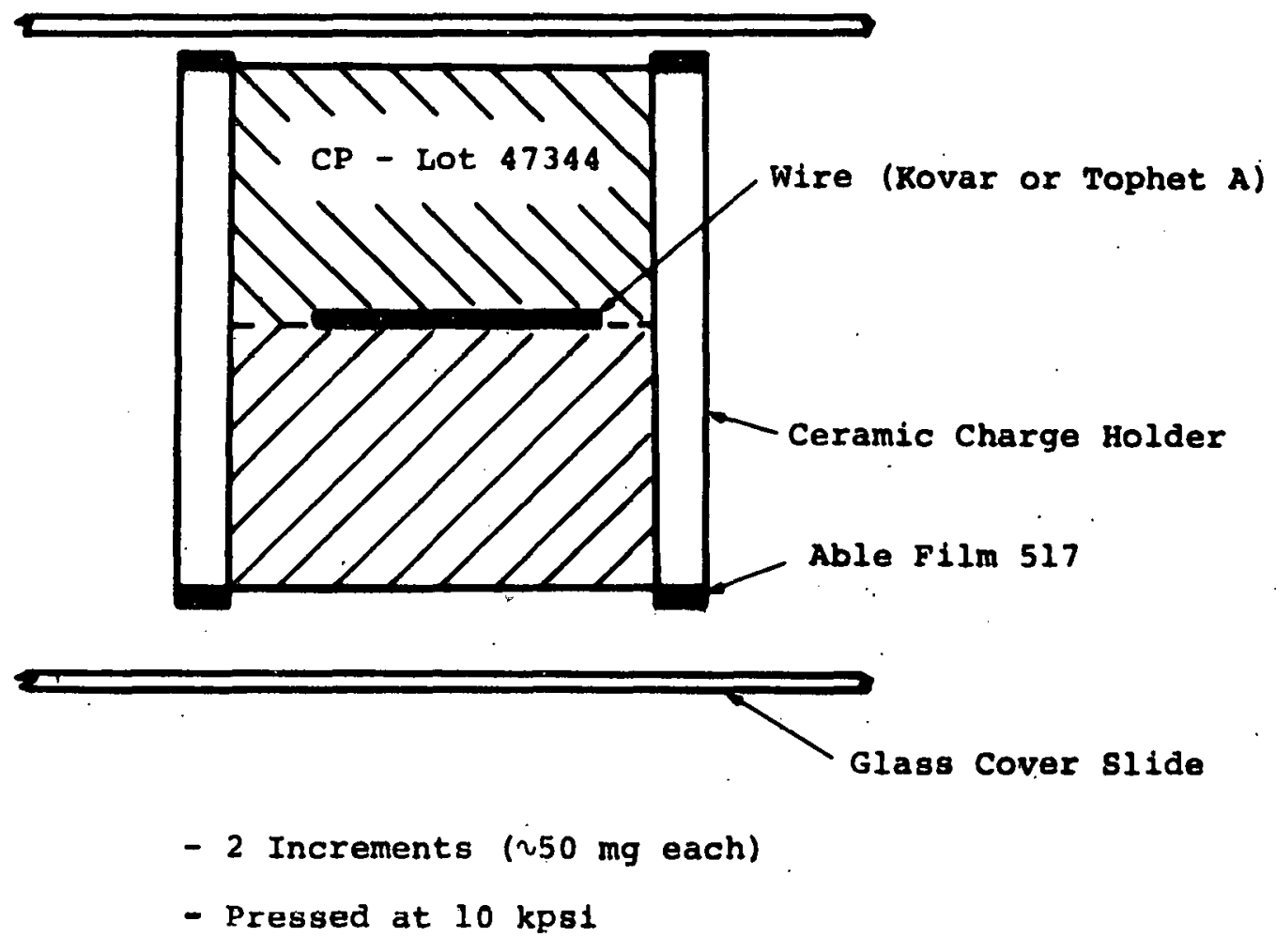

FIGURE IV.C.I $\mathrm{CP} / \mathrm{B} / \mathrm{CaCrO}_{4}$ Coupon Assembly 
DSC curves of the $\mathrm{CP} / \mathrm{B} / \mathrm{CaCrO}_{4}$ after aging showed no difference between the aged materials and the original baseline sample performed at the start of this program. This means that no major exchange of the $\left(\mathrm{ClO}_{4}\right)^{-}$by the $\left(\mathrm{CrO}_{4}\right)^{=}$has taken place even at $928 \mathrm{RH}$. Actual analyses of the $\mathrm{CP} / \mathrm{B} / \mathrm{CaCrO}_{4}$ for degree of reaction, if any, has not taken place because of lack of any analytical procedures to do so.

The next sampling is scheduled for February, 1980, after six months aging :

D. CP Compatibility study (T. M. Massis)

The Mound contract at Unidynamics for compatibility studies was started at SLA on October 31, 1979. SLA's involvement in this contract is to age and ETR the units. Mound will do all test-fire, postmortem and analytical work on the aged units. Table IV.D.I is the proposed aging plan for this endeavor.

TABLE IV.D.I

ACCELERATED THERMAI ACINC

OF SEALED IGNITOR ASSEMBLIES

\begin{tabular}{rccl} 
Temp. & $\begin{array}{c}\text { Quantity } \\
\text { (CP LOt } \\
522 I 1)\end{array}$ & $\begin{array}{c}\text { Quantity } \\
\text { (CP LOt } \\
47345)\end{array}$ & $\frac{\text { Tegt Times }}{2}$ \\
\cline { 2 - 3 } $20^{\circ} \mathrm{C}$ & 10 & 10 & 0,12 years \\
$80^{\circ} \mathrm{C}$ & 21 & 21 & $1,2,4,6,0,10,12$ years \\
$120^{\circ} \mathrm{C}$ & 21 & 21 & $0.5,1,2,3,4,5,6$ years \\
$140^{\circ} \mathrm{C}$ & 21 & 21 & $\begin{array}{l}0.25,0.5,1,1.5,2,2.5, \\
3 \text { years }\end{array}$
\end{tabular}

Date started: $10 / 31 / 79$

3 units removed at each time period

All units to be ETR'd again when removed

1) test fire two

2) postmortem one

All units ETR'd prior to aging

SLA will do aging and ETR

Mound will do test fire and postmortem operations 
E. Structure Determination of Amidine Chelate (M. L. Lieberman)

It has been known that CP decomposes in aqueous solution to form an amidine chelate. NMR analyses had previously suggested that the tetrazole ring was $\mathrm{N}-1$ bonded. If this is correct it seems unlikely that such a reaction product could form via a solid state decomposition upon aging. To verify this bonding E. J. Graeber (5822) and B. Morosin (5154) performed an $x$-ray diffraction single crystal structure determination of the bromide (non-explosive) compound.

Crystals of the amidine chelate (ATCB) are triclinic, PI, with $a=7.450(6), b=13.471(5), c=7.130(5) \AA, \alpha=96.23(6), B=117.30(7)$, $\gamma=79.51(6)^{\circ}$ and $z=2$. Parameters were refined by the least squares method employing $1863 \mathrm{hkl}$ data to $R=0.050$. Cobalt is octahedrally coordinated to four ammine groups with $\langle\mathrm{CO}-\mathrm{N}\rangle=1.96 \AA$, a shorter tetrazole ring nitrogen at $1.91 \AA$ and a chelate ring nitrogen at $1.94 \AA$. The tetrazole ring is $\mathrm{N}-1$ bonded and is a slightly distorted pentagon with mean bond length of $1.34 \AA$. Bromide ions provide a chain in the structure to which the chelated cobalt ions are held together with hydrogen bonds.

A comparison between CP and ATCB is given in Table IV.E.I and Figures IV.E.I-IV.E.5. 
TABLE IV.E.I

CRYSTAL DATA

CP ATCB

\begin{tabular}{|c|c|c|}
\hline 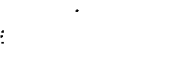 & $\mathrm{CP}$ & ATCB \\
\hline & & \\
\hline space group & $\mathrm{PZ}_{1} / \mathrm{g}$ & Pĩ \\
\hline$a(A)$ & 24. $777(9)$ & $7.450(6)$ \\
\hline b & $7.673(3)$ & 13. 471(5) \\
\hline c & $7.884(3)$ & $7.130(5)$ \\
\hline$\alpha\left(0^{\circ}\right)$ & प्र人 U & $96,23(6)$ \\
\hline $\boldsymbol{B}$ & 10̄. zu(1) & $117.301 \pi$ \\
\hline$\gamma$ & 900 & $79.51(6)$ \\
\hline cell contents & $4\left[\left(\mathrm{CN}_{4} \mathrm{CN}\right)\left(\mathrm{NH}_{3}\right)_{5} \mathrm{CO}\left(\mathrm{ClO}_{4}\right)_{2}\right]$ & $\left.2 \mid\left(\mathrm{CN}_{4} \mathrm{CNH}_{2}\right) \mathrm{NH}\left(\mathrm{NH}_{3}\right)_{4} \mathrm{COBr}_{2}\right)$ \\
\hline 0 (g/cel calc. & 1.974 & 2114 \\
\hline obs. & 1,989 & 2101 \\
\hline
\end{tabular}

CP

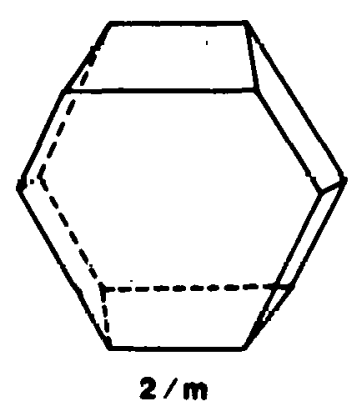

ATCB

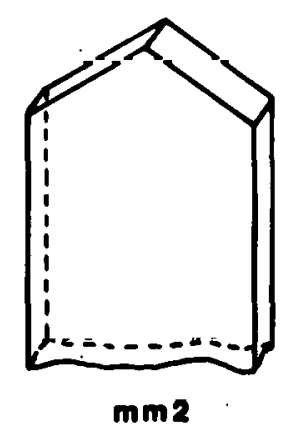

CP: 5-cyanototrazolatopentaamminecobalt(III) perchlorate

ATCB: 5-amidinotetrazolatototra amminocobalt(III) bromido

$$
\text { FIGURE IV.E.1 Crystal Structures }
$$



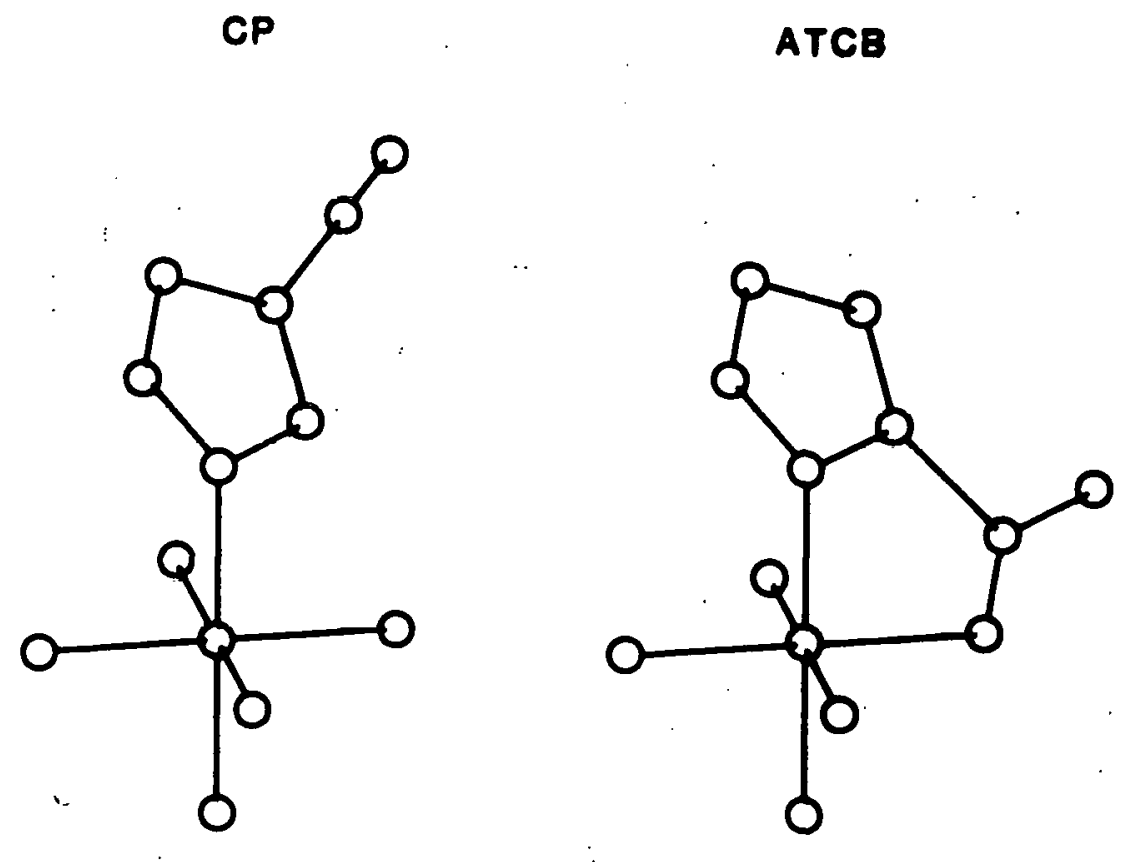

FIGURE IV.E.2 Molecular Structures
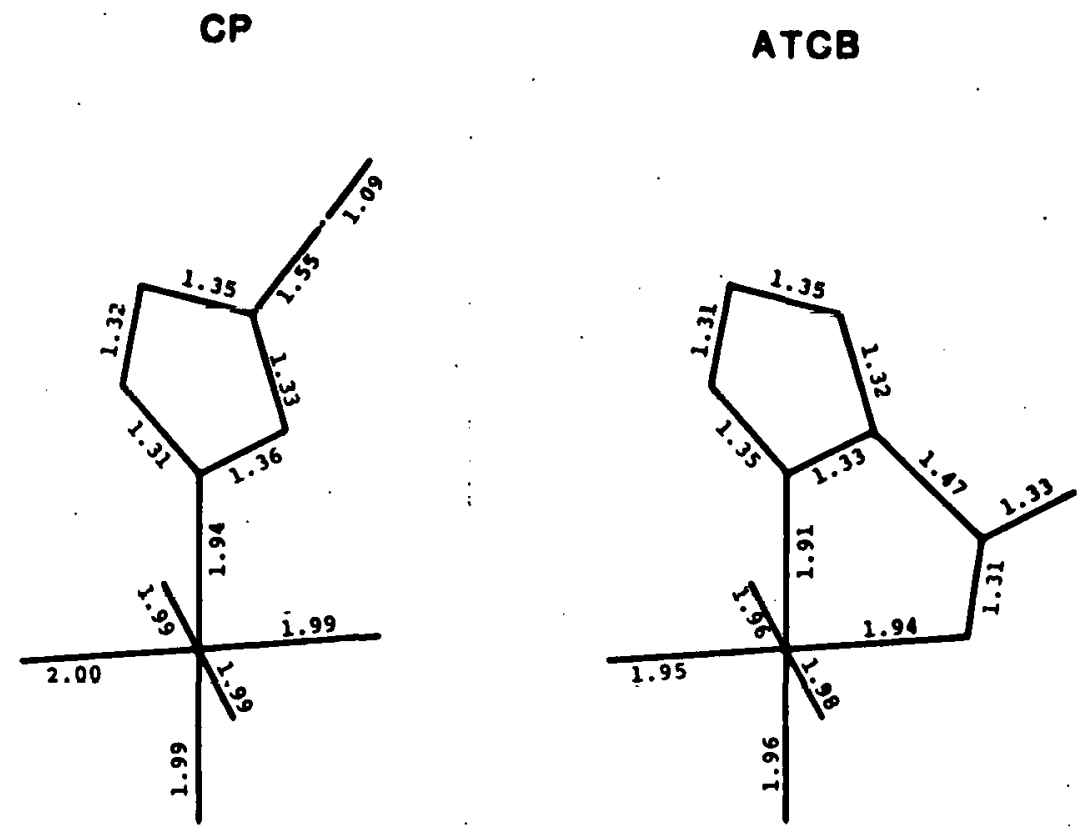

FIGURE IV.E.3 Bond Lengths 


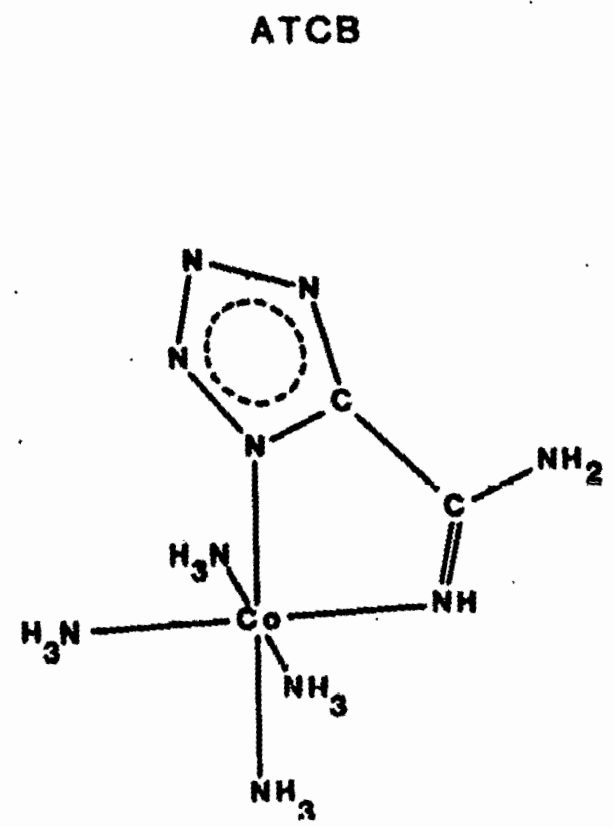

FIGURE IV.E.4 Chemical structure of ATCB

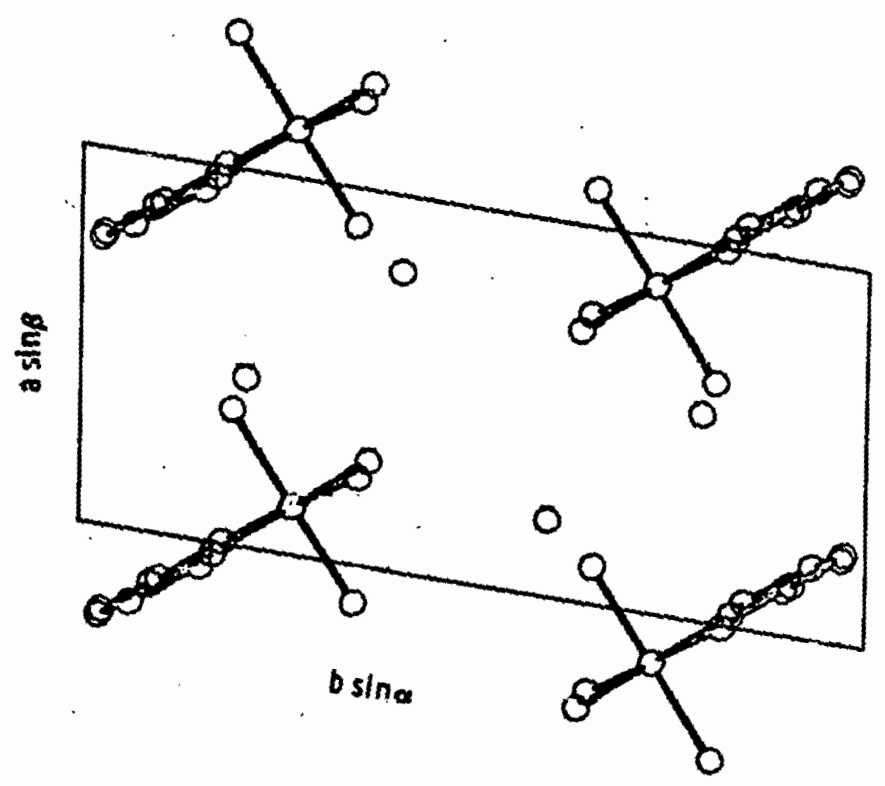

FIGURE IV.E.5 (001) Projection of ATCB 


\section{v. COMPONENTS}

Task Leader - M: L. Lieberman, 2515

Technical Contributors:. D. L. Marchi, 2515

F. J. Villa, 2515

T. K. Ferguson, Mound

D. L. Paisley, Mound

J. Fronabarger, UMC

A. Lause, UMC

A. MC3423 Detonator (F. J. Villa, M. I. Lieberman)

MC3423 development was completed in October. Some work has to be done to determine satisfactory output function. The pressure transducer method of measuring output will be replaced by a dent block test. This change will result in considerable cost savings. Table V.A.l lists significant dates indicating that the final MC3423 design review (Design Review II) occurred in November.

Design verification testing was completed during the reporting period covered by this report. The MC3423 design met all requirements. The method of output testing was not satisfactory and will be changed as indicated at the start of this section. Figure V.A.I shows that gamma as measured by electrothermal response testing remained stable after exposure of the MC3423 to environmental sequence testing.

Previous electrothermal response testing on units manufactured for statistical sensitivity testing indicates that gamma can be used for predicting no-fire capability of the component. This relationship is shown in Figure V.A.2.

MC3423's were fired at currents from 3.5 to 100 amperes. Figure V.A. 3 shows the effect of current on function time.

Eight units were shipped to D. L. Paisley for flash X-ray and laser stereophotography measurements during output. Fixturing is currently 
TABLE V.A.I

\section{MC3423}

\begin{tabular}{|c|c|}
\hline DEVELUUHMENi RéuUEST LetTER & $6 / 12 / 78$ \\
\hline DeVELopMent StaRt & $9 / 8 / 78$ \\
\hline B-ITEM DeCLARATION & $1 / 30 / 79$ \\
\hline Design Review I & $7 / 10 / 79$ \\
\hline CER/DTER HEADER & $7 / 23 / 79$ \\
\hline DESIGN VERIFICATION COMPLETE & $10 / 31 / 79$ \\
\hline CER/DTER COMPONENT & $11 / 16 / 79$ \\
\hline DESIGN REVIEW II & $11 / 27 / 79$ \\
\hline TMS/QER & $8 / 29 / 80$ \\
\hline FPU & $9 / 30 / 80$ \\
\hline
\end{tabular}




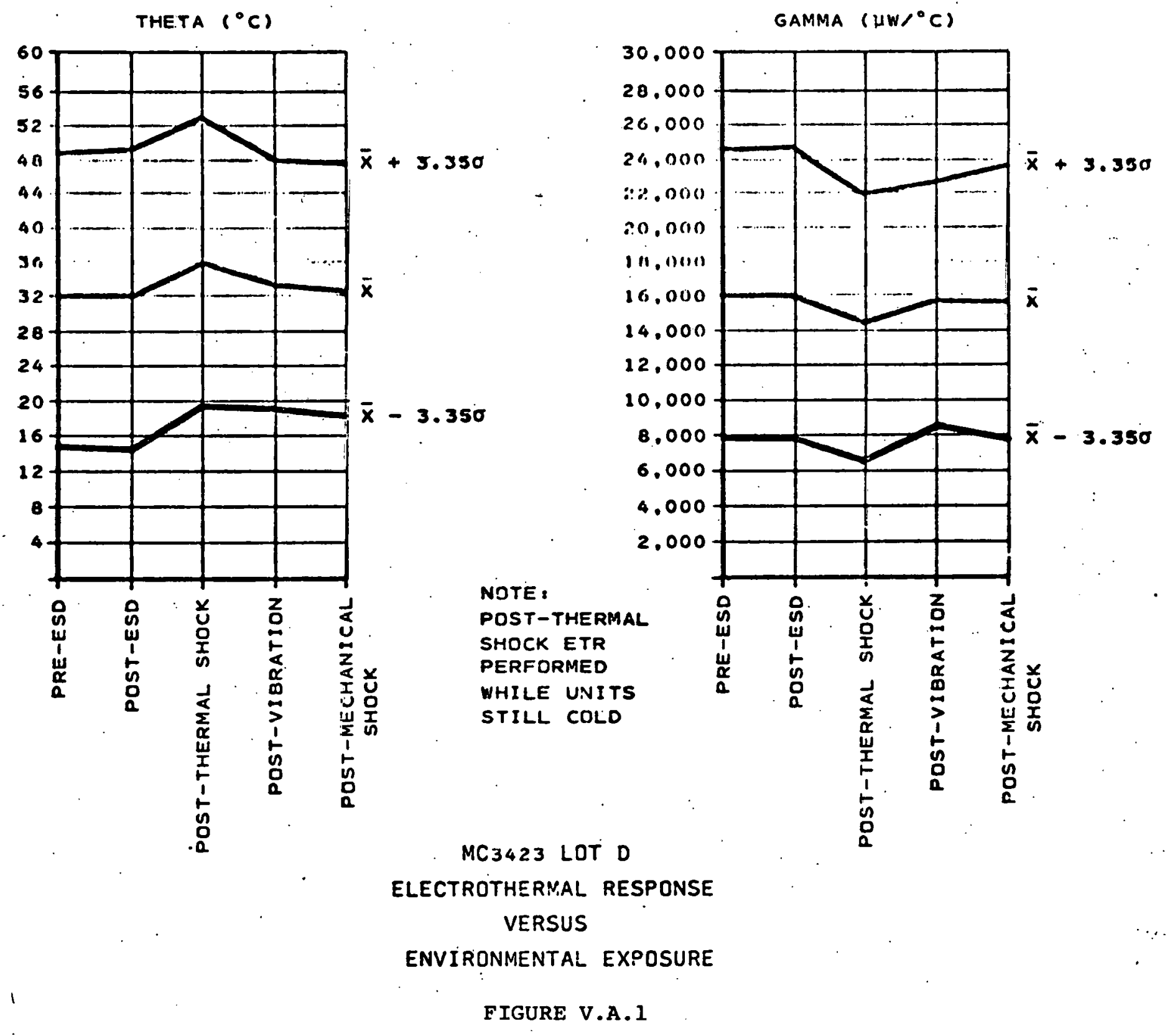




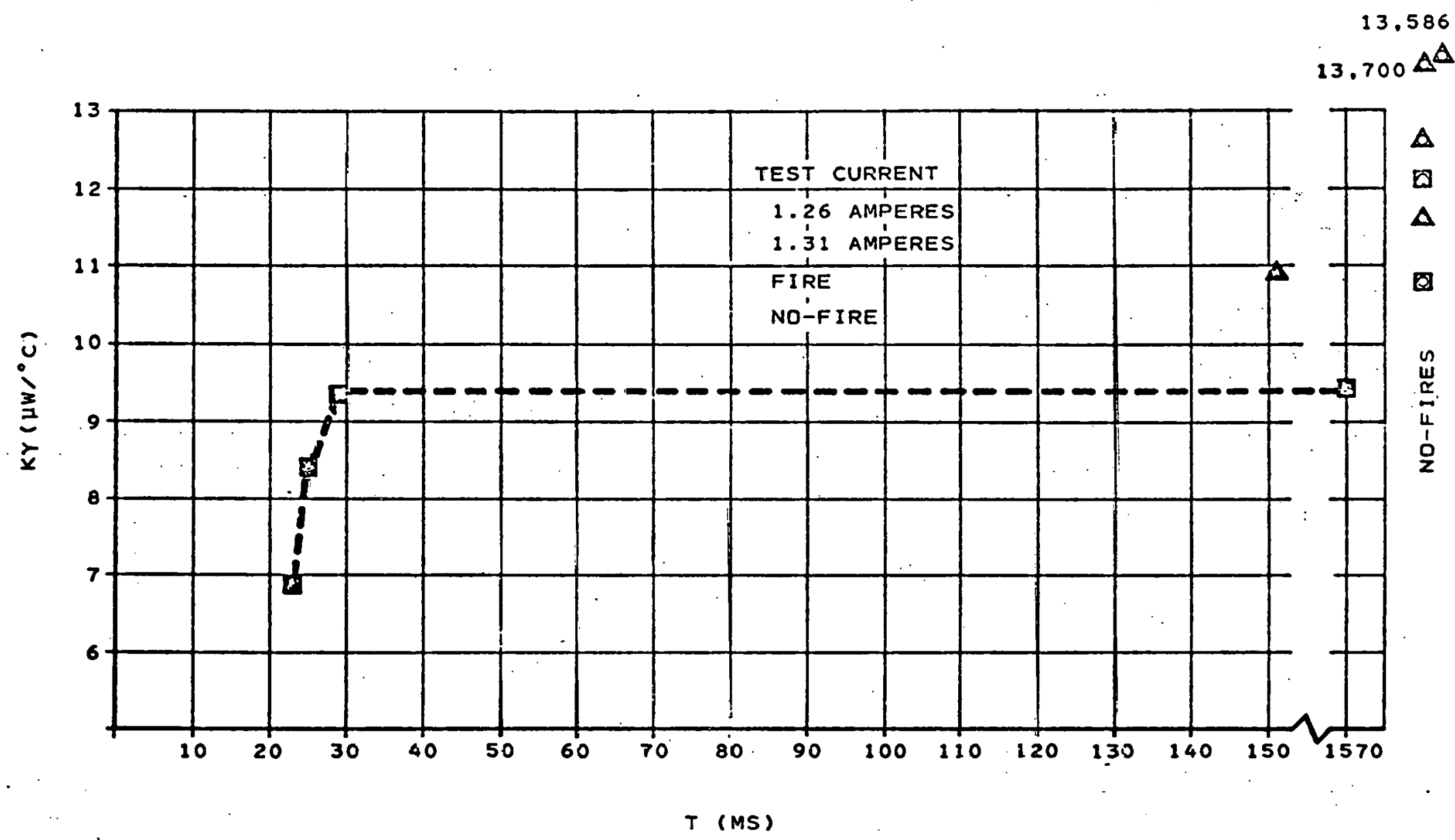

MC3423 DÉTONATOR

5 MINUTE NO-FIRE VS LOW ETR GAMMA

FIGURE V.A.2 


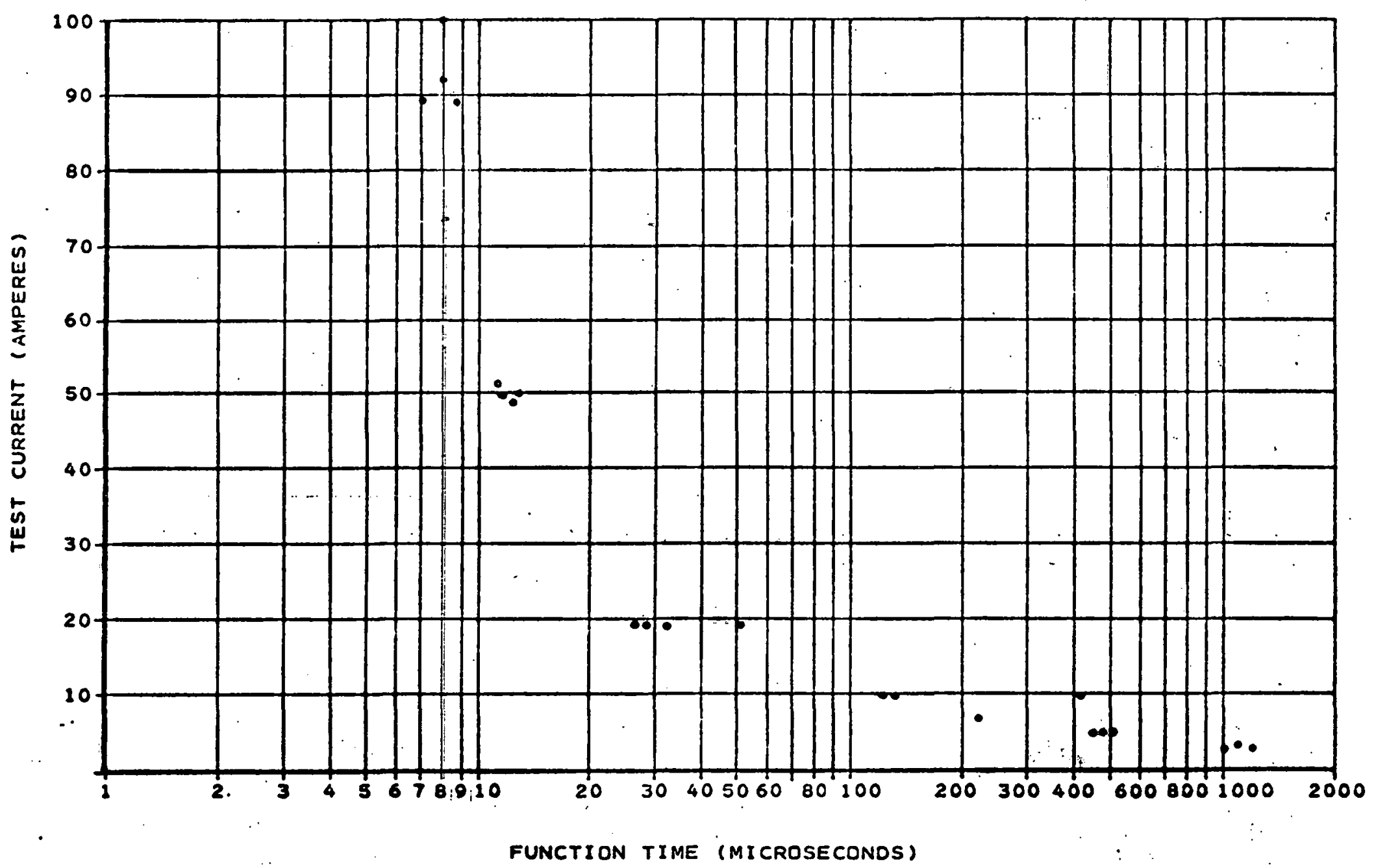

MC3423 DETONATORS

OUTPUT FUNCTION TIME VERSUS TEST CURRENT,

FIGURE V.A.3 
being fabricated and a firing method has been selected. Units are scheduled for testing within several weeks.

B. MC3533 Detonator (D. L. Marchi)

The MC3533 (Figure V.B.1) is a new CP detonator that has application in the W86 Pershing II Earth Penetrator. The physical geometry has been selected and will be on the order of .436" diameter $x .760 "$ in length. Bridgewire powder density is $1.76 \mathrm{Mg} / \mathrm{m}^{3}$ and consolidated pressure is $40 \mathrm{kpsi}$.

Initial ignition studies with MC3423 headers are scheduled for early December 1979 at Unidynamics. These studies will determine the no fire and all fire levels of $1.5 \mathrm{mil}$ and $1.6 \mathrm{mil}$ diameter Tophet $\mathrm{A}$ $1 \Omega$ bridgewires.

An order has been placed with Veler, Inc. of Santa Clara, California for development of a ceramic header. Veler is scheduled to deliver 50 headers to Unidynamics on January 31, 1980; an additional 2000 ceramics will be available at veler by March 31, 1980. Bridging will be done at Unidynamics.

For carly MnE requirements, we will supply MCJJJJ uniLs will a $12 "$ pigtail, 3 pin connector. Final cable will be a twin lead with connectors at each end. (The system will use a 2 wire system--no coaxial cable due to isolation problems, grounds, etc.) A design request letter from Department 2510 to Department 2150 has been sent asking for support in designing a 2 pin dwarf connector. A formal request letter for the interconnecting cable from the MC3533 2 pin connector to the fire set connector will be required from org. 4342 (Pershing II Development Division). A varistor, which may replace or complement the spark gap, is being developed by Org. 2521; Gary Snow and Ray Cooper presently have a contract with Unidynamics for support and some experimentation in this area.

Shock tests are scheduled for early December. These tests are to test confined CP under conditions that simulate g loads that the MC 3533 


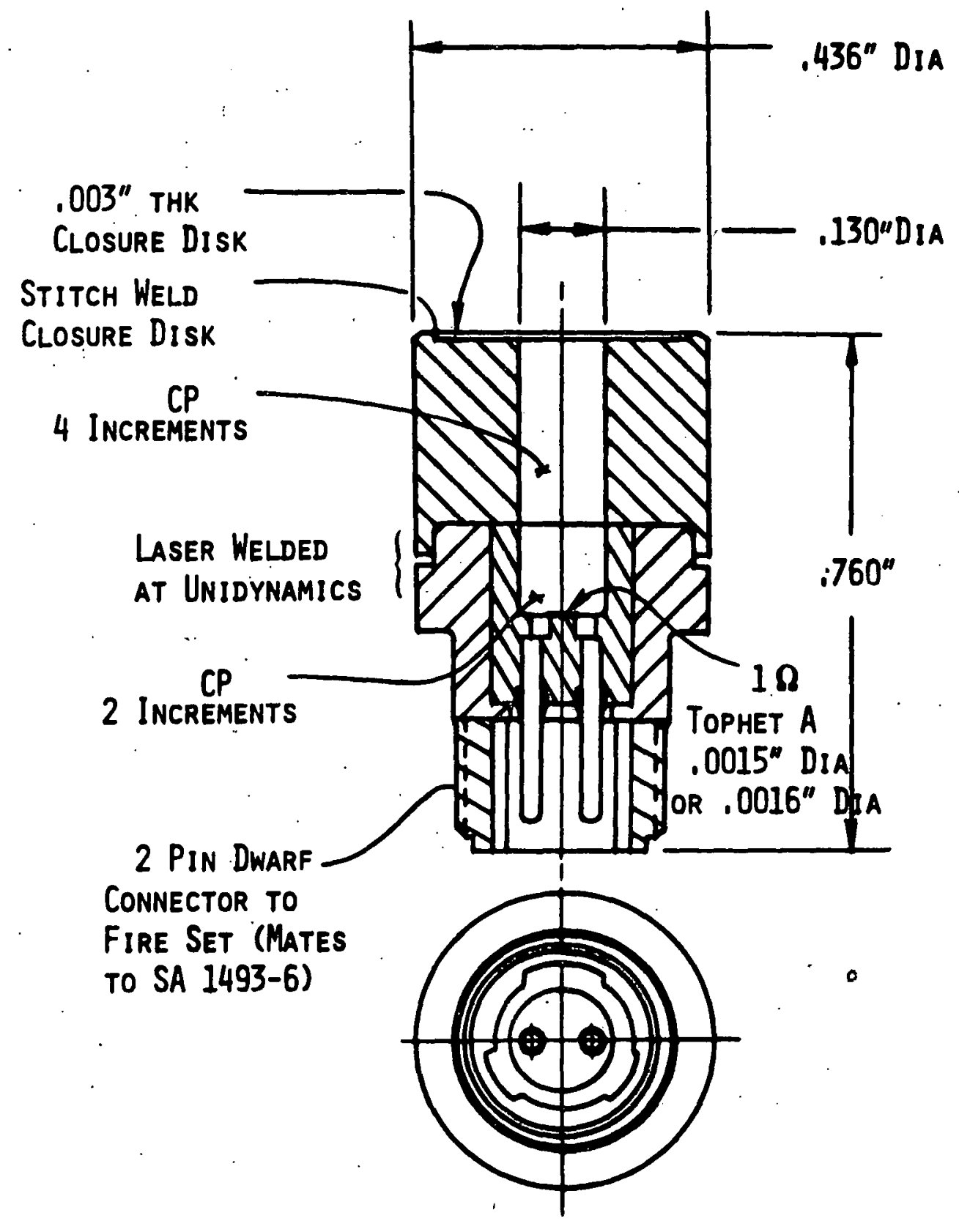

MC3533

FIGURE V.B.1 MC.3.533 Detonator 
may see in application. Six steel test vessels have been loaded with $116 \mathrm{mg}$ of $\mathrm{CP}$ at $10 \mathrm{kpsi}$; these test vehicles will be subjected to a $15,000 \mathrm{~g}$ load for 1 millisecond. The tests will be conducted at Sandia, Area III, and are to establish that CP contained and shocked in this manner will not ignite.

\section{CP Detonator Performance Studies (M. I. Lieberman)}

The goals of the study of CP DDT in detonator hardware were given in the previous quarterly report. (4) During the past quarter, the activity of T. K. Ferguson (Md) has focused on establishing diagnostic procedures.

Four CP detonators were built and loaded for diagnostic evaluation at Test Fire. These units featured a MC3196 header, one ohm bridgewire, and transparent lexan sleeves to allow viewing of the deflagration-todetonation process on the $8 \mathrm{x}$ streak camera. A longitudinal streaking slit was used in an attempt to view the light output along the axis of the clear sleeve.

Initial diagnostic attempts at Test Fire were unsuccessful due to the uncertainty in timing the light output after the bridge pulse. The remaining units will be set up using fiber optics to sense first light and switch on the RMC shutter. The optical filtering system will also be changed to optimize the film record of the CP deflagration. Lexan sleeves of a longer length are being fabricated to continue this experiment which is intended to complement other studies currently in progress and to aid in establishing timing sequences for future studies.

D. MC3196A Detonator (M. L. Lieberman)

Feasibility studies associated with this detonator have continued at Unidynamics. Additional MC3196 igniters have been loaded with various powders and test fired with a Velonix $10 \mathrm{~mJ}, 2.5 \mu \mathrm{s}$ pulse in an attempt to obtain a reliable function time in the range 50-200 $\mu \mathrm{s}$. 
Data obtained, including some reported previously, (4) are given in Table V.D.1. and Figure V.D.1. Duplicate tests of some conditions have been performed. These show that considerable scatter in function time can occur. No further work with $\mathrm{TiH}_{0.65} / \mathrm{KClO}_{4}$ is anticipated because of its significant and undesirable effect on measured resistance. Work with $\mathrm{CP} / \mathrm{Al}_{2} \mathrm{O}_{3}$ mixtures will not be continued for the MC3196A, since the mixtures exhibit ignition failures under test conditions.

TABLE V.D.1

MC3196A TESTS

Material

\begin{tabular}{cccc}
$\begin{array}{c}\text { Loading } \\
\text { Pressure, kpsi }\end{array}$ & $\begin{array}{c}\text { Function } \\
\text { Time, } \mu s\end{array}$ & \\
\cline { 2 - 3 } & 118 & $R_{0}=0.59$ \\
25 & 31 & $R_{0}=0.20$ \\
40 & 27 & $R_{0}=0.14$
\end{tabular}

$338 \mathrm{CP} / 678 \mathrm{Al}_{2} \mathrm{O}_{3}$

$1063,80^{\circ}$

$338 \mathrm{TiH}_{0.65^{167.8}} \mathrm{KClO}_{4}$

25

39,35

40

39,54

$258 \mathrm{CP} / 758 \mathrm{Al}_{2} \mathrm{O}_{3}$

$10 \mathrm{NF}, \mathrm{NF}$

25 NF, -

$40 \quad$ NF, 141

$15.8 \mathrm{CP} / 85 \mathrm{P}^{\circ} \mathrm{Al}_{2} \mathrm{O}_{3}$

$10 \quad \mathrm{NF}, \mathrm{NF}$

$25 \quad \mathrm{NF}, \mathrm{NF}$

40 NF, NF

$338 \mathrm{CP} / 678 \quad \mathrm{Al}_{2} \mathrm{O}_{3}$

$10 \quad \mathrm{NF}$

$3.5 \mathrm{~A} \mathrm{CCU}$

10

NF

$3.5 \mathrm{~A} \mathrm{CCU}$

10

Partial

5.0 A CCU

$958 \mathrm{CP} / 58$ Viton

10

9

$25 \quad 8$

$40 \quad 8$

$\mathrm{CP} / \mathrm{Al}_{2} \mathrm{O}_{3} / \mathrm{CP}^{*} \quad 25 \quad 8,9$ "Layered assembly: $\begin{aligned} & 13-15 \mathrm{mg} \mathrm{CP} / 15-17 \mathrm{mg} \mathrm{Al}_{2} \mathrm{O}_{3} / 12 \mathrm{mg} \mathrm{CP} \text {; all layers } \\ & \text { pressed at } 25 \mathrm{kpsi} .\end{aligned}$ 


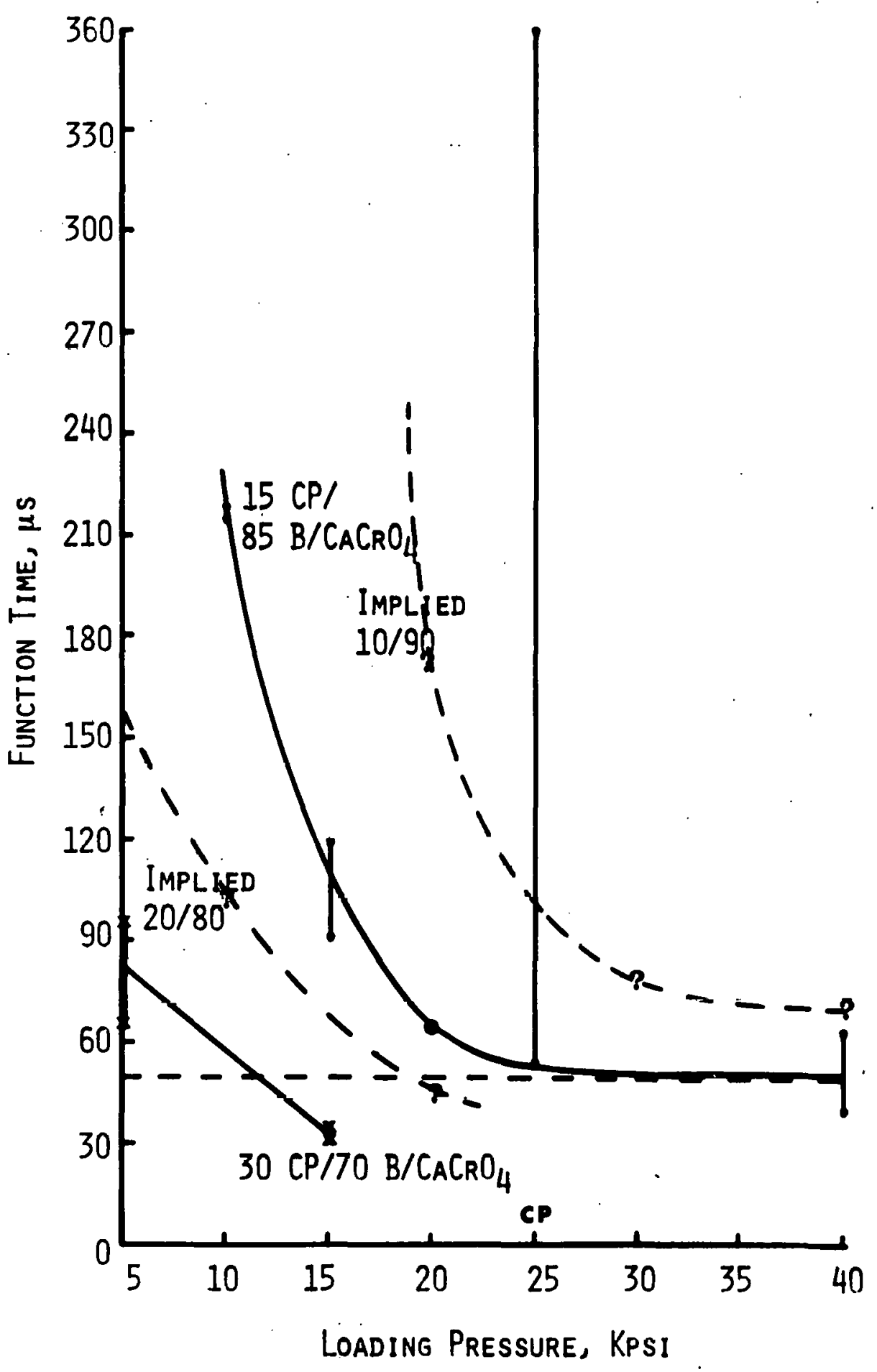

FIGURE V.D.1 MC3196A Function Time Tests 


\section{REFERENCES}

1. M. L. Lieberman, ed., "The Deflagration-to-Detonation Transition Project: Quarterly Report for the Period September through November 1978," SAND78-2409, RS2515/132, February 1979; also M. L. Lieberman, ed., "Activities of the Deflagration-toDetonation Transition Project: Quarterly Report for the Period September through November 1978," SAND79-0837, April 1979.

2. M. I. Lieberman, ed., "The Deflagration-to-Detonation Transition Project: Quarterly Report for the Period December 1978 through February 1979," SAND79-1267, June 1979.

3. M. L. Lieberman, ed., "The Deflagration-to-Detonation Transition Project: Quarterly Report for the Period March 1979 through May 1979," SAND79-1952, October 1979.

4. M. L. Lieberman, ed., "The Deflagration-to-Detonation Transition Project: Quarterly Report for the Period June through August 1979," SAND80-0230/1, January 1980.

5. W. B. Leslie, R. W. Dietzel and J. Q. Searcy, "A New, Inherently Safe Explosive for Low Voltage Detonator Applications," Sixth Symp. of Det'n., San Diego, CA, August 1976.

6. J.W. Fronabarger and A. A. Heckes, "Summary Report on Desensitizing CP Explosive to Electrostatic Discharge via Additives," SAND77-2133, October 1978 .

7. T. M. Massis, P. K. Morenus, and B. R. Steele, "Simulation of Powder Decoupling Phenomena in Electro-Explosive Devices by TMA," SAND80$1098 \mathrm{~J}$, document in preparation. 
Unlimited Release

Distribution:

Combustion Sciences, Inc. 208 Elmwood Road

Champaign, IL 61820

Attn: H. Krier

Mound Facility

Naval Surface Weapons Center White Oak

Silver Spring, MD 20910

Attn: G. Laib

P. O. Box 32

Unidynamics/Phoenix, Inc.

Miamisburg, OH 45342

TO: A. Attalla

K. Bullock

L. W. Collins

P. O. Box 2990

Phoenix, AZ 85062

Attn: J. Fronabarger

A. Läuse

R. J. DeSando

R. Smith

C. E. Gallaher

J. Mohler

H. L. Turner, attn: J. R. Brinkman

R. A. Fischbein

M. A. Woltermann, attn: V. Franchetti

C. Friedman

1132 P. W. Cooper

1533 R. A. Benham

1556 S. A. Ingham, attn: E. A. Igel

2500 J. C. Crawford

2510 D. H. Anderson

2513 J. E. Kennedy, attn: R. J. Burnett

R. W. Dietzel

A. K. Jacobson

W. B. Lesile

D. J, Mullikin

2513 P. I. Stanton

2514 B. H. Van Domelen, attn: G. J. Janser

2515 ․ D. Wilcox, attn: O. L. Burchett

J. K. Lräig

2515 M. L. Lieberman (5)

2515 D. L. Marchi

2515 F. J. V111a

2516 W. G. Perkins, attn: R. J. Buxton

R. G. Jungst

P. K. Morenus

2516 V. M. Loyola

R. N. Roberts

2516 T. M. Massis

3551 E. A. Kjeldganad

4218 J. K. Rice

4310 C. C. Burks, attn:

D. L. McCoy

H. T. Lehman

4330 H. W. Schmitt, attn: P. A. Longmire

O. M. Fligner

W. R. Reynolds

T. A. Moshenrose

5131 I. W. Davison

5154 B. Morosin

5510 D. B. Hayes, attn: J.W. Nunziato

D. W. Larson 
5820 R. E. Whan, attn: N. E. Brown

R. M. Merrill

R. H. Eckelmeyer

E. J. Graeber

D. H. Huskisson

8162 A. S. Rivenes

3141 T. L. Werner

(5)

3151 W. L. Garner for DOE/TIC (3)

3154-3

R. P. Campbell for DOE/TIC

(25) 


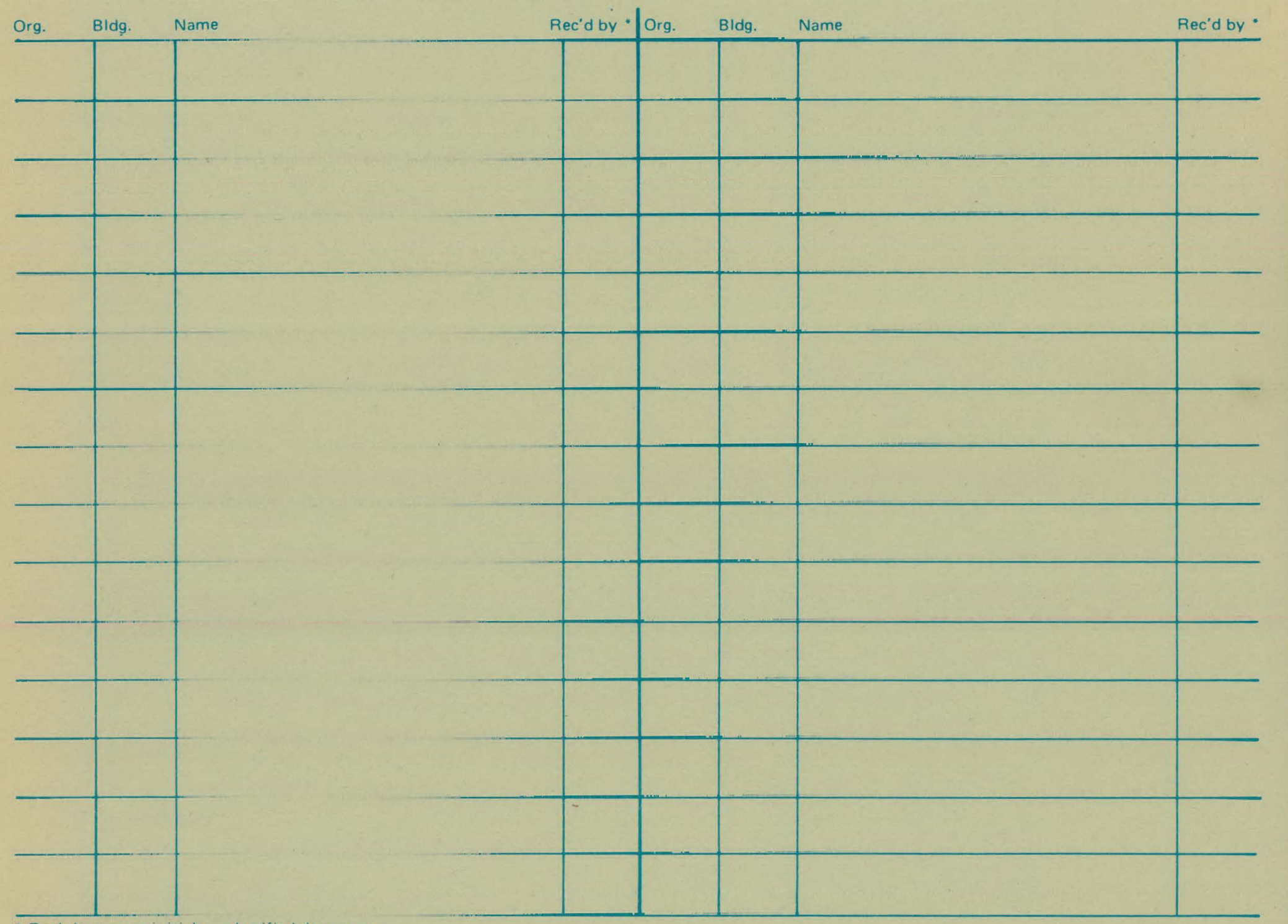

